\title{
INL Seismic Monitoring Annual Report: January 1, 2008 - December 31, 2008
}

S. J. Payne

N. S. Carpenter

J. M. Hodges

R. G. Berg

September 2009

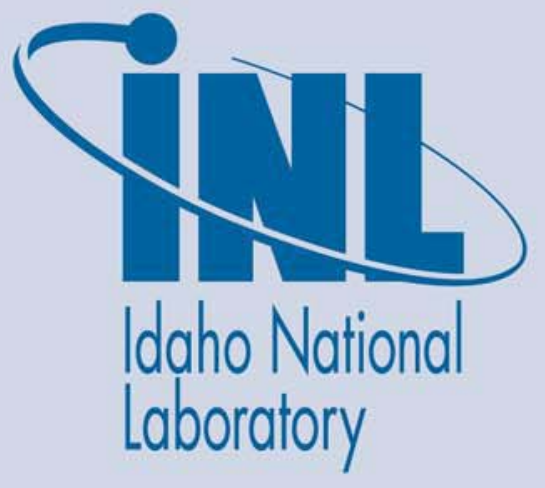

The INL is a U.S. Department of Energy National Laboratory operated by Battelle Energy Alliance 
INL/EXT-09-16687

\title{
INL Seismic Monitoring Annual Report: January 1, 2008 - December 31, 2008
}

\author{
S. J. Payne \\ N. S. Carpenter \\ J. M. Hodges \\ R. G. Berg
}

September 2009

Idaho National Laboratory

Seismic and Structural Analysis

Idaho Falls, Idaho 83415

http://www.inl.gov

Prepared for the

U.S. Department of Energy

Office of Nuclear Energy

Under DOE Idaho Operations Office

Contract DE-AC07-05ID14517 
(Intentionally Blank) 


\section{SUMMARY}

During 2008, the INL Seismic Monitoring Program evaluated 7,284 earthquakes from around the world, the western United States, and local region of the eastern Snake River Plain. 2,396 earthquakes and man-made blasts were evaluated within the local region outside and within a 161-km (or 100-mile) radius of INL. Of these events, 25 were small to moderate size earthquakes ranging in magnitude from 3.0 to 3.9. 823 earthquakes occurred within the 161$\mathrm{km}$ radius of INL and over 300 events were associated with eight different earthquake swarms which were located in active regions of the Basin and Range Province that surrounds the eastern Snake River Plain. Eight microearthquakes in 2008 of magnitude (M) 2.0 and less were located within the eastern Snake River Plain, seven at or near the Craters of the Moon National Monument and one within the INL boundary. Further analyses of the anomalously deep focal depths (15 to $42 \mathrm{~km}$ ) and different waveform characteristics of all Craters of the Moon National Monument events (1999-2008) suggest association with magmatic processes. From 1972 to 2008, INL located 36 other small-magnitude microearthquakes $(\mathrm{M}<2.0)$ at depths $(<11 \mathrm{~km})$ within the eastern Snake River Plain and attributes these events to regional tectonic tensional stresses. 
(Intentionally Blank) 


\section{ACKNOWLEDGEMENTS}

We thank Alan Marley for his continued support. We also thank staff at the University of Utah Seismograph Stations, U. S. Geological Survey, Montana Bureau of Mines and Geology, and BYU-Idaho for their earthworm data shares. 
(Intentionally Blank) 


\section{CONTENTS}

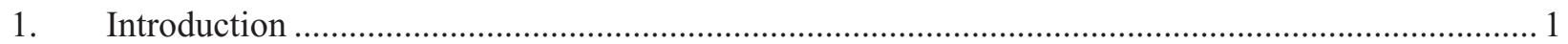

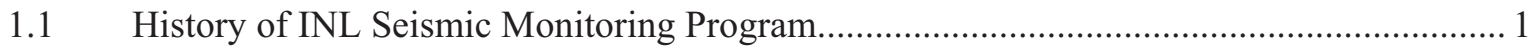

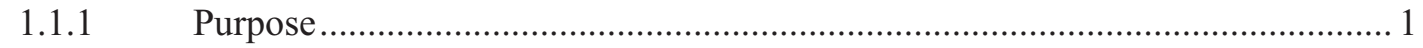

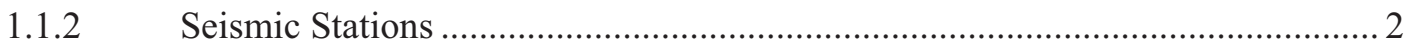

1.1.3 Strong Motion Accelerographs ............................................................. 2

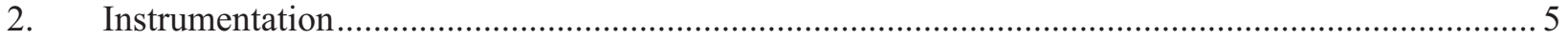

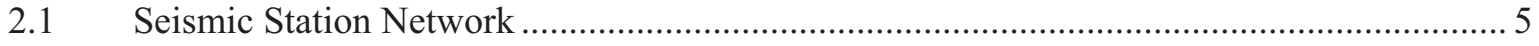

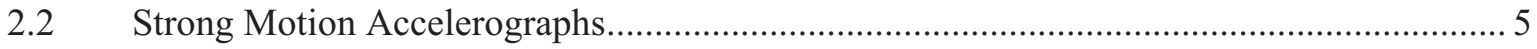

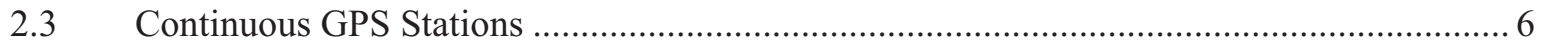

2.4 Seismic Data Acquisition and Analysis System ........................................................ 7

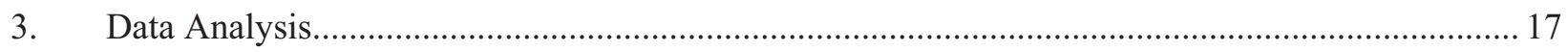

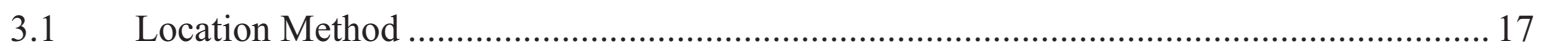

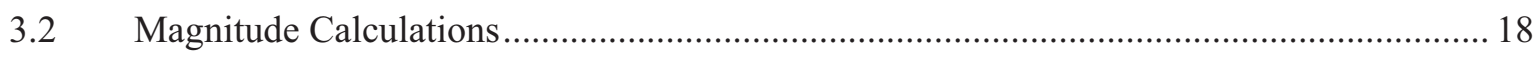

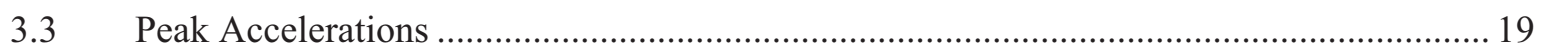

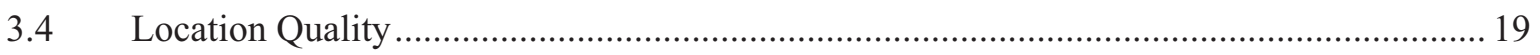

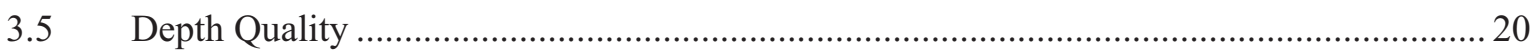

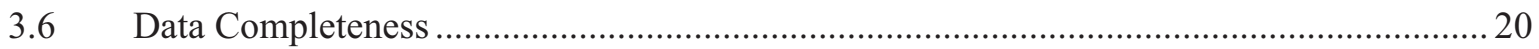

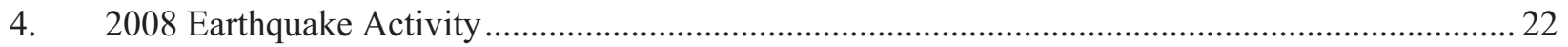

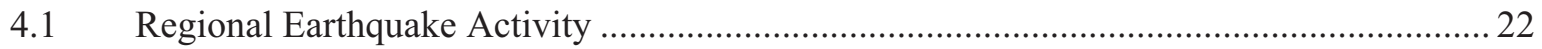

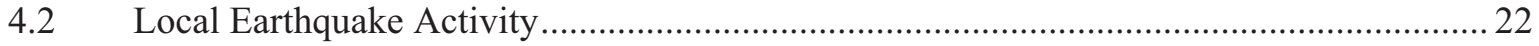

4.3 Earthquakes Within the Eastern Snake River Plain........................................................ 23

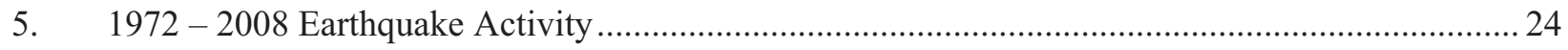

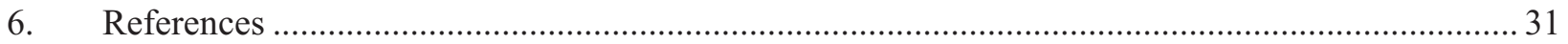


(Intentionally Blank) 


\section{FIGURES}

Figure 1. Map shows locations of the earthquake reporting area within the $161-\mathrm{km}$ (100 mile) radius of the INL, Basin and Range normal faults, and volcanic rift zones.

Figure 2. Locations of INL seismic stations and stations monitored by INL that are operated by other institutions.

Figure 3. Numbers of SMAs located at INL

Figure 4. Locations of the continuous GPS stations co-located at INL seismic stations and operated by the Plate Boundary Observatory (PBO) under the EarthScope Science Program.

Figure 5. Map shows epicenters of earthquakes for magnitudes greater than 3.0 during 2008.

Figure 6. Map shows location of the M6.0 earthquake near Wells, NV and locations of INL seismic stations and accelographs that recorded ground motions.

Figure 7. Map shows epicenters of earthquakes within the 161-km radius of INL from January 1 , 2008 to December 31, 2008.

Figure 8. Map shows epicenters of earthquakes and year of occurrence at Craters of the Moon National Monument from 1999-2008.

Figure 9. Map shows epicenters of earthquakes from 1972 to 2008 within the 161-km radius of INL... 30 
(Intentionally Blank) 


\section{TABLES}

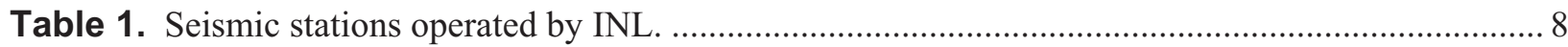

Table 2. Agencies and stations from which INL receives data shares............................................. 11

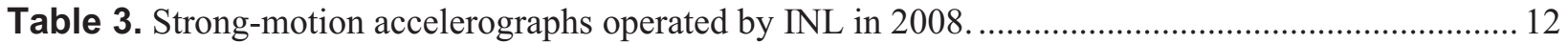

Table 4. Continuous GPS sites co-located with INL seismic stations. ............................................... 13

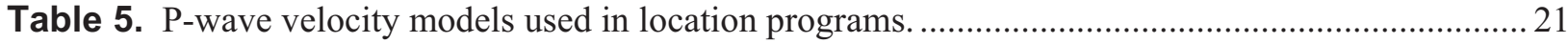

Table 6. Peak accelerations measured at INL accelerographs for the 21 February 2008 M 6.0 Wells,

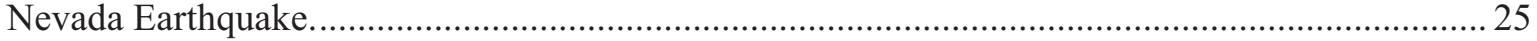


(Intentionally Blank) 


\section{ACRONYMS}

\begin{tabular}{|c|c|}
\hline ANL & Argonne National Laboratory \\
\hline BLM & Bureau of Land Management \\
\hline CFA & Central Facilities Area \\
\hline $\mathrm{COM}$ & Craters of the Moon National Monument \\
\hline DAAS & Data Acquisition/Analysis System \\
\hline DOE & Department of Energy \\
\hline DSL & Digital Subscriber Line \\
\hline EFS & Experimental Field Station \\
\hline ESRP & Eastern Snake River Plain \\
\hline GPS & Global Positioning System \\
\hline INL & Idaho National Laboratory \\
\hline INTEC & Idaho Nuclear Technology and Engineering Center \\
\hline IP & Internet Protocol \\
\hline IRC & INL Research Center \\
\hline LOFT & Loss of Fluid Test \\
\hline MFC & Materials and Fuels Complex \\
\hline NEIC & National Earthquake Information Center \\
\hline NRF & Naval Reactor Facility \\
\hline PBF & Power Burst Facility \\
\hline PBO & Plate Boundary Observatory \\
\hline P-wave & Compressional Wave \\
\hline RTC & Reactor Technology Complex \\
\hline RWMC & Radioactive and Waste Management Complex \\
\hline S-wave & Shear Wave \\
\hline
\end{tabular}


SMC Special Manufacturing Complex

SMA Strong Motion Accelerograph

SSCs Structures, Systems, and Components

STC Science and Technology Complex

TA Transportable Array

TAN Test Area North

TRA Test Reactor Area

USGS United States Geological Survey 


\section{INL Seismic Monitoring Annual Report: January 1, 2008 - December 31, 2008}

\section{Introduction}

The Idaho National Laboratory (INL) has accumulated 36 years of earthquake data (1972-2008). This report covers the earthquake activity from January 1, 2008 through December 31, 2008 within a 161$\mathrm{km}\left(100\right.$-mile) radius from the center of the INL designated as $43^{\circ} 39.00^{\prime} \mathrm{N}, 112^{\circ} 47.00^{\prime} \mathrm{W}$ (Figure 1). The report is a continuation of previous annual reports on earthquake activity surrounding the eastern Snake River Plain (ESRP) and within and near the INL. It discusses the earthquake activity that has occurred around the local region and within the 161-km radius of the INL. It discusses the seismic station and strong motion accelerograph instrumentation used to record earthquake data and how they were analyzed. It also includes a brief discussion of continuous GPS (Global Positioning System) stations colocated at INL seismic stations.

\subsection{History of INL Seismic Monitoring Program}

\subsubsection{Purpose}

The purpose of the INL Seismic Monitoring Program is to provide the INL with earthquake data and staff expertise to support the requirements set forth by Presidential executive orders, DOE directives, orders, and standards, and the Nuclear Regulatory Commission for seismic safety of: Structures, Systems, and Components (SSCs); workers and the public; and operations at INL of reactors and waste management activities. The program supports safety of operations through continuous monitoring of earthquake activity, the development of INL seismic design criteria, assessments of seismic hazards for existing facilities and acquisition of major new programs, and early warning of potential future volcanic eruptions near INL. For example, the earthquake data are used to assess seismic hazards and develop seismic design criteria for the INL as required by DOE Order 420.1A "Facility Safety" (DOE, 2003).

The INL Seismic Monitoring Program operates 27 permanent seismic stations for the purpose of determining the time, location, and size of earthquakes occurring in the vicinity of the INL. The seismic data are compiled to develop an historical database that defines the zones and frequency of earthquake activity. Seismic stations are located within and around the INL near potential earthquake sources that include major range-bounding normal faults and volcanic rift zones (Figure 1). Additionally, thirteen seismic stations have GPS receivers at them for the purpose of determining rates of crustal deformation. GPS velocities are used to identify regions of higher crustal deformation rates (such as Yellowstone, Wyoming) relative to regions of lower deformation rates (Snake River Plain, Idaho).

The INL Seismic Monitoring Program operates 24 strong-motion accelerographs (SMAs) for the purpose of recording strong ground motions from local moderate or major earthquakes. The SMAs are located within INL buildings to determine the response of these buildings to ground motions in the event of a large earthquake. Several SMAs are located at "free-field" sites (not within buildings) at INL facility areas and are used to determine the levels of earthquake ground motions at the ground (rock or soil) surface. SMAs are also co-located with several INL seismic stations to record acceleration data and assess attenuation effects of small to large magnitude normal faulting earthquakes. 


\subsubsection{Seismic Stations}

The INL seismic network has evolved from a single analog station to its current configuration of 27 digital seismic stations. The INL Seismic Monitoring Program also records data from seismic stations owned and operated by other seismic networks. The INL seismic network began with a single station in 1971 and expanded to three stations by October of 1972. In 1977, the INL began monitoring a station operated by BYU-Idaho in Rexburg, Idaho, and the INL installed two additional stations in 1979. From 1979 to 1985, the INL monitored earthquake activity using six seismic stations. In 1985, the INL installed a simulated Wood-Anderson system to improve the capabilities of measuring the magnitude of local earthquakes $\left(3.0 \leq \mathrm{M}_{\mathrm{L}} \leq 5.0\right)$. During 1986, the INL began receiving seismic data from a station located in Pocatello, Idaho and operated by the University of Utah in Salt Lake City, Utah. Also, in 1986, the INL began receiving data from a station located near Palisades Reservoir, Idaho that is operated by BYUIdaho. A seismic station within the INL boundaries was added to the INL seismic network in 1987.

From 1990 to 1994, INL seismic network under went a major expansion of seismic stations. During 1990, four seismic stations were installed within the INL boundaries. From 1991 to 1992, thirteen new stations were installed in support of construction and operation of the proposed New Production Reactor at INL. Shallow boreholes $(<20 \mathrm{~m})$ were drilled for seismic stations located within the ESRP. Also, monitoring of BYU-Idaho seismic station near Palisades Reservoir was terminated in 1991 to accommodate the addition of the new INL seismic stations. In 1994, two new INL seismic stations were installed near Gray's Lake, Idaho.

Several changes occurred to seismic stations from 1999 to 2003. During 1999, the INL Howe Scarp, Idaho (HWSI) seismic station was relocated further east to a new location now referred to as the Howe Fault, Idaho or HWFI because of a lawsuit filed against the Bureau of Land Management (BLM). With the implementation of the EARTHWORM computer software in 2000, up to 14 stations from several nearby networks were being recorded in real-time along with the INL seismic stations. During 2001-2003, analog seismic instruments at all INL seismic stations were replaced with digital instruments. In 2003, the University of Utah transferred ownership of the Pocatello, Idaho (PTI) seismic station to the INL Seismic Monitoring Program at which time a digital seismic station was installed. With addition of the PTI station, INL currently operates 27 seismic stations.

In 2007, INL began recording data from Transportable Array (TA) seismic stations deployed in Idaho as part of the EarthScope Science program funded under the National Science Foundation. These seismic stations are three-component broadband stations that are temporarily deployed for 18-24 months in a grid that systematically covers the United States. One TA station is co-located at the INL's Crow's Nest, Idaho (CNCI) seismic station. Additionally, the INL began acquiring data from the National Earthquake Information Center's Intermountain West network. As with the TA stations, these stations employ three-component, broadband seismometers.

\subsubsection{Strong Motion Accelerographs}

The INL began an accelerograph network by installing SMAs in buildings at INL facility areas, and more recently at free-field sites for both rock and soil conditions. In 1973, the INL began an accelerograph network by installing eleven SMAs in critical INL facilities. Three were located within buildings at the Idaho Nuclear Technology and Engineering Center (INTEC) (formerly referred to as Idaho Chemical Processing Plant - ICPP), two within the Materials and Fuels Complex (MFC) facilities (formerly referred to as Argonne National Laboratory - ANL), three within the Power Burst Facility (PBF), two within buildings at the Reactor Technology Complex (RTC) (formerly referred to as Test Reactor Area - TRA), and one at the Old Fire Station (OFS). From 1978 to 1979, four SMAs were installed at Test Area North (TAN) within the Containment Test facility (formerly referred to as Loss of 
Fluid Test - LOFT facility). Just prior to the October $1983 \mathrm{M}_{\mathrm{s}} 7.3$ Borah Peak, Idaho earthquake, one SMA was installed at the INL Research Center (IRC), which is now part of the Science and Technology Complex (STC) in Idaho Falls, Idaho. Following the 1983 earthquake, two SMAs were installed within buildings at the Naval Reactor Facility (NRF). In 1984, two additional SMAs were placed within buildings at INTEC. During 1990, one SMA was installed at the Central Facilities Area (CFA). A digital SMA was co-located with an analog SMA at MFC in 1993. In 1996, two free-field SMA sites were installed, one at NRF and the other at PBF. In 1997, one SMA was installed as a free-field site at the Radioactive Waste Management Complex (RWMC). In 2003, the SMAs were upgraded to digital NetDAS SMAs. At that time, one NetDAS digital SMA replaced two SMAs co-located at Building ANL767 (Kinemetrics analog SMA-1 and digital SSA-2 accelerograhs). The SMA on the crane beam at PBF620 was not upgraded, but removed due to decommissioning activities.

Over the years, several SMAs have been relocated because buildings have been decommissioned and demolished. In 1995, the SMA at OFS was moved to a storage building directly behind the fire station because the fire station was decommissioned. In 1997 when the storage building was demolished, this SMA was relocated to the Experimental Field Station (EFS). In 1996, the Containment Test facilities or LOFT facilities were decommissioned. Three of the SMAs from LOFT were moved to the TAN Hot Shop and one was placed at the TAN Air Monitoring building. In 1997, the SMA at CFA was relocated to CFA-1607 Refueling Building. In 2004, the TAN Air Monitoring building was demolished so the SMA was removed and was reinstalled in 2005 as a free-field near the TAN Hot Shop. In 2004, the PBF building was demolished and the three SMAs were removed. The SMAs were reinstalled in 2005 as freefield sites near PBF and RWMC. In 2006, four SMAs at TAN were removed due to demolition of the TAN Hot Shop. In 2007, two of these SMAs were reinstalled; one was installed at the Special Manufacturing Complex (SMC) and the other at a free-field site east of SMC. In 2008, one SMA was removed and three SMAs were installed as a result of building demolition activities. One SMA at INTEC in building CPP-668 was removed. This SMA and two others were reinstalled at TAN, RTC, and the New Production Reactor (NPRI) seismic station.

Three-component accelerometers were added to some of the seismic stations. In 2002, accelerometers were added to four seismic stations: Bear Canyon (BCYI), Gray's Range (GRRI), NPRI, and HWFI,. In 2003, accelerometers were added to seismic stations Telchick Spring, Idaho (TCSI), Split Crater (SPCI), and PTI. During 2008, the INL Accelerograph Network operated up to 24 SMAs within or near INL Site facility areas and 6 three-component accelerometers at seismic stations. 


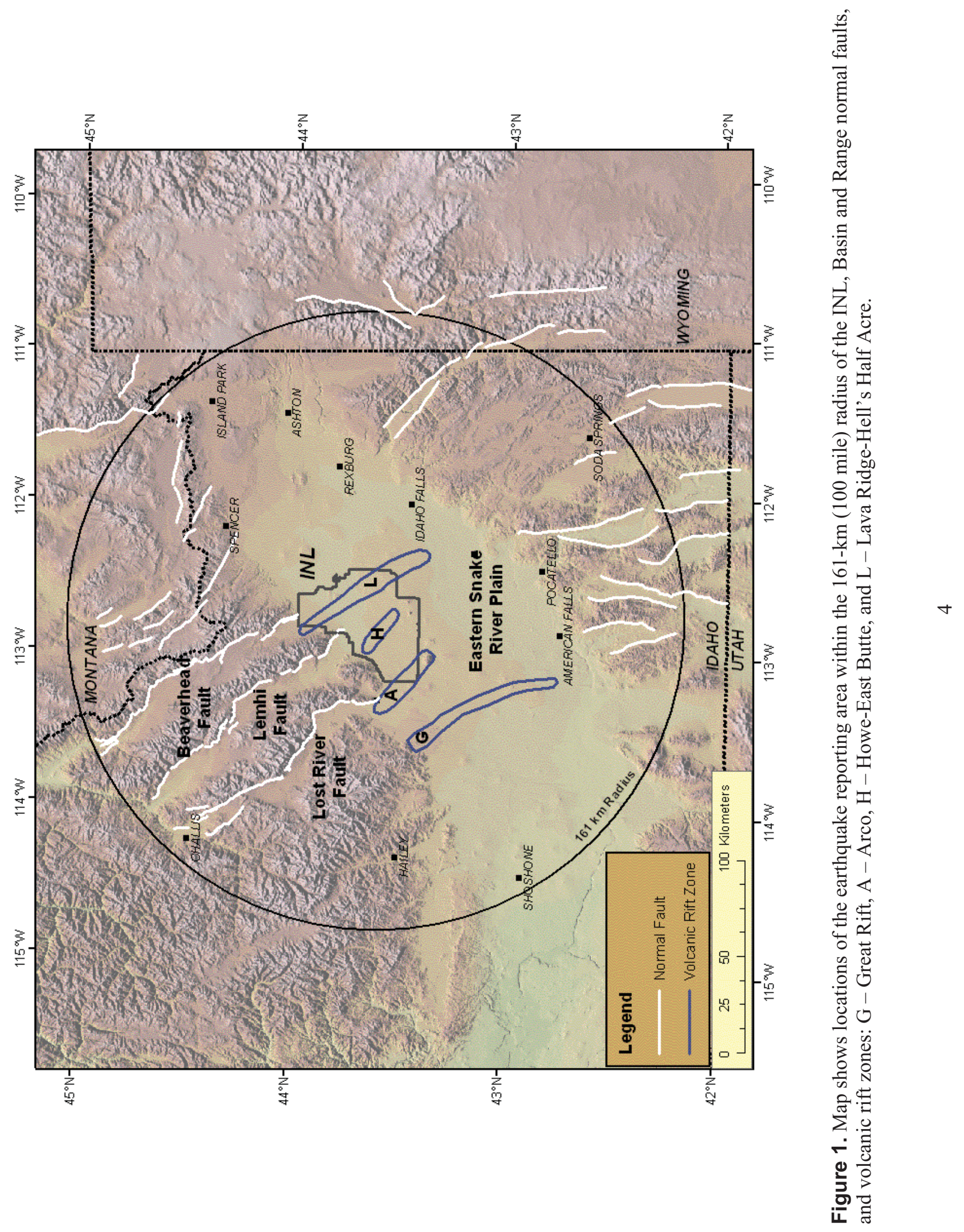




\section{Instrumentation}

\subsection{Seismic Station Network}

During 2008, the INL Seismic Monitoring Program operated 27 permanent seismic stations and monitored up to 65 seismic stations from other nearby seismic networks (Figure 2). Table 1 lists the name, location, and date of installation for the seismic stations owned and operated by the INL Seismic Monitoring Program. Table 2 lists the name, location, and operation dates of seismic stations owned by other agencies. Table A-1 (Appendix A) lists the information for the EarthScope Science Program TA stations. The INL recorded seismic data from these other seismic stations to improve the quality of earthquake locations within the 161-km radius of INL.

Instrumentation for INL seismic stations consists of digital recorders, one- and three-component seismometers, and three-component accelerometers. The digital recorder is a DAQSystems NetDAS field unit, which is an embedded LINUX computer with a GPS clock and Symmetric Research 24 bit digitizer. The NetDAS units have nearly 22 bits of data resolution over \pm 20 volts for a four-channel unit or \pm 10 volts for an eight-channel unit. Four channel units (NetDAS-CH4) are located at seismic stations that have one or three sensors; eight channel units (NetDAS-CH8) are at seismic stations that have more than three sensors (such as three seismometers and three accelerometers). The seismic stations have preamplifiers that improve signal to noise ratios. The NetDAS digitizes data at the seismic station and time stamps the data with accuracies greater than 0.001 seconds. The seismic signals are transmitted by FreeWave Technologies DGR115 $900 \mathrm{MHz}$ Wireless Modem radios. These radios use standard IP (Internet Protocol) networking features that are included in the embedded LINUX.

Single-component seismic stations have vertically oriented velocity sensors (or seismometer) that are a Mark Products model L-4C, Teledyne Geotech (TG) model S-13 or TG model S-13 Jr. seismometer buried within $3 \mathrm{~m}$ of the ground surface. All seismic stations located within the ESRP have their verticalcomponent seismometer located at the bottom of $18 \mathrm{~m}$ or greater borehole to help dampen wind and cultural noise (Seismic, 1993). Seismic stations with horizontally-oriented velocity sensors have two Teledyne Geotech model S-13 seismometers located within a concrete vault, in addition to the verticallyoriented sensor. Seismic stations with acceleration sensors have Applied MEMs Inc. model SF1500A, SF2500A, or SF3000L tri-axial accelerometers.

Where AC power is not available, seismic stations are powered by batteries, solar panels, and at some locations small wind generators. Radio frequency compatible antennas transmit and receive the seismic signals. Several seismic stations are used as relay stations to allow transmission of seismic signals to the IRC in Idaho Falls. The seismic data are relayed by digital radios or internet Digital Subscriber Line (DSL) links (Appendix A). The data are acquired through EARTHWORM data shares on the Internet (discussed in Section 2.5). Digital seismograms are continuously displayed on three of four computer monitors referred to as "Webicorders." The fourth monitor displays a map of current earthquakes located by the INL Seismic Monitoring Program.

\subsection{Strong Motion Accelerographs}

The INL accelerograph network has 24 strong-motion accelerographs at INL Site facilities; 23 are located at the INL Site and 1 is located in the IRC at the STC. Table 3 lists the location and date of installation for each of the SMAs in operation. There are 1 to 5 accelerographs at each INL Site facility area (Figure 3). During 2008, earthquakes did not trigger SMAs located within INL facilities. 
In 2008, one SMA was removed and three SMAs were installed as a result of building demolition activities. An SMA at INTEC in building CPP-668 was removed and the building was demolished. This SMA and two others were reinstalled at other locations, building TAN-601 (first floor), building TRA670 (first floor), and the NPRI seismic station (Table 3). Two of these instruments were from a building at TAN that was demolished in 2006.

INL SMAs are DAQSystems NetDAS digital accelerographs that have Applied MEMS SiFlex SF2500 tri-axial accelerometers. Each SMA is set to trigger and record to compact flash when ground motions exceed 2500 counts, which is equivalent to about $0.005 \mathrm{~g}$. The record lengths are set for $30 \mathrm{~s}$ of pre- and post-trigger thresholds. The tri-axial accelerometers have two horizontal components oriented in an orthogonal manner, generally aligned in the north-south and east-west directions. Appendix B lists the accelerometer orientation and instrument response for the horizontal and vertical components of each SMA. SMAs at free-field sites have GPS clocks to synchronize the internal clocks to an absolute time system. For some SMAs at free-field sites and locations within buildings, acceleration data are transmitted to the IRC via digital radios or the Internet. Other SMAs record data on compact flash disks that are retrieved by INL seismic personnel using a laptop PC computer.

\subsection{Continuous GPS Stations}

The INL Seismic Monitoring Program has a geodetic network for the purpose of monitoring horizontal crustal deformation in support of INL seismic hazards assessments. GPS data are used to investigate active crustal deformation that is on the order of millimeters of movement per year within the ESRP, the surrounding Basin and Range, and Yellowstone Plateau. GPS data define regions of high velocity gradients (or strain rates) having more frequent damaging earthquakes (e.g., Yellowstone Hebgen Lake, Montana) than regions of low velocity gradients (e.g., eastern Snake River Plain). The regional spatial patterns of GPS data also help constrain the fundamental geodynamic processes that drive active continental deformation in the western United States.

During 2008, INL collected additional GPS phase data and teamed with Dr. Robert King at the Massachusetts Institute of Technology to process INL GPS phase data. In 2007, INL personnel installed GPS receivers at eight INL seismic stations bringing the total number of INL continuous GPS sites to thirteen (Table 4). As part of the Plate Boundary Observatory (PBO) under the EarthScope Science Program, there are currently 18 other continuous GPS sites near the Snake River Plain (Figure 4). One of these GPS receivers is co-located at INL's Great Rift, Idaho (GTRI) seismic station. In addition to continuously operating GPS sites, INL personnel collected GPS phase data at several campaign GPS sites. Dr. King processed all of INL's GPS phase data acquired up to 2008 and located within the ESRP and surrounding Basin and Range. He combined the INL GPS data with other data in the region to produce a velocity field that encompasses the Pacific Northwest. Locally, the horizontal GPS velocities indicate the Basin and Range is extending at a rate that is an order of magnitude greater than the Snake

River Plain, which is thought to explain its relative low seismicity (Payne et al. 2008a; Payne et al. 2008b; Payne et al. 2008c).

An INL continuous GPS station consists of a Trimble NetRS GPS receiver connected to a L1/L2 dual frequency choke ring antenna. The antenna is attached to a $2.4 \mathrm{~m}$ steel rod that is drilled into a rock outcrop to a depth of about $1 \mathrm{~m}$. Above ground the antenna is stabilized using a much larger PVC pipe filled with sand. This reduces the amount of wind noise within the GPS data, improving the accuracy. The NetRS receivers continuously collect GPS phase data. The phase data are relayed along with the seismic station data to DSL links, which are then accessed from the Internet at the IRC. Also, the phase data are downloaded daily from the Internet and archived by University NAVSTAR Consortium (UNAVCO). 


\subsection{Seismic Data Acquisition and Analysis System}

The INL records earthquake data on a computer Data Acquisition/Analysis System (DAAS) at the IRC. INL began recording earthquake data on the DAAS June 8, 1991 using the U. S. Geological Survey (USGS) CUSP processing software. Since 2001, significant upgrades have been made to the DAAS as a result of computer hardware and software advances. The USGS CUSP data acquisition and analysis software that supported use of the TIMIT program were replaced with the earthquake analysis program SEISAN (developed by the University of Bergen, Norway) in 2002 and the USGS EARTHWORM processing software in 2003. From June 1991 to November 2002, earthquake data were analyzed using the USGS TIMIT program. As of December 2002, earthquake data are now being analyzed using the SEISAN program. Use of the SEISAN and EARTHWORM programs facilitated the upgrades of seismic stations and SMAs to the NetDAS digital units, allowing concurrent waveform analyses of both velocity and acceleration data. Instrument responses of the NetDAS units at seismic stations and SMAs are now routinely determined and are integrated into the SEISAN database (see Appendices B and C). All digital earthquake data are also routinely archived to removable media after analysis.

The EARTHWORM program constantly monitors the ratios of the short-term average divided by the long-term average (STA/LTA) of incoming data. This involves comparing the short-term average (1-s window) of the seismic data to a longer-term average, which is the background noise or voltage level determined over a time interval of $20 \mathrm{~s}$. The program determines that an earthquake has occurred when the STA/LTA ratios for several stations within a subnet exceed a threshold value. When an earthquake is detected, the seismograms for all stations within triggered subnets and the time codes are saved in a file on a disk. This file is labeled with a sequential number based on the date and time of the trigger for later reference to the earthquake in the SEISAN database. Each seismogram has $30 \mathrm{~s}$ of pre-event data and 20 $\mathrm{s}$ of post-event data stored within the file. In some instances, earthquakes have low-amplitude emergent P-waves with larger amplitude S-waves. When this occurs the DAAS may trigger on the S-waves instead of the P-waves, thus, saving $30 \mathrm{~s}$ of pre-event time allows recording of the P-waves also.

The earthquake detection software is set up to trigger on earthquakes detected by several stations within a subnet. Subnets contain several stations that are located in a small area and which are likely to detect the same local earthquake. Subnets are specified for stations in close proximity to each other and their relationship to known seismic sources. For the ESRP though, a subnet was created for detection of small magnitude $(\mathrm{M}<0.5)$ microearthquakes. All INL seismic stations usually detect earthquakes of magnitude 1.5 .

The EARTHWORM program also enables data sharing with other seismic networks in near real time over the Internet. The INL provides data from various seismic stations to the University of Utah, Montana Bureau of Mines and Geology, and National Earthquake Information Center (NEIC), which in return provide data to INL (Table 2). EARTHWORM records seismic data from INL and these other agencies, which are analyzed using the SEISAN program. In 2007, data from EarthScope's TA stations and the NEIC's Intermountain West seismic network were added to the data shares. These data increased the earthquake-detection sensitivity and enhanced the azimuth coverage and magnitude determinations of earthquakes within the 161-km radius of INL, particularly for earthquakes in the southern and western parts of the ESRP and to the northwest in the Basin and Range mountains. 
Table 1. Seismic stations operated by INL.

\begin{tabular}{|c|c|c|c|c|c|c|}
\hline Code & Station Name & Types of Sensors & $\begin{array}{l}\text { Latitude } \\
\text { North } \\
\left({ }^{\circ}\right)\end{array}$ & $\begin{array}{l}\text { Longitude } \\
\text { West } \\
\left({ }^{\circ}\right) \\
\end{array}$ & $\begin{array}{l}\text { Elevation } \\
(\mathrm{m})\end{array}$ & $\begin{array}{c}\text { Date } \\
\text { Installed } \\
\text { (Month/Year) }\end{array}$ \\
\hline ARNI & $\begin{array}{l}\text { Argonne North, } \\
\text { Idaho }\end{array}$ & $\begin{array}{c}\text { Borehole Vertical } \\
\text { Seismometer; GPS } \\
\text { Receiver }\end{array}$ & 43.6667 & 112.6235 & 1533 & 09/1990 \\
\hline BCYI & Bear Canyon, Idaho & $\begin{array}{l}\text { Vertical } \\
\text { Seismometer; } \\
\text { Three-component } \\
\text { Accelerometers; } \\
\text { GPS Receiver }\end{array}$ & 44.3108 & 113.4052 & 2194 & 05/1992 \\
\hline CBTI & Cedar Butte, Idaho & $\begin{array}{l}\text { Borehole Vertical } \\
\text { Seismometer }\end{array}$ & 43.3875 & 112.9115 & 1734 & $07 / 1986$ \\
\hline COMI & $\begin{array}{c}\text { Craters of the Moon, } \\
\text { Idaho }\end{array}$ & $\begin{array}{l}\text { Three-component } \\
\text { Seismometers }\end{array}$ & 43.4618 & 113.5938 & 1890 & 03/1992 \\
\hline $\mathrm{CNCI}$ & $\begin{array}{c}\text { Crows Nest Canyon, } \\
\text { Idaho }\end{array}$ & $\begin{array}{c}\text { Vertical } \\
\text { Seismometer }\end{array}$ & 43.9283 & 113.4522 & 1914 & 05/1992 \\
\hline CRBI & $\begin{array}{l}\text { Circular Butte, } \\
\text { Idaho }\end{array}$ & $\begin{array}{c}\text { Borehole Vertical } \\
\text { Seismometer; GPS } \\
\text { Receiver }\end{array}$ & 43.8303 & 112.6345 & 1520 & $11 / 1987$ \\
\hline ECRI & Eagle Creek, Idaho & $\begin{array}{c}\text { Vertical } \\
\text { Seismometer }\end{array}$ & 43.0535 & 111.3705 & 2086 & 08/1994 \\
\hline EMI & $\begin{array}{c}\text { Eightmile Canyon, } \\
\text { Idaho }\end{array}$ & $\begin{array}{c}\text { Vertical } \\
\text { Seismometer; GPS } \\
\text { Receiver }\end{array}$ & 44.0742 & 112.9262 & 1963 & 04/1992 \\
\hline GBI & $\begin{array}{l}\text { Big Grassy Butte, } \\
\text { Idaho }\end{array}$ & $\begin{array}{c}\text { Borehole Vertical } \\
\text { Seismometer; GPS } \\
\text { Receiver }\end{array}$ & 43.9875 & 112.0633 & 1541 & $10 / 1981$ \\
\hline GRRI & Grays Range, Idaho & $\begin{array}{l}\text { Vertical } \\
\text { Seismometer; } \\
\text { Three-component } \\
\text { Accelerometers; } \\
\text { GPS Receiver }\end{array}$ & 42.9380 & 111.4217 & 2207 & 08/1994 \\
\hline GTRI & Great Rift, Idaho & $\begin{array}{c}\text { Borehole Vertical } \\
\text { Seismometer; GPS } \\
\text { Receiver* }\end{array}$ & 43.2440 & 113.2410 & 1522 & $05 / 1992$ \\
\hline HHAI & $\begin{array}{l}\text { Hell's Half Acre, } \\
\text { Idaho }\end{array}$ & $\begin{array}{l}\text { Borehole Vertical } \\
\text { Seismometer }\end{array}$ & 43.2950 & 112.3795 & 1371 & 06/1992 \\
\hline HPI & Howe Peak, Idaho & $\begin{array}{c}\text { Vertical } \\
\text { Seismometer; GPS } \\
\text { Receiver }\end{array}$ & 43.7113 & 113.0983 & 2597 & $10 / 1972$ \\
\hline
\end{tabular}


Table 1. Continued.

\begin{tabular}{|c|c|c|c|c|c|c|}
\hline Code & Station Name & Types of Sensors & $\begin{array}{l}\text { Latitude } \\
\text { North } \\
\left({ }^{\circ}\right)\end{array}$ & $\begin{array}{c}\text { Longitude } \\
\text { West } \\
\left({ }^{\circ}\right) \\
\end{array}$ & $\begin{array}{c}\text { Elevation } \\
(\mathrm{m})\end{array}$ & $\begin{array}{c}\text { Date } \\
\text { Installed } \\
\text { (Month/Year) }\end{array}$ \\
\hline HWFI & Howe Fault, Idaho & $\begin{array}{l}\text { Three-component } \\
\text { Seismometers; } \\
\text { Three-component } \\
\text { Accelerometers; } \\
\text { GPS Receiver }\end{array}$ & 43.9257 & 113.0973 & 1743 & $10 / 1999$ \\
\hline ICI & $\begin{array}{l}\text { Italian Canyon, } \\
\text { Idaho }\end{array}$ & $\begin{array}{c}\text { Vertical } \\
\text { Seismometer; GPS } \\
\text { Receiver }\end{array}$ & 44.3293 & 112.9412 & 2463 & 04/1992 \\
\hline IRCI & $\begin{array}{l}\text { INL Research } \\
\text { Center, Idaho }\end{array}$ & $\begin{array}{c}\text { Low-gain } \\
\text { Three-component } \\
\text { Seismometers }\end{array}$ & 43.5153 & 112.0333 & 1442 & $11 / 1988$ \\
\hline JGI & $\begin{array}{l}\text { Juniper Gulch, } \\
\text { Idaho }\end{array}$ & $\begin{array}{l}\text { Three-component } \\
\text { Seismometers }\end{array}$ & 44.0927 & 112.6768 & 1657 & $11 / 1979$ \\
\hline $\mathrm{KBI}$ & Kettle Butte, Idaho & $\begin{array}{l}\text { Borehole Vertical } \\
\text { Seismometer }\end{array}$ & 43.5907 & 112.3767 & 1678 & 05/1992 \\
\hline LJI & $\begin{array}{l}\text { Lemhi Junction, } \\
\text { Idaho }\end{array}$ & $\begin{array}{c}\text { Vertical } \\
\text { Seismometer }\end{array}$ & 43.8208 & 112.8440 & 1643 & 05/1990 \\
\hline LLRI & $\begin{array}{l}\text { Little Lost River, } \\
\text { Idaho }\end{array}$ & $\begin{array}{l}\text { Three-component } \\
\text { Seismometers }\end{array}$ & 43.7230 & 112.9330 & 1476 & $05 / 1990$ \\
\hline NPRI & $\begin{array}{l}\text { New Production } \\
\text { Reactor, Idaho }\end{array}$ & $\begin{array}{l}\text { Three-component } \\
\text { Seismometers; } \\
\text { Three-component } \\
\text { Accelerometers }\end{array}$ & 43.5975 & 112.8272 & 1495 & 09/1990 \\
\hline PTI & Pocatello, Idaho & $\begin{array}{l}\text { Vertical } \\
\text { Seismometer; } \\
\text { Three-component } \\
\text { Accelerometers; } \\
\text { GPS Receiver }\end{array}$ & 42.8703 & 112.3702 & 1670 & $10 / 1984$ \\
\hline PZCI & $\begin{array}{l}\text { Patelzick Creek, } \\
\text { Idaho }\end{array}$ & $\begin{array}{c}\text { Vertical } \\
\text { Seismometer; GPS } \\
\text { Receiver }\end{array}$ & 44.3410 & 112.3172 & 2073 & $12 / 1991$ \\
\hline SMBI & Sixmile Butte, Idaho & $\begin{array}{l}\text { Borehole Vertical } \\
\text { Seismometer }\end{array}$ & 43.5022 & 113.2677 & 1716 & 05/1992 \\
\hline SPCI & Split Crater, Idaho & $\begin{array}{l}\text { Three-component } \\
\text { Seismometers; } \\
\text { Three-component } \\
\text { Accelerometers }\end{array}$ & 43.4500 & 112.6370 & 1553 & 06/1992 \\
\hline
\end{tabular}


Table 1. Continued.

\begin{tabular}{ccccccc}
\hline Code & Station Name & Types of Sensors & $\begin{array}{c}\text { Latitude } \\
\text { North } \\
\left({ }^{\circ}\right)\end{array}$ & $\begin{array}{c}\text { Longitude } \\
\text { West } \\
\left({ }^{\circ}\right)\end{array}$ & $\begin{array}{c}\text { Elevation } \\
(\mathrm{m})\end{array}$ & $\begin{array}{c}\text { Date } \\
\text { Installed } \\
(\text { Month/Year) }\end{array}$ \\
\hline TCSI & $\begin{array}{c}\text { Telchick Spring, } \\
\text { Idaho }\end{array}$ & $\begin{array}{c}\text { Vertical } \\
\text { Seismometer; GPS } \\
\text { Receiver }\end{array}$ & 43.6193 & 113.4783 & 1731 & $05 / 1992$ \\
TMI & $\begin{array}{c}\text { Taylor Mountain, } \\
\text { Idaho }\end{array}$ & $\begin{array}{c}\text { Three-component } \\
\text { Seismometers; } \\
\text { GPS Receiver }\end{array}$ & 43.3057 & 111.9182 & 2179 & $10 / 1972$ \\
\hline *- GPS instrumentation is owned by the Plate Boundary Observatory under the EarthScope Science Program. & \\
\hline
\end{tabular}


Table 2. Agencies and stations from which INL receives data shares.

\begin{tabular}{|c|c|c|c|c|c|c|}
\hline Code & Station Name & $\begin{array}{l}\text { Latitude } \\
\text { North }\left({ }^{\circ}\right)\end{array}$ & $\begin{array}{c}\text { Longitude } \\
\text { West }\left({ }^{\circ}\right)\end{array}$ & $\begin{array}{c}\text { Elevation } \\
(\mathrm{m})\end{array}$ & \multicolumn{2}{|c|}{$\begin{array}{c}\text { Operating Dates } \\
\text { (Month/Year) }\end{array}$} \\
\hline \multicolumn{7}{|c|}{ National Earthquake Information Center, Golden, Colorado } \\
\hline AHID & Auburn, Idaho & 42.7653 & 111.1003 & 1960 & $11 / 1997$ & Pres \\
\hline BW06 & Boulder, Wyoming & 42.7667 & 109.5582 & 2224 & $05 / 1996$ & Pres \\
\hline DCID1 & Drake Creek, Idaho & 43.5945 & -111.1845 & 1871 & $03 / 2005$ & Pres \\
\hline HLID & Hailey, Idaho & 43.5625 & 114.4063 & 1498 & 08/1988 & Pres \\
\hline IMW & Indian Meadows, Wyoming & 43.8970 & -110.9392 & 2646 & $07 / 1980$ & Pres \\
\hline LOHW & Long Hollow, Wyoming & 43.6123 & -110.6037 & 2121 & $01 / 1986$ & Pres \\
\hline RRI2 & Red Ridge, Idaho & 43.3473 & -111.3202 & 2558 & $07 / 1986$ & Pres \\
\hline TPAW & Teton Pass, Wyoming & 43.4902 & -110.9507 & 2512 & $01 / 1986$ & Pres \\
\hline \multicolumn{7}{|c|}{ University of Utah, Salt Lake City, Utah } \\
\hline BEI & Bear River Range, Idaho & 42.1167 & 111.7823 & 1859 & $11 / 1984$ & Pres \\
\hline BMUT & Black Mountain, Utah & 41.9582 & 111.2342 & 2243 & $10 / 1979$ & Pres \\
\hline MCID & Moose Creek, Idaho & 44.1903 & 111.1827 & 2149 & $12 / 1995$ & Pres \\
\hline MLI & Malad Range, Idaho & 42.0268 & 112.1255 & 1896 & $10 / 1974$ & Pres \\
\hline NPI & North Pocatello, Idaho & 42.1473 & 112.5183 & 1640 & $04 / 1975$ & Pres \\
\hline YMC & Maple Creek, Wyoming & 44.7593 & 111.0062 & 2073 & $12 / 1983$ & Pres \\
\hline YPP & Pitchstone Plateau, Wyoming & 44.2710 & 110.8045 & 2707 & 08/1996 & Pres \\
\hline \multicolumn{7}{|c|}{ Montana Bureau of Mines and Geology, Butte, Montana } \\
\hline MCMT & McKenzie Canyon, Montana & 44.8277 & 112.8488 & 2323 & 09/1989 & Pres \\
\hline MOMT & Monida, Montana & 44.5933 & 112.3943 & 2220 & $10 / 1995$ & Pres \\
\hline TPMT & Teepee Creek, Montana & 44.7298 & 111.6657 & 2518 & $10 / 1992$ & Pres \\
\hline
\end{tabular}


Table 3. Strong-motion accelerographs operated by INL in 2008.

\begin{tabular}{|c|c|c|c|c|}
\hline INL Site Facility Area & Building Number & Location & SMA Code & Year Installed \\
\hline MFC & ANL-767 & Basement & EBR & 1973 \\
\hline MFC & ANL-768 & Basement & FCF & 1973 \\
\hline CFA & CFA-1607 & Free-field & CFAF & 1996 \\
\hline CFA & EFS & Free-field & EFSF & 1997 \\
\hline INTEC* & CPP-668 & Free-field & CPPF & 1992 \\
\hline INTEC & CPP-601 & First Floor & CPP1 & 1973 \\
\hline INTEC & СРP-601 & Second Basement & $\mathrm{CPP} 2$ & 1973 \\
\hline INTEC & CPP-666 & Second Floor & FAS1 & 1984 \\
\hline INTEC & CPP-666 & Second Basement & FAS2 & 1984 \\
\hline NPRI & NA & Free-field & NPRF & 2008 \\
\hline NRF & NRF-768 & Free-field & NRFF & 1996 \\
\hline $\mathrm{NRF}$ & NRF-A1W & First Floor & $\mathrm{A} 1 \mathrm{~W}$ & 1983 \\
\hline $\mathrm{NRF}$ & NRF-S1W & First Floor & $\mathrm{S} 1 \mathrm{~W}$ & 1983 \\
\hline PBF & NA & Free-field & PBFF & 2005 \\
\hline $\mathrm{PBF}$ & NA & Free-field & ARAF & 2005 \\
\hline RTC & TRA-602 & Free-field & TRAF & 2003 \\
\hline RTC & TRA-670 & Basement & TRA2 & 1996 \\
\hline RTC & TRA-670 & First Floor & TRA3 & 2008 \\
\hline RWMC & NA & Free-field & RWMC & 1997 \\
\hline RWMC & NA & Free-field & RWME & 2005 \\
\hline STC & IRC-602 & First Floor & IRC & 1983 \\
\hline TAN & NA & Free-field & TANA & 2007 \\
\hline TAN & TAN-601 & First Floor & TANH & 2008 \\
\hline TAN & $\mathrm{SMC}$ & First Floor & $\mathrm{SMC}$ & 2007 \\
\hline \multicolumn{5}{|l|}{ NA - Not within a building. } \\
\hline
\end{tabular}


Table 4. Continuous GPS sites co-located with INL seismic stations.

\begin{tabular}{|c|c|c|c|c|c|}
\hline Code & Station Name & $\begin{array}{l}\text { Latitude } \\
\text { North }\left(^{\circ}\right)\end{array}$ & $\begin{array}{l}\text { Longitude } \\
\text { West }\left(^{\circ}\right)\end{array}$ & $\begin{array}{c}\text { Elevation } \\
\text { (m) }\end{array}$ & Year Installed \\
\hline ARNG & Argonne North, Idaho & 43.6667 & 112.6235 & 1533 & 2005 \\
\hline BCYI & Bear Canyon, Idaho & 44.3108 & 113.4052 & 2194 & 2003 \\
\hline CRBG & Circular Butte, Idaho & 43.8303 & 112.6345 & 1520 & $2007^{\mathrm{a}}$ \\
\hline EMIG & Eightmile Canyon, Idaho & 44.0742 & 112.9262 & 1963 & 2005 \\
\hline GBIG & Big Grassy Butte, Idaho & 43.9875 & 112.0633 & 1541 & $2007^{\mathrm{a}}$ \\
\hline GRRG & Grays Range, Idaho & 42.9380 & 111.4217 & 2207 & $2007^{\mathrm{a}}$ \\
\hline GTRG & Great Rift, Idaho & 43.2440 & 113.2410 & 1522 & $1998^{b}$ \\
\hline HPIG & Howe Peak, Idaho & 43.7113 & 113.0983 & 2597 & 2005 \\
\hline HWFG & Howe Fault, Idaho & 43.9257 & 113.0973 & 1743 & $2007^{\mathrm{a}}$ \\
\hline ICIG & Italian Canyon, Idaho & 44.3293 & 112.9412 & 2463 & 2007 \\
\hline PTIG & Pocatello, Idaho & 42.8703 & 112.3702 & 1670 & $2007^{\mathrm{a}}$ \\
\hline PZCG & Patelzick Creek, Idaho & 44.3410 & 112.3172 & 2073 & $2007^{\mathrm{a}}$ \\
\hline TCSG & Telchick Spring, Idaho & 43.6193 & 113.4783 & 1731 & 2005 \\
\hline TMIG & Taylor Mountain, Idaho & 43.3057 & 111.9182 & 2179 & $2007^{\mathrm{a}}$ \\
\hline \multicolumn{6}{|c|}{$\begin{array}{l}\text { a - Although hardware was installed for the GPS receiver in } 2007 \text {, the receiver began acquiring phase data in } \\
2008 \text {. }\end{array}$} \\
\hline \multicolumn{6}{|c|}{$\begin{array}{l}\text { b - Co-located at INL's seismic station GTRI, but operated by the Plate Boundary Observatory under the } \\
\text { EarthScope Science Program. }\end{array}$} \\
\hline
\end{tabular}




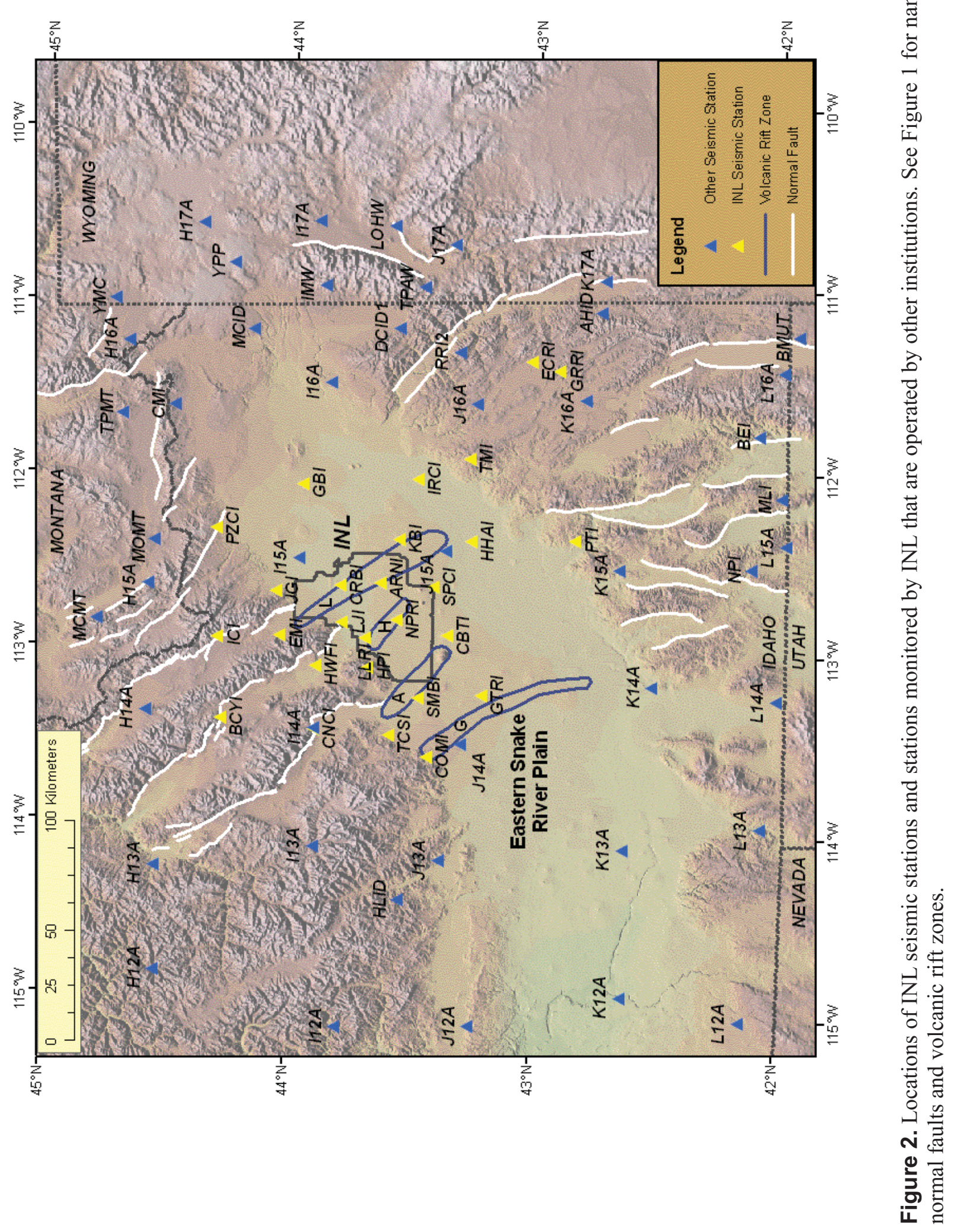




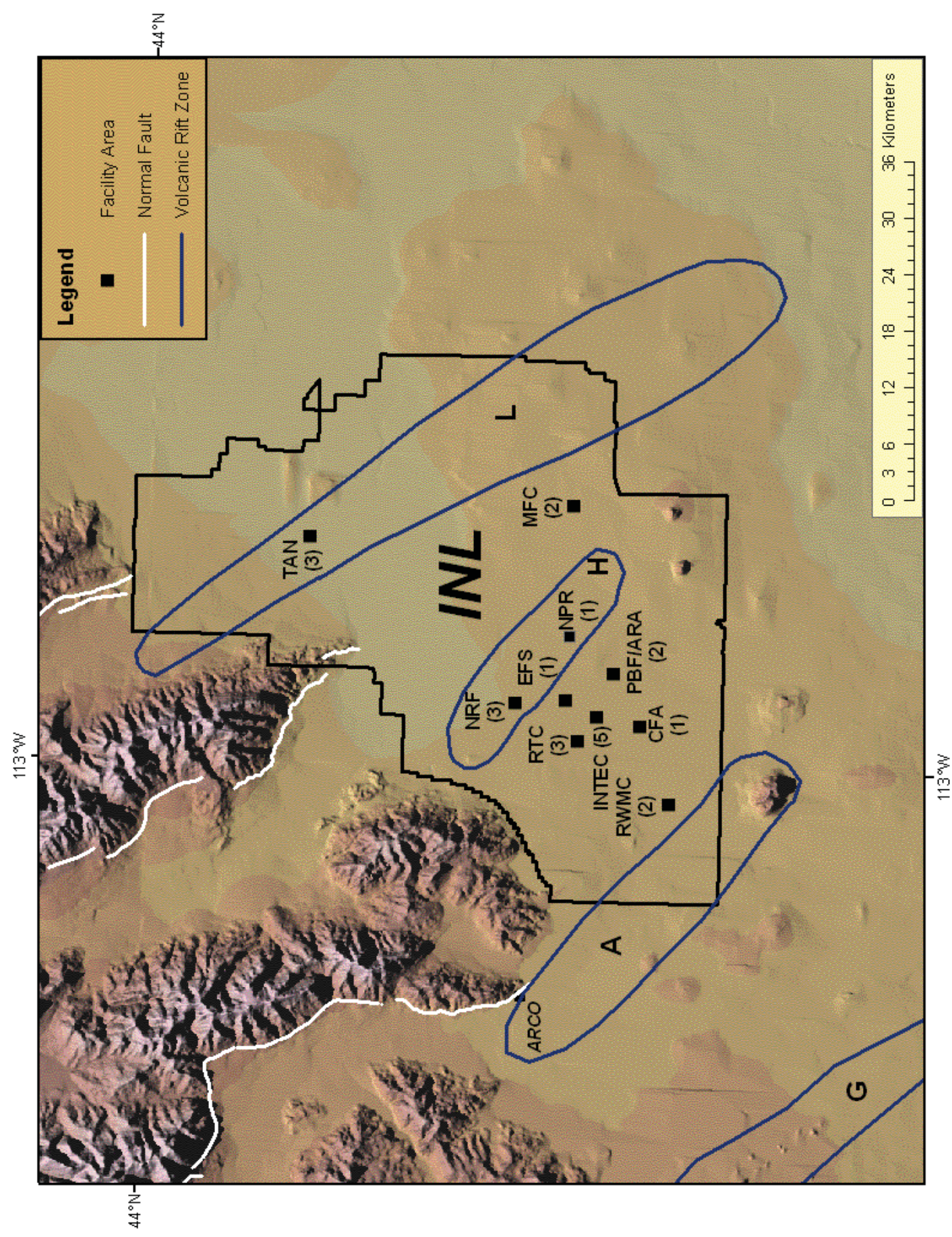

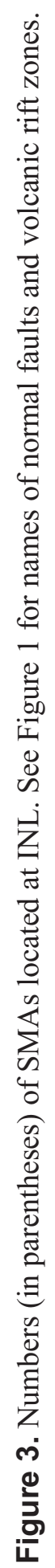




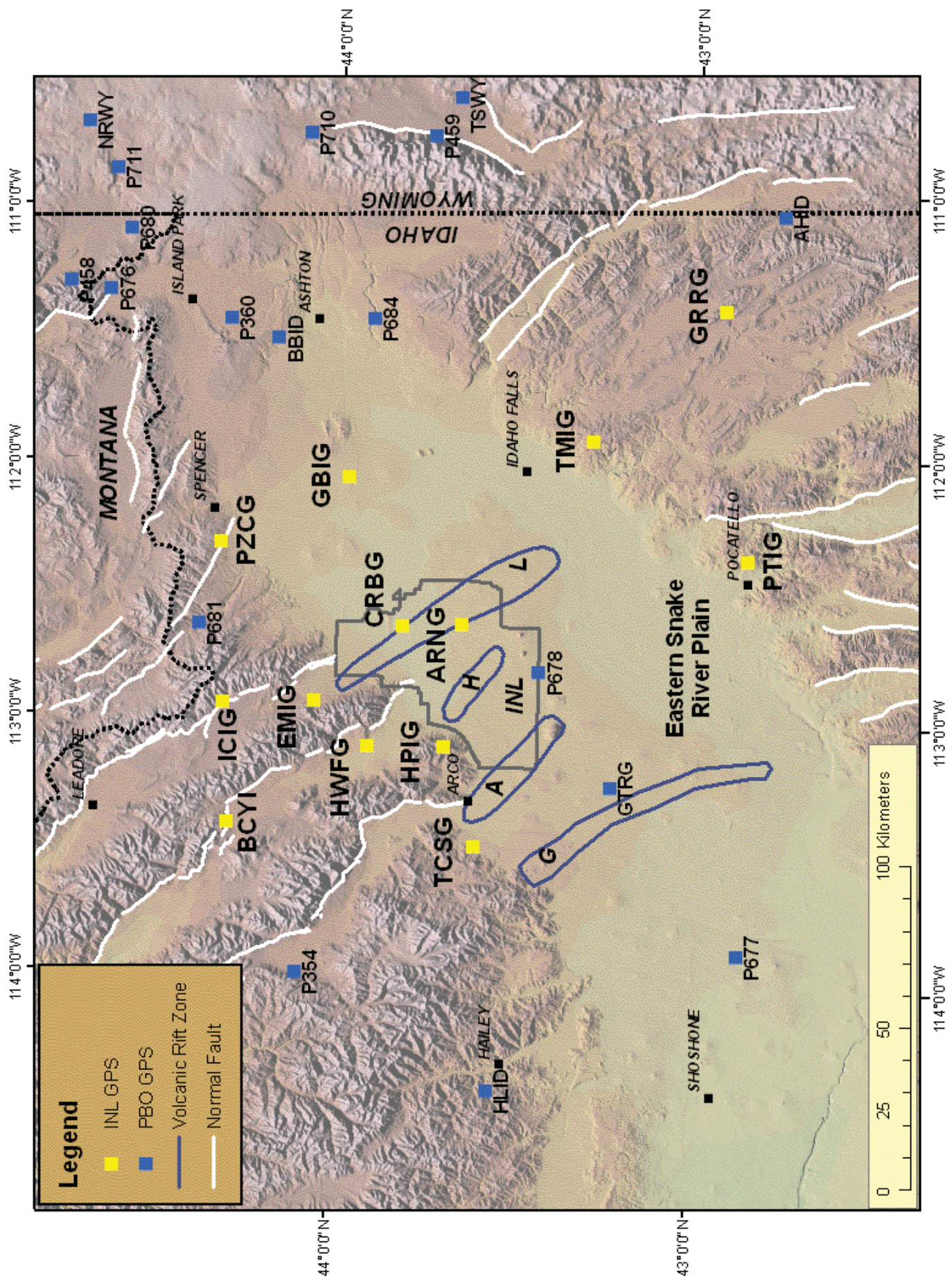

oิ

2
0
0
0
0
0
0
0

量

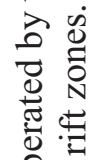

을

हี

을

苟 完

记 总

的

当

त

चै है

웜

ํํㄴ

.0

跑

थू

号

을

节

8)

岂.

๘ี Оั.

总

+

桴竞 


\section{Data Analysis}

Digital seismograms are analyzed using the SEISAN program to determine the earthquake's location, magnitude, and peak ground accelerations. SEISAN displays multiple seismograms on a computer screen with corresponding time codes having accuracy of $\pm 0.001 \mathrm{~s}$. P- and S-phase arrival times of the seismograms are selected with accuracies up to $0.01 \mathrm{~s}$. Duration and/or amplitude of a seismic signal is selected and then used to calculate the magnitude of an earthquake. The arrival times, durations, and amplitudes measured for an earthquake are saved in a computer file directly from the SEISAN program. The HYPOINVERSE program is used to compute the location. Two methods may be used to calculate the final magnitude of an earthquake depending on its size. Amplitudes of the accelerograms are also measured using the SEISAN program, then processed using a separate program that outputs peak horizontal and vertical accelerations. The locations and magnitudes of the earthquakes are plotted on maps to assess seismically active regions near the INL.

\subsection{Location Method}

The HYPOINVERSE computer program (Klein, 1989) is used to determine locations for all local earthquakes recorded. Phase data files (arrival times of the earthquake) from the output of SEISAN are input into the HYPOINVERSE location program. According to Zollweg and Sprenke (1995), stable locations are usually obtained from about seven to ten arrival times (P- and S-waves combined) for recorded events that are not surrounded by INL seismic stations. Within the INL network, stable locations can be obtained with a minimum of six arrival times. Because of the density and sensitivity of the INL seismic network, the majority (usually more than $90 \%$ ) of earthquakes located within the 161-km radius have a minimum of six arrival times. However, some earthquakes are located with fewer than six arrival times and, thus, their locations have larger errors. Seismic stations from other agencies monitored by the INL provide coverage outside the INL network and phase arrivals from these stations supplement phase data from INL stations in an attempt to reduce location errors.

Four P-wave velocity models are used in the HYPOINVERSE location program depending on the location of the earthquakes (Table 5). The "ESRP" velocity model is used for locating earthquakes that occur within the ESRP including the mountainous terrain on the northern and eastern edge of the Plain (Olsen et al., 1979; Sparlin et al., 1979; Braile and Smith, 1979; and Ackerman, 1979). The "INL ESRP" velocity model is used to locate earthquakes that occur on the ESRP and are near or within the INL Site boundaries. This model was developed from Sparlin et al. (1982) and Braile et al. (1982) and checked with respect to a few microearthquakes located within the ESRP (Jackson et al., 1989). The "BPEAK" velocity model is used for locating earthquakes that occur in the Borah Peak aftershock area and the mountainous terrain northwest of the Plain (Richins et al., 1987). Finally, the "SMT" velocity model is used to locate earthquake in southwestern Montana (Stickney, 1997). For all velocity models, a P-wave velocity to S-wave velocity ratio of 1.75 is used (Bones, 1978; Greensfelder and Kovach, 1982; and Richins et al., 1987).

Other notable parameters used in the HYPOINVERSE location program are the starting focal depth, set to $5 \mathrm{~km}$, and the distance cutoff for arrival weighting, set to $50 \mathrm{~km}$. Zollweg and Sprenke (1995) evaluated the parameters chosen for the HYPOINVERSE program used by INL. They determined that the parameters chosen yield good location results despite the poor coverage in azimuth of earthquakes outside the network. An evaluation of the difference between the observed and computed latitude and longitude was less than $0.25 \mathrm{~km}$. 


\subsection{Magnitude Calculations}

Magnitudes are determined using two methods 1) coda magnitudes using signal duration of digital seismograms and 2) local magnitudes using amplitudes from digital seismograms. A coda magnitude $\left(\mathrm{M}_{\mathrm{c}}\right)$ is calculated for an earthquake using several signal durations measured from the seismograms of different seismic stations. A local magnitude $\left(\mathrm{M}_{\mathrm{L}}\right)$ is calculated using the largest peak-to-peak trace amplitude measured from digital waveforms and the Richter magnitude equation. If a magnitude cannot be determined for a local earthquake, then magnitudes determined by other seismic networks may be used. These include the University of Utah, Montana Bureau of Mines and Geology, NEIC, the University of Nevada, Reno, and the University of Washington. The summary list of earthquakes in Appendix D lists the type of magnitude calculated and what institution reported the magnitude.

For the signal duration method, the following expression is used to calculate coda magnitude at a station (Arabasz et al., 1979):

$\mathrm{M}_{\mathrm{c}}=-3.13+2.74 \log \tau+0.0012 \Delta$

Where:

$\tau=$ Total signal duration recorded at the station in seconds;

$\Delta=$ Epicentral distance from the station in $\mathrm{km}$.

The duration is measured from the start of the earthquake signature (P-wave arrival) to the end of the coda, where the signal fades into the background noise of the trace. The final magnitude is determined by averaging the coda magnitude calculated for each seismogram. The SEISAN program automatically selects the duration of the earthquake when the P-wave arrival time is selected. Equation (1) is usually used to estimate magnitudes for events located by the HYPOINVERSE location program.

Local magnitudes calculated from the digital seismograms are based on the Richter magnitude scale. Richter (1958) defined the local magnitude scale from the following equation:

$\mathrm{M}_{\mathrm{L}}=\log \mathrm{A}-\log \mathrm{A}_{\mathrm{o}}$

Where:

$\mathrm{A}=$ Recorded maximum trace amplitude from the zero-line measured in millimeters on a standard seismogram;

$\mathrm{A}_{\mathrm{o}}=$ Maximum trace amplitude from the zero-line in millimeters for a selected standard earthquake.

Dr. Richter developed the scale for a standard earthquake of magnitude 3.0 at $100 \mathrm{~km}$ for $\mathrm{A}_{\mathrm{o}}=0.001 \mathrm{~mm}$ and amplitude of $1.0 \mathrm{~mm}$ measured on the standard seismogram. He constructed a table of magnitudes based on distance and - $\log \mathrm{A}_{\mathrm{o}}$ for maximum trace amplitudes recorded on the standard Wood-Anderson seismogram.

SEISAN has a program that uses equation [2] with amplitudes measured on a synthetic WoodAnderson digital seismogram. The program allows the user to convert waveforms recorded on the horizontal channels of accelerometers and seismometers at INL seismic stations to synthetic WoodAnderson seismograms. The SEISAN program uses the instrument response information contained in 
Appendix B for accelerograms and Appendix C for seismograms to calculate synthetic Wood-Anderson seismograms at a magnification of 2800. The user then selects the largest peak-to-peak amplitude (or A) in millimeters from the digital display of the synthetic Wood-Anderson seismogram. The SEISAN program then uses the distance of the simulated Wood-Anderson station to the earthquake's epicenter and one-half the peak-to-peak amplitude to determine local magnitude using Richter's table. The program determines the local magnitude for the amplitude selected.

\subsection{Peak Accelerations}

Peak horizontal and vertical accelerations are determined for accelerograms (or acceleration time histories) using the SEISAN program (Section 2.4). SEISAN displays the horizontal and vertical accelerograms for some free-field SMAs located at the INL and accelerometers co-located with the seismic stations. The SEISAN program allows the user to correct the accelerograms by removing the instrument responses listed in Appendices A and B. A separate program is used to measure the largest zero-to-peak acceleration amplitude from the corrected acceleration time history.

\subsection{Location Quality}

Comparisons between earthquake locations determined by the INL and locations determined by other temporary networks or NEIC have been used to approximate locations errors of earthquake epicenters (Jackson et al., 1993a). This method was very general and yielded an approximation of the quality of the INL earthquake locations. In 1995, the State of Idaho requested Zollweg and Sprenke (1995) to perform an independent assessment of the INL Seismic Monitoring Program. Zollweg and Sprenke (1995) evaluated the location accuracy of the INL seismic network by two methods: 1) directly comparing INL locations to well-located earthquakes; and 2) indirectly by evaluating the network bias or non-random error through varying independent permutations (or combinations) of recording stations.

For the first method, twenty-two earthquakes having high-quality locations determined from a temporary seismic network installed near Challis, Idaho from July 1, 1992 to July 12, 1992 (by Boise State University) were compared to INL locations for these earthquakes. The earthquakes were located about $120 \mathrm{~km}$ from the center of INL, had varying magnitudes ranging from 1.9 to 4.5 , and had absolute errors less than $1 \mathrm{~km}$. The epicenters determined by INL seismic stations for these events differed by 1.6 to $11.5 \mathrm{~km}$ with an average of $7.1 \mathrm{~km}$. The differences in locations were dependent on magnitude, with the smaller magnitude earthquakes tending to have greater differences in locations (Zollweg and Sprenke, 1995). These results are similar to the earlier estimates of an error radius of $5 \mathrm{~km}$ for a comparison to high-quality locations of the aftershocks from the $\mathrm{M}_{\mathrm{s}} 7.3$ October 28, 1983 earthquake (Jackson et al., 1993a). However it is noted that this estimate for an error radius was based on having five stations in the INL seismic network at that time. The closest station to the aftershocks was at a distance of $50 \mathrm{~km}$ or more.

The second method used by Zollweg and Sprenke (1995) evaluates the network bias. Unless all earthquakes are located using exactly the same groups of stations and phases (P-and S-waves), the relative locations will be affected by a non-random error or network bias. The network bias is important for the smaller earthquakes that make up the majority of the events in an earthquake catalog since fewer stations usually record smaller earthquakes. Five earthquakes located northwest of the INL seismic network and ranging in magnitude from 1.8 to 3.8 were used in the analysis. Because INL operated 26 seismic stations at the time of the assessment, there were millions of possible combinations of recording stations. Zollweg and Sprenke (1995) chose to vary the combination of the ten most influential phase arrivals for the permutation analysis. The locations for most of the permutations clustered about radii ranging from 6.5 to $11 \mathrm{~km}$. For the magnitude 3.8 earthquake, $8 \%$ of the permutations resulted in a linear 
band extending $100 \mathrm{~km}$. Zollweg and Sprenke (1995) suggested that earthquakes located with fewer Swave arrival times have less well-constrained locations. Some of the larger earthquakes, like the magnitude 3.8 earthquake, have fewer S-wave arrival times because the signals saturate the instrumentation and onset of the S- wave is indistinguishable from the P-waves. Earthquakes with more than three $\mathrm{S}$-wave-arrival times resulted in better-constrained locations.

\subsection{Depth Quality}

The HYPOINVERSE location program also calculates depth to the hypocenter. Focal depths calculated by this program are not accurate for many of the earthquakes recorded by the INL seismic network for two reasons: 1) the station spacing is usually greater than twice the focal depth of the earthquake recorded; and 2) the earthquake usually occurs outside of the network. To calculate accurate focal depths, the earthquake must occur within the seismic network or at a distance equal to or less than its focal depth. Although focal depths are listed in Appendix D, they should be interpreted within the context of the limitations discussed in this section unless otherwise indicated.

\subsection{Data Completeness}

Local earthquakes are easily discriminated from other seismic data such as local mine blasts, air blasts (or sonic booms), and distant (worldwide) and regional earthquakes occurring far outside of the INL seismic network. For example, man-made blasts are easily discriminated from earthquakes on the basis of waveform characteristics, the time the event occurred, and the location of the event. The NEIC earthquake website listing is regularly inspected to confirm consistency with the INL earthquake catalog for magnitudes 2.5 and greater (the cutoff magnitude for NEIC earthquake locations).

Detection threshold can provide a measure of completeness for the INL earthquake catalog. It is defined as the magnitude level at which the seismic network will nearly always locate an earthquake. Zollweg and Sprenke (1995) evaluated the detection threshold by plotting the cumulative number of earthquakes as a function of magnitude to determine the lowest magnitude point that the curve begins to flatten. Zollweg and Sprenke (1995) determined the detection threshold to be a magnitude 1.3 anywhere within a 100-mile radius around INL. Their conclusion was based on a plot of 1360 earthquakes for an 18-month period. Since the seismic stations are all located within $90 \mathrm{~km}$ of the center of INL, they suggested that the detection threshold is magnitude 0.8 within the network on the ESRP. The analysis of Zollweg and Sprenke (1995) suggests that the INL earthquake catalog is complete for magnitudes above 1.3 within a 100 -mile radius of INL and may be complete for magnitudes as low as 0.8 within the

network. Hardware and software upgrades for the current DAAS have increased detection sensitivities on the order of magnitude 0.0 which allow recording of small magnitude microearthquakes within ESRP. 
Table 5. P-wave velocity models used in location programs.

\begin{tabular}{|c|c|c|c|c|}
\hline Velocity Model Code & $\begin{array}{l}\text { Velocity } \\
(\mathrm{km} / \mathrm{sec})\end{array}$ & $\begin{array}{l}\text { Depth to Top of } \\
\text { Layer }(\mathrm{km})\end{array}$ & $\begin{array}{c}\text { Layer Thickness } \\
(\mathrm{km})\end{array}$ & References \\
\hline \multirow[t]{4}{*}{ ESRP } & 4.90 & 0.00 & 2.00 & \multirow{4}{*}{$\begin{array}{l}\text { Olsen et al., 1979; } \\
\text { Sparlin et al., 1979; } \\
\text { Braile \& Smith, 1979; } \\
\text { Ackerman, } 1979 .\end{array}$} \\
\hline & 6.00 & 2.00 & 15.00 & \\
\hline & 6.70 & 17.00 & 23.00 & \\
\hline & 7.90 & 40.00 & Half-space & \\
\hline \multirow[t]{7}{*}{ INL ESRP } & 3.30 & 0.00 & 1.00 & \multirow{7}{*}{$\begin{array}{l}\text { Sparlin et al., 1982; } \\
\text { Braile et al., 1982; } \\
\text { Jackson et al., } 1989 .\end{array}$} \\
\hline & 4.90 & 1.00 & 2.00 & \\
\hline & 5.30 & 3.00 & 2.00 & \\
\hline & 6.15 & 5.00 & 2.00 & \\
\hline & 6.53 & 7.00 & 10.00 & \\
\hline & 6.80 & 17.00 & 23.00 & \\
\hline & 8.00 & 40.00 & Half-space & \\
\hline \multirow[t]{5}{*}{ BPEAK } & 4.75 & 0.00 & 1.64 & \multirow[t]{5}{*}{ Richins et al., 1987.} \\
\hline & 5.59 & 1.64 & 5.31 & \\
\hline & 6.16 & 6.95 & 11.05 & \\
\hline & 6.80 & 18.00 & 22.00 & \\
\hline & 8.00 & 40.00 & Half-space & \\
\hline \multirow[t]{4}{*}{ SMT } & 5.52 & 0.00 & 5.86 & \multirow[t]{4}{*}{ Stickney, 1997.} \\
\hline & 6.12 & 5.86 & 12.78 & \\
\hline & 6.74 & 18.64 & 20.05 & \\
\hline & 8.00 & 38.69 & Half-space & \\
\hline
\end{tabular}




\section{2008 Earthquake Activity}

During 2008, INL recorded 7,284 independent triggers from earthquakes that occurred worldwide, in the western United States, and in the local region of the ESRP. Within the local region, INL located 2,396 earthquakes and man-made blasts outside and within a 161-km (or 100-mile) radius of INL. Of these, twenty-five were small to moderate size earthquakes ranging in magnitude from 3.0 to 3.9 and 823 earthquakes occurred within the 161-km radius of INL.

\subsection{Regional Earthquake Activity}

Eighteen earthquakes of magnitudes from 3.0 to 3.9 occurred in the immediate region outside the 161-km radius of INL. Eleven of these earthquakes with magnitudes (M) from M 3.0 to M 3.9 occurred in 2008 as part of a large swarm in Yellowstone National Park (east of Island Park in Figure 5), which consisted of more than 900 earthquakes that spanned the time period from 26 December 2008 to 8 January 2009. The swarm was centered beneath Yellowstone Lake and exhibited a northward migration of epicenters. Three earthquakes in this swarm were reported felt by local residents: M 3.5 and M 3.2 events on 27 December 2008 and the M 3.9 event on 28 December 2008. Earlier in 2008, three other earthquakes occurred in Yellowstone National Park. The first M 3.7 event occurred on 9 January 2008, the second M 3.1 event occurred on 12 March 2008, and the third M 3.4 event occurred on 24 March 2008. The largest event was reported felt by local residents. To the west of Yellowstone National Park, two earthquakes of M 3.2 and M 3.0 occurred on 24 June 2008 and 31 August 2008, respectively. Further west, an M 3.1 event on 25 March 2008 occurred near Dillon, MT. One earthquake M 3.3 occurred southeast of Pocatello, ID just outside the 161-km radius. Residents felt this event on 16 August 2008.

INL also recorded the 21 February 2008 M 6.0 mainshock that occurred near Wells, Nevada and 250 aftershocks that occurred from 21 February 2008 to 31 March 2008. The mainshock was located more than $300 \mathrm{~km}$ (190 miles) from INL facilities and was not reported felt at INL. The earthquake did not trigger SMAs that are located within buildings at the INL Site. Free-field accelerographs (not within buildings) and accelerometers co-located with seismic stations recorded acceleration data. Peak accelerations are listed in Table 6, and the locations of the accelerometers relative to the mainshock epicenter are shown in Figure 6.

\subsection{Local Earthquake Activity}

There were 823 earthquakes located within the 161-km radius of INL, which occurred within the ESRP and in the surrounding Basin and Range Province (Figure 7). The large number of earthquakes within the 161-km radius of INL is the result of eight different earthquake swarms that occurred throughout the year. Six of the seven earthquakes of M 3.0 to M 3.7 were associated with these swarms. Eight earthquakes occurred within the ESRP; seven near Craters of the Moon National Monument and one within the INL boundary.

Eight earthquake swarms occurred in central Idaho, in southwestern Montana, near the IdahoWyoming border, and in southeastern Idaho. The central-Idaho earthquake swarm, which occurred southeast of Stanley, ID, included the M 3.7 event of 26 November 2008 and M 3.6 event of 27 November 2008 and had 51 earthquakes associated with it (Figure 7). This swarm began 25 November 2008 and ended on 29 December 2008. Another swarm of earthquakes occurred east of Stanley and southwest of Challis, ID near Clayton, ID. This short-duration swarm began on 2 November 2008, ended 4 November 2008, and included 22 events. Throughout the year, 62 events were associated with the aftershock zone of the 1983 Borah Peak earthquake along the northwest-trending Lost River fault south of Challis. 
Three earthquake swarms occurred along the east-west trending Centennial fault in southwestern Montana, which is north of Spencer, ID (Figure 7). The first swarm of 26 events began 22 February 2008 and included the M 3.1 and M 3.0 events of 22 February 2008 and 23 February 2008, respectively. The swarm was located near the west end of the Centennial fault. The second swarm of 14 events occurred to the east of the first swarm near the center of the Centennial fault beginning 4 March 2008 and ending 28 March 2008. The time period of second swarm overlapped with the third swarm, but was located to the west of the first swarm near Lima Reservoir. The third swarm of 36 events began 26 March 2008 and ended 14 April 2008.

Two earthquake swarms occurred near the Idaho-Wyoming border southeast of Ashton, ID and near the north-south trending Teton fault (Figure 7). The first swarm had only 12 events and lasted one day on 9 July 2008 with the largest event of M 2.0. The second swarm of $M<2.6$ events occurred in the footwall of the east-dipping Teton fault and included 28 events. This swarm began 30 October 2008 and ended 5 November 2008.

An earthquake swarm with 112 events occurred within the scattered events covering southeastern Idaho east of Pocatello, ID (Figure 7). The earthquake swarm began 14 May 2008, continued over three months, and ended 31 August 2008. Two events of M 3.0 and M 3.2 occurred on 14 May 2008 and 22 July 2008, respectively. Neither event was felt by local residents.

\subsection{Earthquakes within the Eastern Snake River Plain}

During 2008, eight small-magnitude earthquakes occurred within ESRP, one of which was located within the INL boundary (Figure 7). The event of M 1.5 occurred in the central part of INL on 9 October 2008. Its focal depth was shallow at $3.9 \mathrm{~km}$, typical of past microearthquakes observed within the ESRP (e.g., Jackson et al. 1993b). Another event occurred within the ESRP and was located south of the INL boundary. The M 1.1 event of 3 October 2008 had an uncharacteristically deep, though poorly constrained, focal depth of $37 \mathrm{~km}$.

Six other earthquakes of uncharacteristic focal depths and waveform character were located within and around Craters of the Moon National Monument (COM) during 2008. Adding to the three similar events which occurred 2007, Carpenter and Payne (2009) performed additional studies of these events. After re-analysis of all INL events within the ESRP and adjacent Basin and Range near the northern end of COM, twelve earthquakes of magnitudes from 0.5 to 2.5 and depths from 16 to $42 \mathrm{~km}$ were found from 1999 through 2008 in the study area (Figure 8). Eight events with stable, well-constrained locations nucleated at mid-crustal depths from 15 to $25 \mathrm{~km}$ below the surface, six of which occurred from February, 2007 through November, 2008. Confidence of the hypocenter depths was gained by searching for root mean square travel-time residual minima through fixed event depths, plotting predicted arrivals on waveforms, and relocating events with subsets of arrivals (P- and S-phases).

The COM events are anomalous for two reasons: Firstly, the hypocenter depths are uncharacteristic as ESRP earthquakes have occurred at depths of less than $10 \mathrm{~km}$ and nearby Basin and Range events typically occur at depths of $15 \mathrm{~km}$ or less. The observed focal depths are significant as they are located near and around base of the mid-crustal sill where magma is thought to reside and at depths hypothesized to be source regions for dikes. Secondly, the character of the waveforms differs dramatically from typical brittle-fracture earthquakes observed in the ESRP and Basin and Range. Upon inspection, waveforms from several of these earthquakes are quite similar to waveforms recorded from long-period volcanic events in other active volcanic regions, including having dominant frequencies of less than $2 \mathrm{~Hz}$. 


\section{5. $1972-2008$ Earthquake Activity}

Earthquakes in 2008 were located within and around the ESRP that have been active in the past (Figure 9). Of the more than 10,000 earthquakes shown in Figure 9, only 48 small-magnitude microearthquakes $\left(\mathrm{M}_{\mathrm{L}} \leq 2.0\right)$ have occurred within the ESRP near the region of the INL (excluding events near Ashton and Island Park). Of these, 13 events have anomalous focal depths and may be associated with magmatic processes at or near COM. The other 35 events have shallow focal depths $(<11 \mathrm{~km})$, more typical of earthquakes associated with regional tectonic tensional stresses. Even though microearthquakes have occurred within the ESRP, earthquake monitoring by the INL seismic network for the last 36 years indicates that the ESRP has been seismically inactive relative to the surrounding Basin and Range Province (Jackson et al., 1993b). 
Table 6. Peak accelerations measured at INL accelerographs for the 21 February 2008 M 6.0 Wells, Nevada Earthquake.

\begin{tabular}{|c|c|c|c|c|c|c|}
\hline & \multicolumn{5}{|c|}{ Peak Acceleration (g) } & \multicolumn{2}{c|}{$\begin{array}{c}\text { Distance from Earthquake } \\
\text { Epicenter }\end{array}$} \\
\hline Station Code & Maximum & North & East & Vertical & $(\mathrm{km})$ & (miles) \\
\hline PTI & 0.0048 & 0.0048 & 0.0048 & 0.0021 & 281 & 175 \\
\hline RWME & 0.0015 & 0.0015 & 0.0015 & 0.0009 & 304 & 189 \\
\hline RWMC & 0.0013 & 0.0013 & 0.0012 & 0.0006 & 306 & 190 \\
\hline NRFF & 0.0011 & 0.0011 & 0.0011 & 0.0005 & 324 & 201 \\
\hline
\end{tabular}




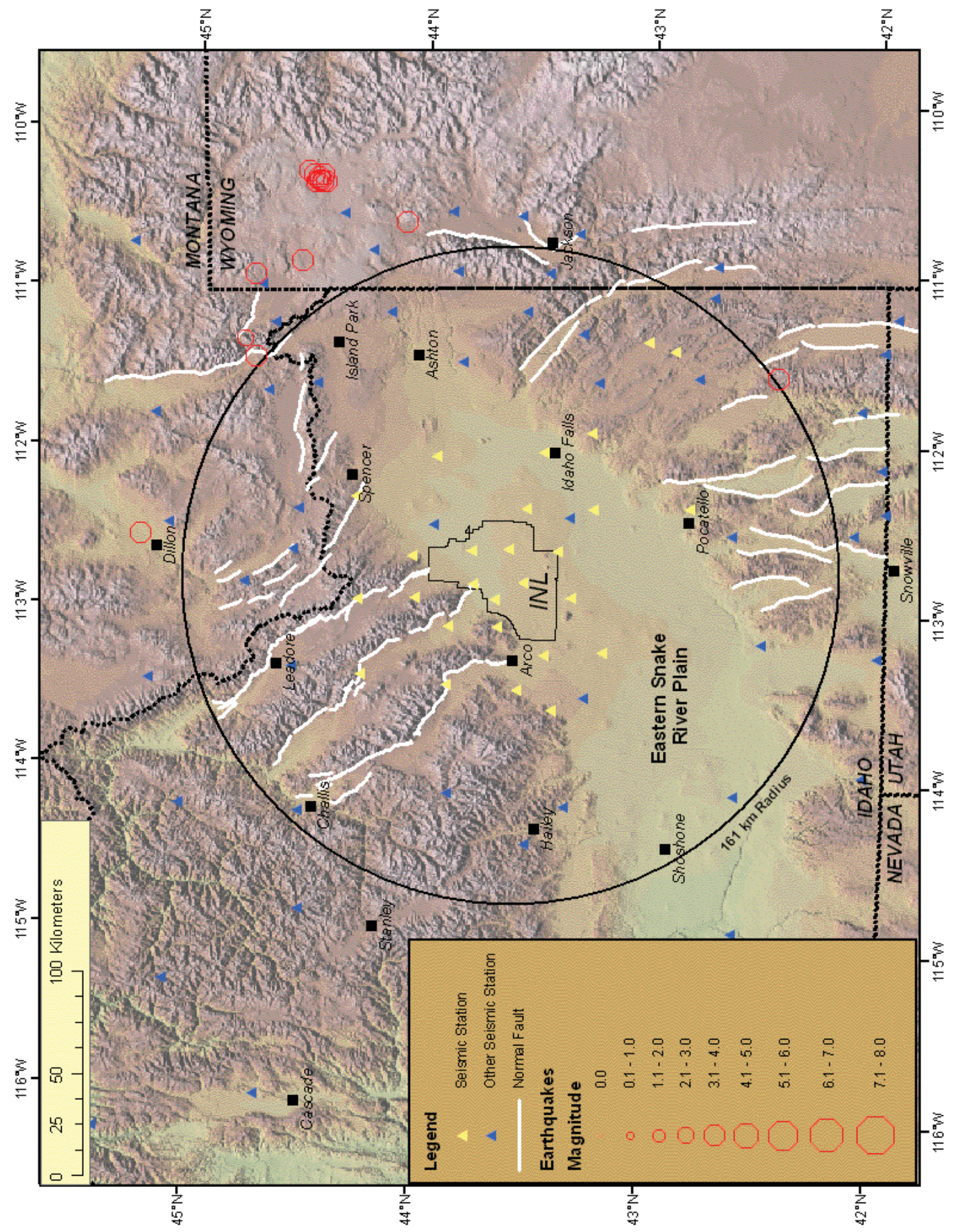

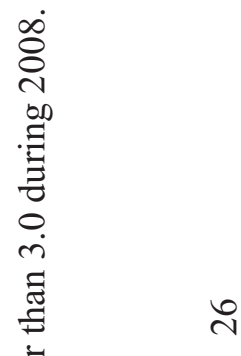




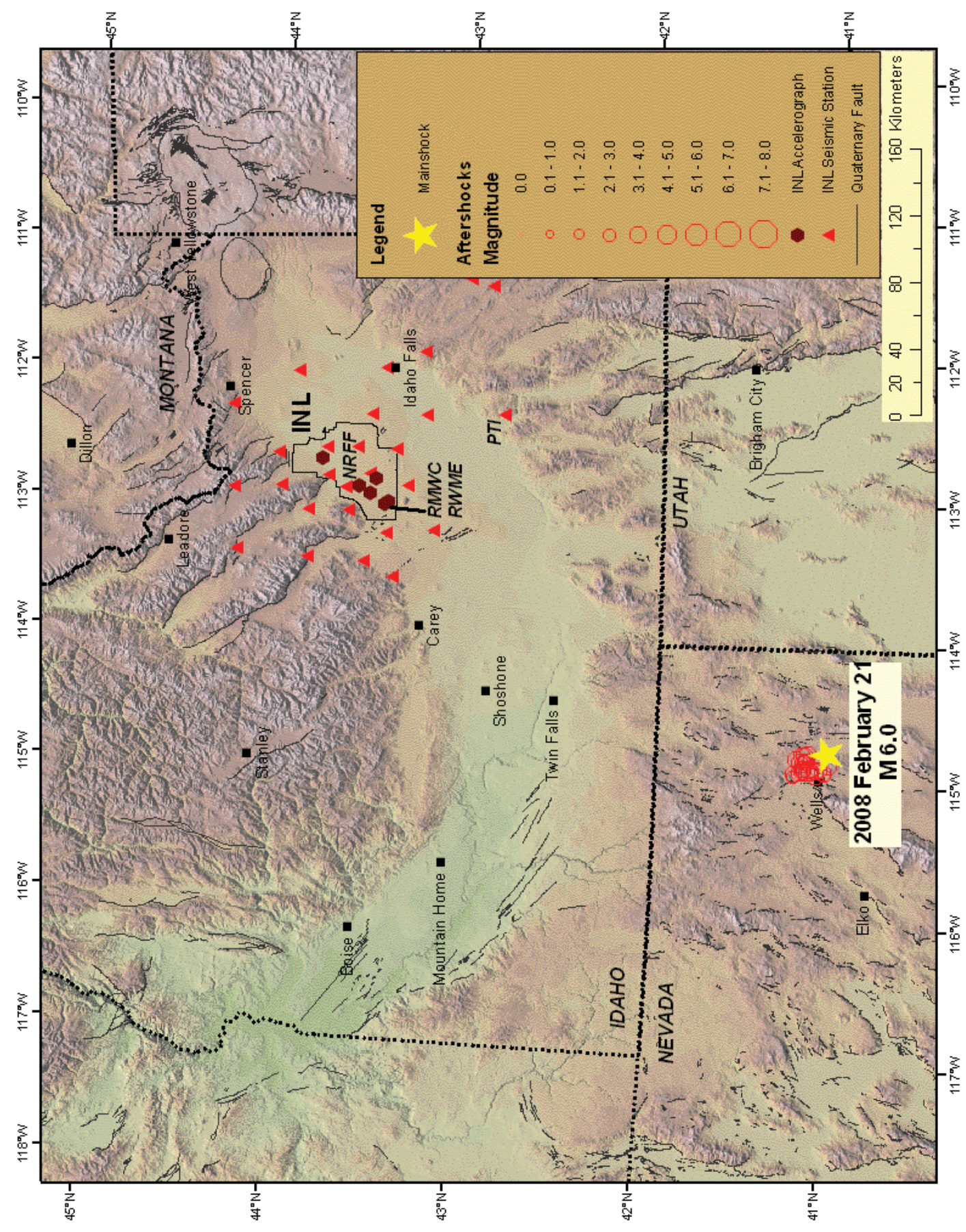

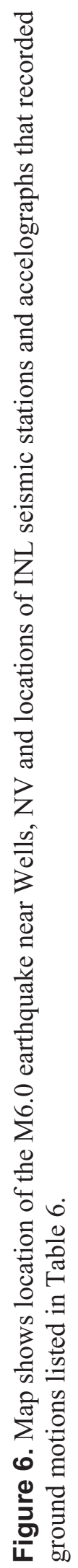




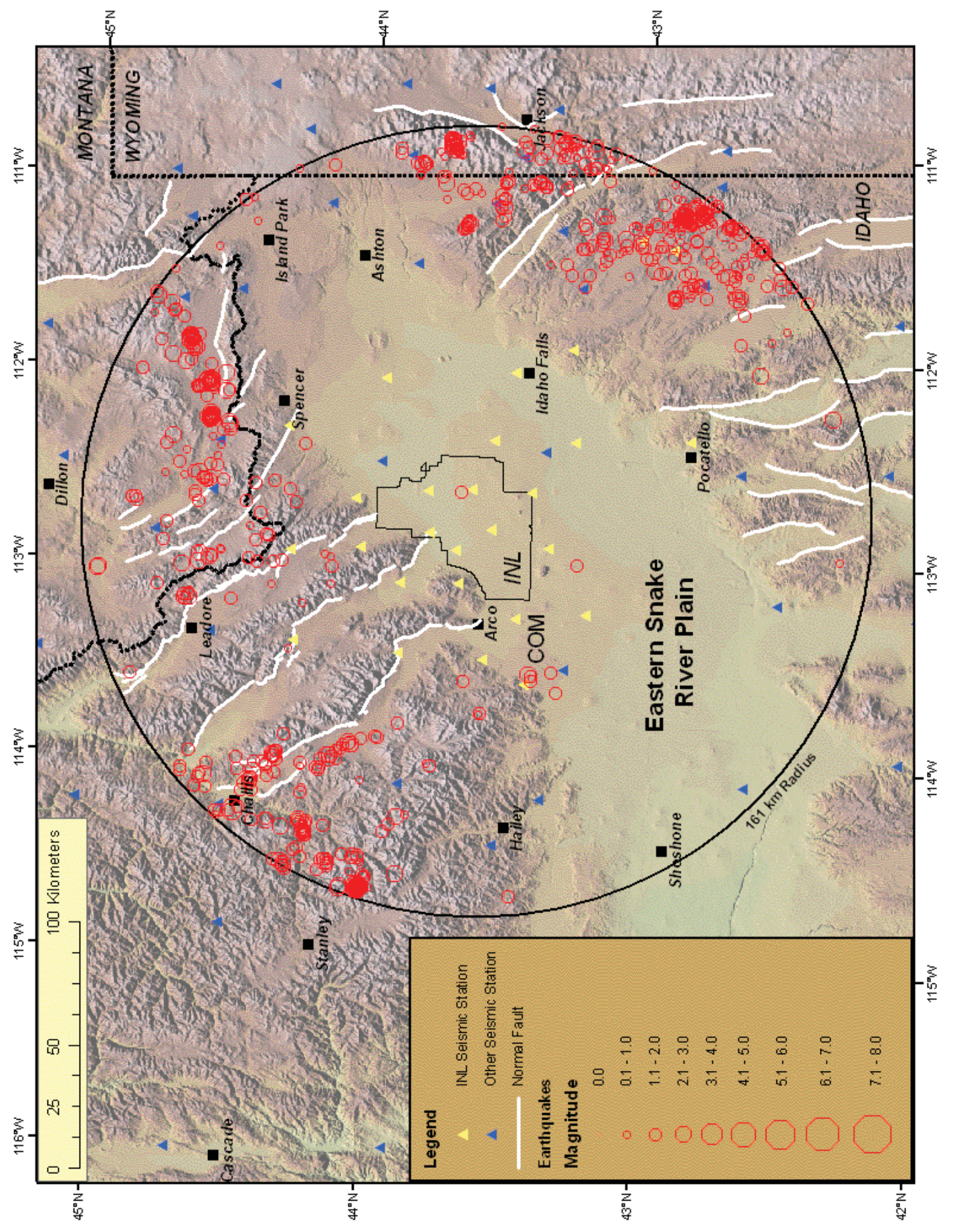

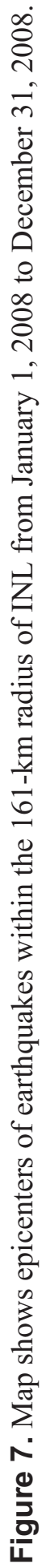




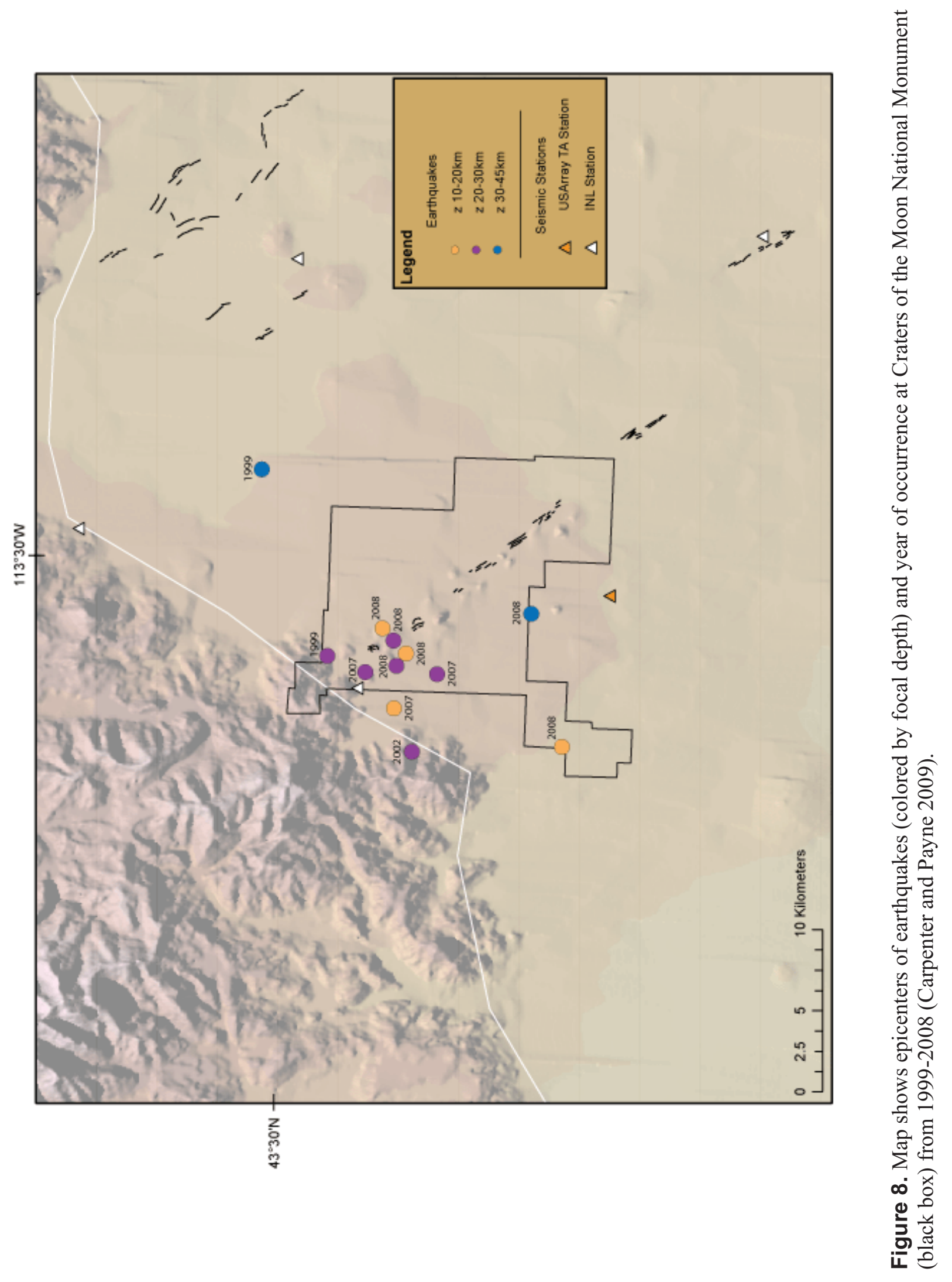




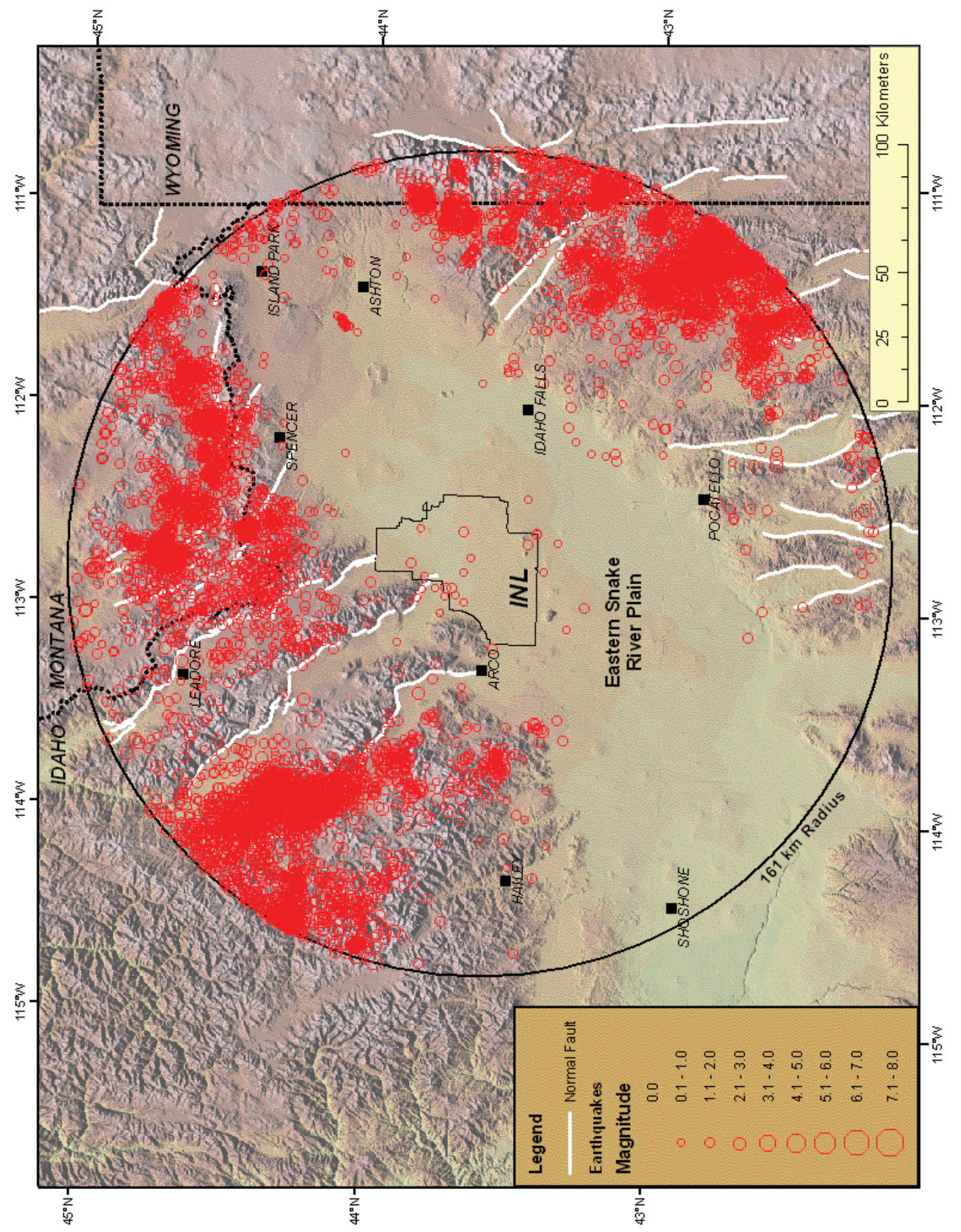

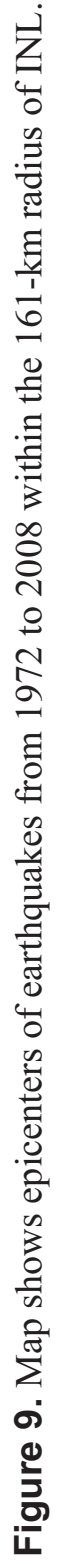




\section{References}

Ackerman, H. D. (1979). Velocity Structure to 3000-Meter Depth at the Idaho National Engineering Laboratory, Eastern Snake River Plain (abstract), EOS Transactions, American Geophysical Union, v. 60 , no. 46 , p. 942.

Anders, M. H., J. W. Geissmann, L. A. Piety and J. T. Sullivan (1989). Parabolic Distribution of Circumeastern Snake River Plain Seismicity and Latest Quaternary Faulting: Migratory Pattern and Association with the Yellowstone Hotspot, Journal of Geophysical Research, v. 94, no. 2, p. 1589-1621.

Arabasz, W. J., R. B. Smith, and W. D. Richins (1979). Earthquake Studies Along the Wasatch Front, Utah: Network Monitoring, Seismicity, and Seismic Hazards, Earthquake Studies in Utah - 1850 to 1978, W. J. Arabasz, R. B. Smith, and W. D. Richins, Editors, published by the University of Utah, p. 253-286.Bones, D. B. (1978). Seismicity of the Intermountain Seismic Belt in Southeastern Idaho and Western Wyoming, and Tectonic Implications, unpublished M. S. Thesis, University of Utah.

Braile, L. W. and R. B. Smith (1979). The Structure of the Crust in the Yellowstone-Snake River Plain Area and Adjacent Provinces and Implications for Crustal Evolution (abstract), EOS Transactions, American Geophysical Union, v. 60, no. 46, p. 941.

Braile, L. W., R. B. Smith, J. Ansorge, M. R. Baker, M. A. Sparlin, C. Prodehl, M. M. Schilly, J. H. Healy, ST. Mueller, and K. H. Olsen (1982). The Yellowstone-Snake River Plain Seismic Profiling Experiment: Crustal Structure of the Eastern Snake River Plain, Journal of Geophysical Research, v. 87 , no. B4, p. 2597-2609.

Carpenter, N. S. and S. J. Payne (2009). Deep, Long-Period Earthquakes in and around Craters of the Moon National Monument, Idaho, Seismological Research Letters, v. 80, p. 350.

DOE (2003). Facility Safety, U.S. Department of Energy, DOE Order 420.1A.

DOE-ID (2002). DOE-ID Architectural and Engineering Standards, U.S. Department of Energy Idaho Operations Office, Idaho Falls, Idaho, Issue Number 29, September.

Greensfelder, R. W. and R. L. Kovach (1982). Shear Wave Velocities and Crustal Structure of the Eastern Snake River Plain, Idaho, Journal of Geophysical Research, v. 87, no. B4, p. 2643-2653.

Griscom, M. and W. J. Arabasz (1979). Local magnitude $\left(\mathrm{M}_{\mathrm{L}}\right)$ in the Wasatch front and Utah region: Wood Anderson calibration, coda-duration estimates of $\mathrm{M}_{\mathrm{L}}$, and $\mathrm{M}_{\mathrm{L}} \mathrm{vs}_{\mathrm{B}}$, Earthquake Studies in Utah - 1850 to 1978, W. J. Arabasz, R. B. Smith, and W. D. Richins, Editors, published by University of Utah, p. 433-444.

Jackson, S. M. and D. M. Anderson (1986). INEL Seismograph Stations Annual Report: January 1 December 31, 1985, EG\&G Internal Technical Report ST-ES-03-86, March, 33 p.

Jackson, S. M., D. M. Anderson, G. S. Carpenter, H. K. Gilbert, S. M. Martin, and P. J. Permann (1989). The 1988 INEL Microearthquake Survey near the Western Edge of the eastern Snake River Plain, EG\&G Internal Technical Report EGG-BEG-8665, August, 48 p. 
Jackson, S. M., G. S. Carpenter, D. M. Anderson, D. L. Scott, J. L. Casper, and R. B. Powell (1993a). INEL Seismograph Stations Annual Report: January 1 - December 31, 1992, EG\&G Internal Technical Report EGG-EELS-004, 114 p.

Jackson, S. M., I. G. Wong, G. S. Carpenter, D. M. Anderson, and S. M. Martin (1993b). Contemporary Seismicity in the eastern Snake River Plain, Idaho based on Microearthquake Monitoring, Bulletin of the Seismological Society of America, v. 83, no. 3, June, p. 680-695.

Klein, F. W. (1989). User's Guide to HYPOINVERSE, a program for VAX computers to solve for earthquake locations and magnitudes, U. S. Geological Survey Open File Report 89-314.

Kuntz, M. A., B. Skipp, M.A. Lanphere, W. E. Scott, K.L. Pierce, G.B. Dalrymple, D.E. Champion, G.F. Embree, W.R. Page, L.A. Morgan, R.P. Smith, W.R. Hackett, and D.W. Rodgers (1994). Geologic map of the Idaho National Engineering Laboratory and adjoining areas, eastern Idaho; U.S. Geological Survey Miscellaneous Investigation Map, I-2330, 1:100,000 scale.

Olsen, K. H., E. F. Homuth, J. N. Stewart, R. N. Felch, T. G. Handel, and P. A. Johnson (1979). Upper Crustal Structure Beneath the Eastern Snake River Plain Interpreted from Seismic refraction Measurements Near Big Southern Butte, Idaho (abstract), EOS Transactions American Geophysical Union, v. 60, no. 46, p. 941.

Qamar, A., R. Ludwin, R. S. Crosson, and S. D. Malone (1987). Earthquake hypocenters in Washington and Oregon: 1982-1986, Washington Division of Geology and Earth Resources, Information Circular 84.

Payne, S. J., R. McCaffrey, and R. W. King (2008a). Strain Rates and Contemporary Deformation in the Snake River Plain and Surrounding Basin and Range From GPS and Seismicity, Geology, v. 36, p. 647-650.

Payne, S. J., R. W. King, and R. McCaffrey (2008b). Crustal Rotation and Deformation in the Snake River Plain and Northern Basin and Range Province, Invited*, Geological Society of America Abstracts with Programs, 263-4, October.

Payne, S. J., R. W. King, S. A. Kattenhorn, and R. McCaffrey (2008c). Accommodation of Right-lateral Shear Along the Northwest Boundary of the Snake River Plain, Idaho, EOS Trans. Am. Geophys. Union, 89(53), Fall Meet. Suppl. Abstract

Reasenberg, P. A. and D. Oppenheimer (1985). FPFIT, FPPLOT and FPPAGE: Fortran computer programs for calculating and displaying earthquake fault plane solutions, U.S. Geological Survey Open File Report 85-739, 25 p.

Richins, W. D., J. C. Pechmann, R. B. Smith, C. J. Langer, S. K. Goter, J. E. Zollweg, and J. J. King (1987). The 1983 Borah Peak, Idaho Earthquake and Its Aftershocks, Bulletin of the Seismological Society of America, v. 77, no. 3, p. 694-723.

Richter, C. F. (1958). Elementary Seismology, W. H. Freenam and Company, San Francisco, p. 340-342.

Scott, W. E., K. L. Pierce, and M. H. Hait, Jr. (1985). Quaternary Tectonic Setting of the 1983 Borah Peak Earthquake, Central Idaho, Bulletin of the Seismological Society of America, v. 75, no. 4, p. 1053-1066. 
Seismic (1993). INEL Seismic Network: Seismic station boreholes, EG\&G Idaho, Inc., Idaho Falls, Idaho Engineering Design File EDF-SEIS-0003, 28 p.

Sparlin M., L. W. Braile, M. R. Baker, and R. B. Smith (1979). Interpretation of Seismic Profiles Across the Eastern Snake River Plain (abstract), EOS Transactions American Geophysical Union, v. 60, no. 46 , p. 941.

Sparlin, M. A., L. W. Braile and R. B. Smith (1982). Crustal Structure of the Eastern Snake River Plain Determined from Ray Trace Modeling of Seismic Refraction Data, Journal of Geophysical Research, v. 87, no. B4, p. 2619-2633.

Stickney, M.C. (1997). Seismic source zones in southwest Montana, Montana Bureau of Mines and Geology, Butte, Montana Open-file report 366.

Stickney, M. C., and M. J. Bartholomew (1987). Seismicity and Late Quaternary Faulting of the Northern Basin and Range Province, Montana and Idaho, Bulletin of the Seismological Society of America, v. 77 , no. 5 , p. $1602-1625$.

Stickney, M.C. and D.R. Lageson (1999). The 1999 Red Rock Valley, Montana earthquake: Seismological constraints and structural model, EOS, Transactions, American Geophysical Union, v. 80 , No. 66 , p. F725.

Zollweg, J.E., and K. F. Sprenke (1995). Review of Idaho National Engineering Laboratory Seismographic Networks and Seismic Hazard Program, prepared for the State of Idaho INEL Oversight Program, Technical Report 95-01, 72 p. 
(Intentionally Blank) 


\section{Appendix A \\ Seismic Network Information}


(Intentionally Blank) 


\section{Appendix A}

\section{Seismic Network Information}

\section{EarthScope Science Program}

USArray is a component of the EarthScope Science Program to capture high-resolution images of structure of the continental lithosphere and deeper mantle using passive seismic events such as earthquakes that occur worldwide. Broadband seismometers are being deployed in N-S transects across the United States for 18-24 months. While installed in Idaho, the USArray's Transportable Array (TA) stations enhance detection and coverage of local earthquakes for the INL Seismic Monitoring Program. The TA stations that were recorded by the INL and used to compute earthquake locations and magnitudes during part of 2008 are listed in Table A-1. 
Table A-1. EarthScope Science Program Transportable Array seismic stations monitored by INL.

\begin{tabular}{|c|c|c|c|}
\hline Code & Longitude West $\left({ }^{\circ}\right)$ & Latitude North $\left(^{\circ}\right)$ & Elevation $(\mathrm{m})$ \\
\hline G11A & -116.2680 & 45.3997 & 1343 \\
\hline G12A & -115.3257 & 45.1285 & 1780 \\
\hline G13A & -114.2329 & 45.0931 & 1538 \\
\hline G14A & -113.4604 & 45.2432 & 2140 \\
\hline G15A & -112.4887 & 45.1660 & 1857 \\
\hline G16A & -111.8046 & 45.2285 & 1769 \\
\hline G17A & -110.7398 & 45.3212 & 1574 \\
\hline $\mathrm{H} 10 \mathrm{~A}$ & -116.7474 & 44.5890 & 882 \\
\hline H11A & -116.0127 & 44.7035 & 1525 \\
\hline $\mathrm{H} 12 \mathrm{~A}$ & -114.8554 & 44.5494 & 1777 \\
\hline H13A & -114.2545 & 44.5642 & 1563 \\
\hline H14A & -113.3674 & 44.6165 & 1933 \\
\hline H15A & -112.6439 & 44.6173 & 1957 \\
\hline $\mathrm{H} 16 \mathrm{~A}$ & -111.2478 & 44.7038 & 2080 \\
\hline H17A & -110.5762 & 44.3951 & 2400 \\
\hline $\mathrm{I} 10 \mathrm{~A}$ & -116.8029 & 44.0860 & 782 \\
\hline $\mathrm{I} 11 \mathrm{~A}$ & -115.9578 & 43.9121 & 1288 \\
\hline I12A & -115.1328 & 43.7945 & 1849 \\
\hline I13A & -114.1169 & 43.9146 & 2104 \\
\hline $\mathrm{I} 14 \mathrm{~A}$ & -113.4518 & 43.9286 & 1897 \\
\hline $\mathrm{I} 15 \mathrm{~A}$ & -112.4850 & 43.9997 & 1470 \\
\hline I16A & -111.4868 & 43.8756 & 1744 \\
\hline I17A & -110.5759 & 43.9200 & 2134 \\
\hline $\mathrm{J} 10 \mathrm{~A}$ & -116.7670 & 43.4275 & 748 \\
\hline $\mathrm{J} 11 \mathrm{~A}$ & -115.8278 & 43.4151 & 1302 \\
\hline $\mathrm{J} 12 \mathrm{~A}$ & -115.0980 & 43.2500 & 1587 \\
\hline $\mathrm{J} 13 \mathrm{~A}$ & -114.1742 & 43.3979 & 1552 \\
\hline $\mathrm{J} 14 \mathrm{~A}$ & -113.5178 & 43.3234 & 1649 \\
\hline $\mathrm{J} 15 \mathrm{~A}$ & -112.4334 & 43.3998 & 1497 \\
\hline $\mathrm{J} 16 \mathrm{~A}$ & -111.6119 & 43.2741 & 2004 \\
\hline $\mathrm{J} 17 \mathrm{~A}$ & -110.7118 & 43.3629 & 1975 \\
\hline K10A & -116.8705 & 42.7779 & 1701 \\
\hline K11A & -116.0323 & 42.7713 & 914 \\
\hline $\mathrm{K} 12 \mathrm{~A}$ & -114.9029 & 42.6360 & 1091 \\
\hline K13A & -114.0840 & 42.6493 & 1222 \\
\hline $\mathrm{K} 14 \mathrm{~A}$ & -113.1760 & 42.5452 & 1387 \\
\hline K15A & -112.5305 & 42.6852 & 1566 \\
\hline K16A & -111.5884 & 42.8321 & 1885 \\
\hline K17A & -110.9201 & 42.7507 & 1922 \\
\hline L10A & -116.4711 & 42.0773 & 1537 \\
\hline L11A & -115.7541 & 42.1669 & 1511 \\
\hline L12A & -115.0162 & 42.1460 & 1756 \\
\hline L13A & -113.9444 & 42.0886 & 1482 \\
\hline L14A & -113.2398 & 42.0343 & 1528 \\
\hline L15A & -112.3860 & 42.0041 & 1645 \\
\hline L16A & -111.4319 & 42.0149 & 2013 \\
\hline
\end{tabular}




\section{INL Seismic Network Telemetry}

Digital radios, Internet, and DSL links transmit seismic data from INL seismic stations and freefield SMAs to the IRC. Some seismic stations are used as relay links to transmit several seismic stations to a DSL drop point or directly to the IRC. Figure A-1 shows the telemetry configuration during 2008. 


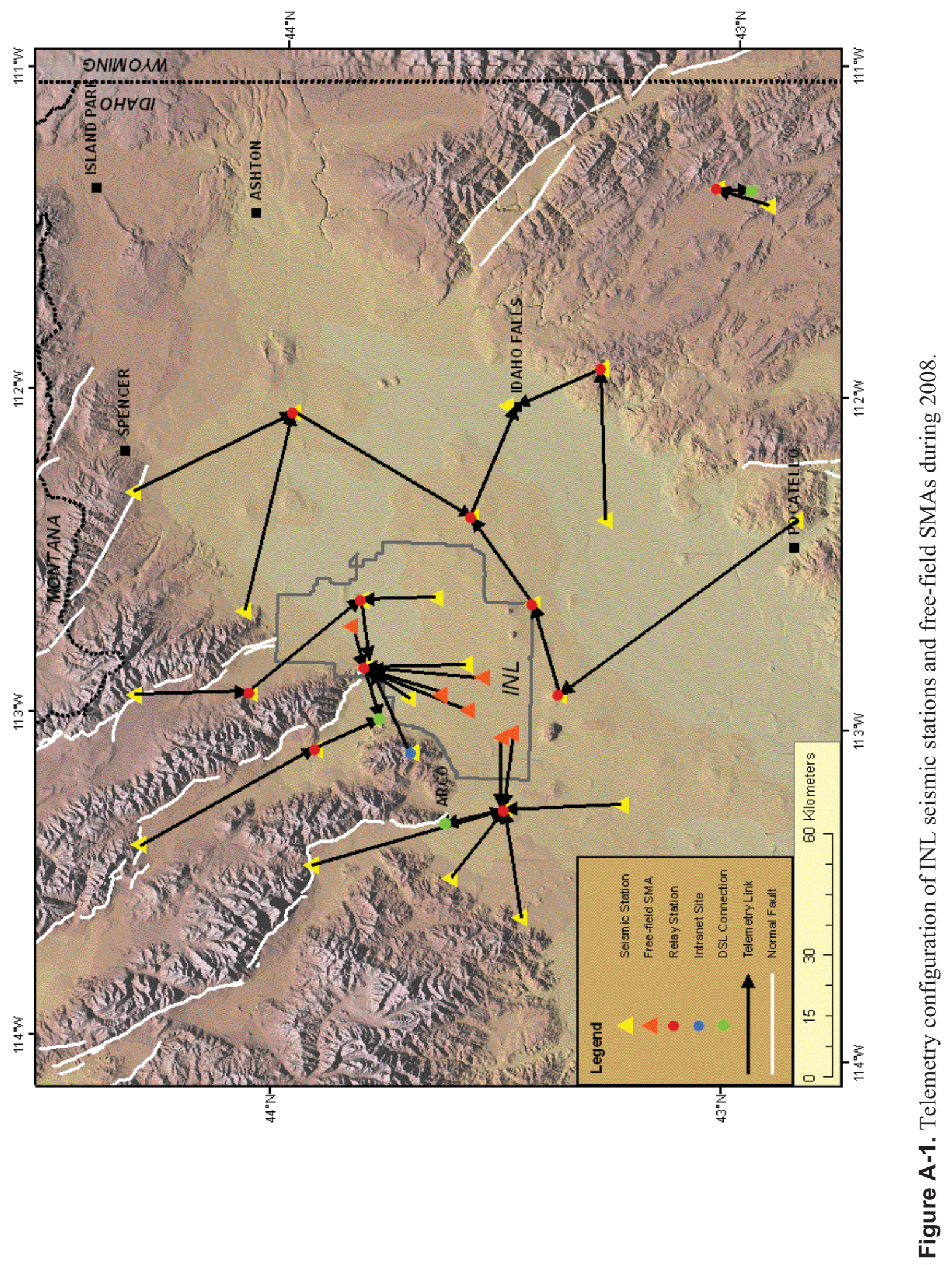


Appendix B

Instrument Response of NetDAS SMAs 
(Intentionally Blank) 


\section{Appendix B}

\section{Instrument Response of NetDAS SMAs}

\section{B.1 Method for Determining Amplitude Response}

The instrument response of the NetDAS-SMA is used to convert the measured counts of ground motion amplitude to units of $\mathrm{g}$. Instrument responses for NetDAS units that have accelerometers mounted within the unit are determined by conducting 1-g (acceleration of gravity) tilt tests. These tests are done on a leveled pad at the IRC seismic lab or on the actual leveled pad at their physical location listed in Table 3. These 1-g tilt tests provide a relationship between the number of digitizer counts and the 1-g offset. Equation B-1 provides the conversion from the measured count level to actual $\mathrm{g}$ level for the recorded motion. Trigger threshold accelerations and counts/g are listed for NetDAS units with SMAs in Table B-1 using equation:

$$
\text { Acceleration }(\mathrm{g})=\text { Counts }_{(\text {Measured or target) }} /(\text { Counts } / g)
$$

For accelerographs without internally installed accelerometers within the NetDAS units, Equation B-1 does not apply; there is a frequency dependent amplitude response, which is discussed further in Appendix C. The frequency response information for the NetDAS-4CH should be applied to the acceleration data recorded by these external-type accelerometers. Table B-2 lists the instrument response for these accelerometers using the methods discussed in Appendix C.

Tables B-1 and B-2 list the beginning and ending dates for the time periods that the instrument responses are applicable. If changes occurred to SMA or seismic station instrumentation (such as accelerometer or NetDAS unit) during the year, then more than one range of dates are listed for a location. Also, note that the building numbers and locations for the SMA codes are listed in Table 3. 


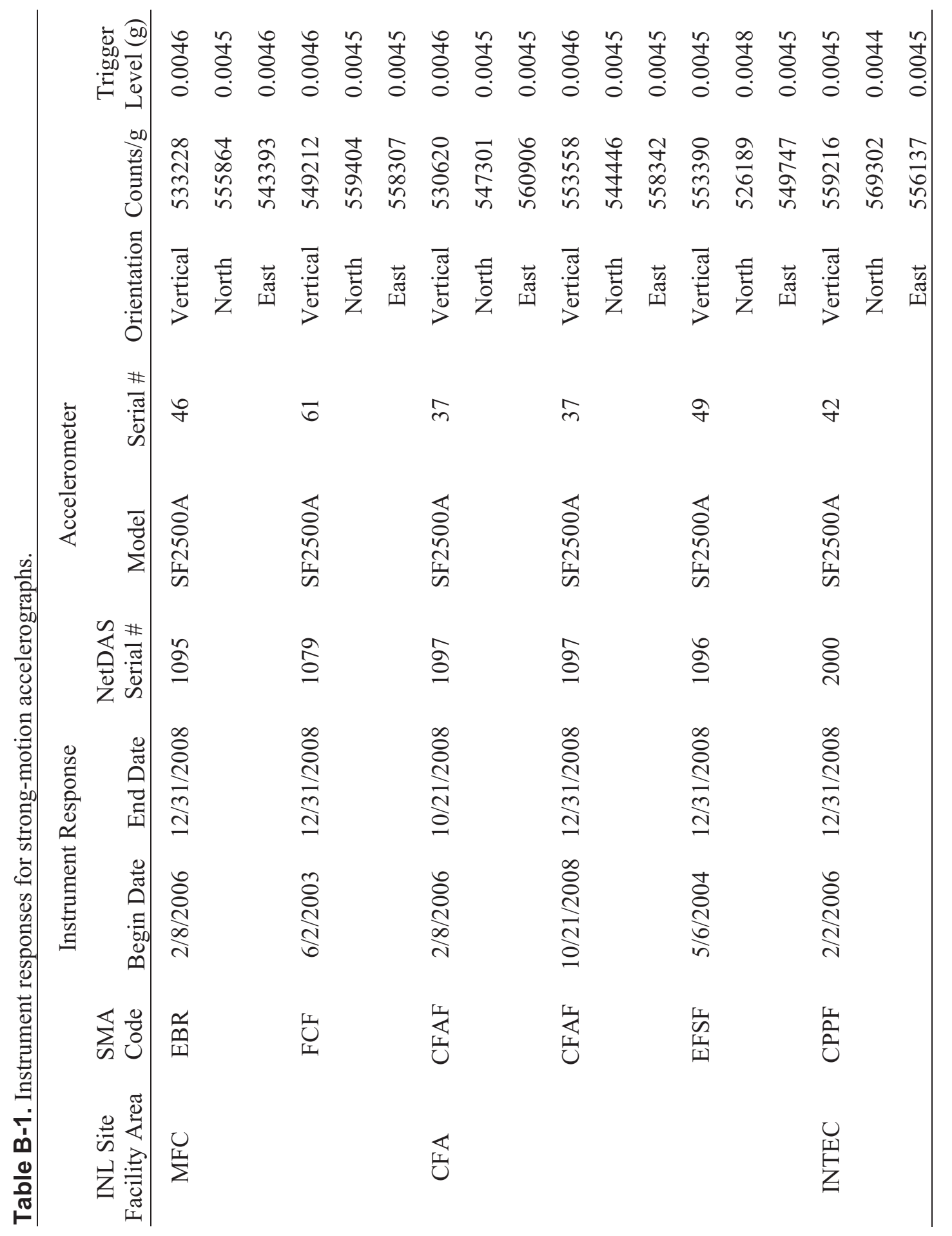




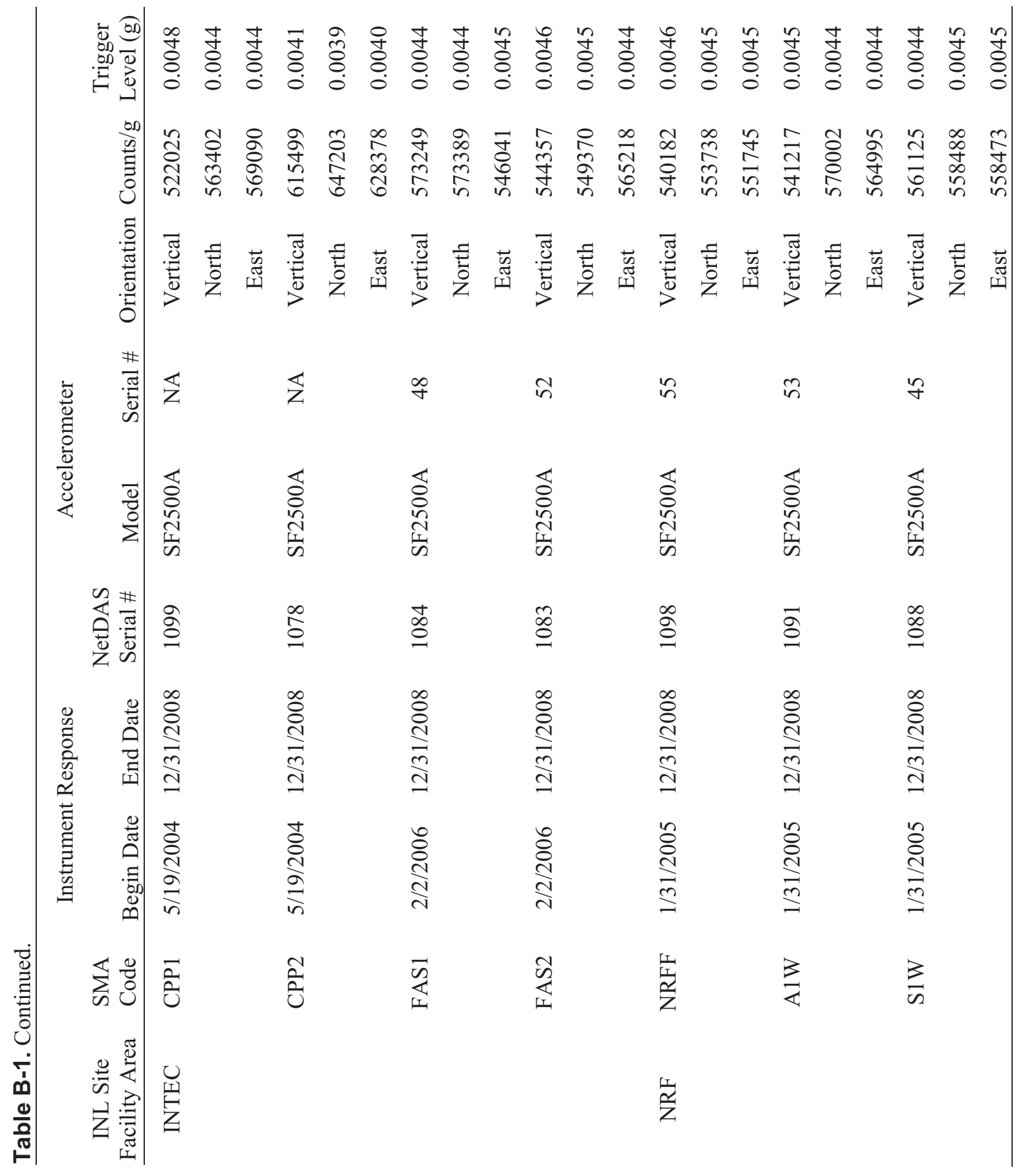




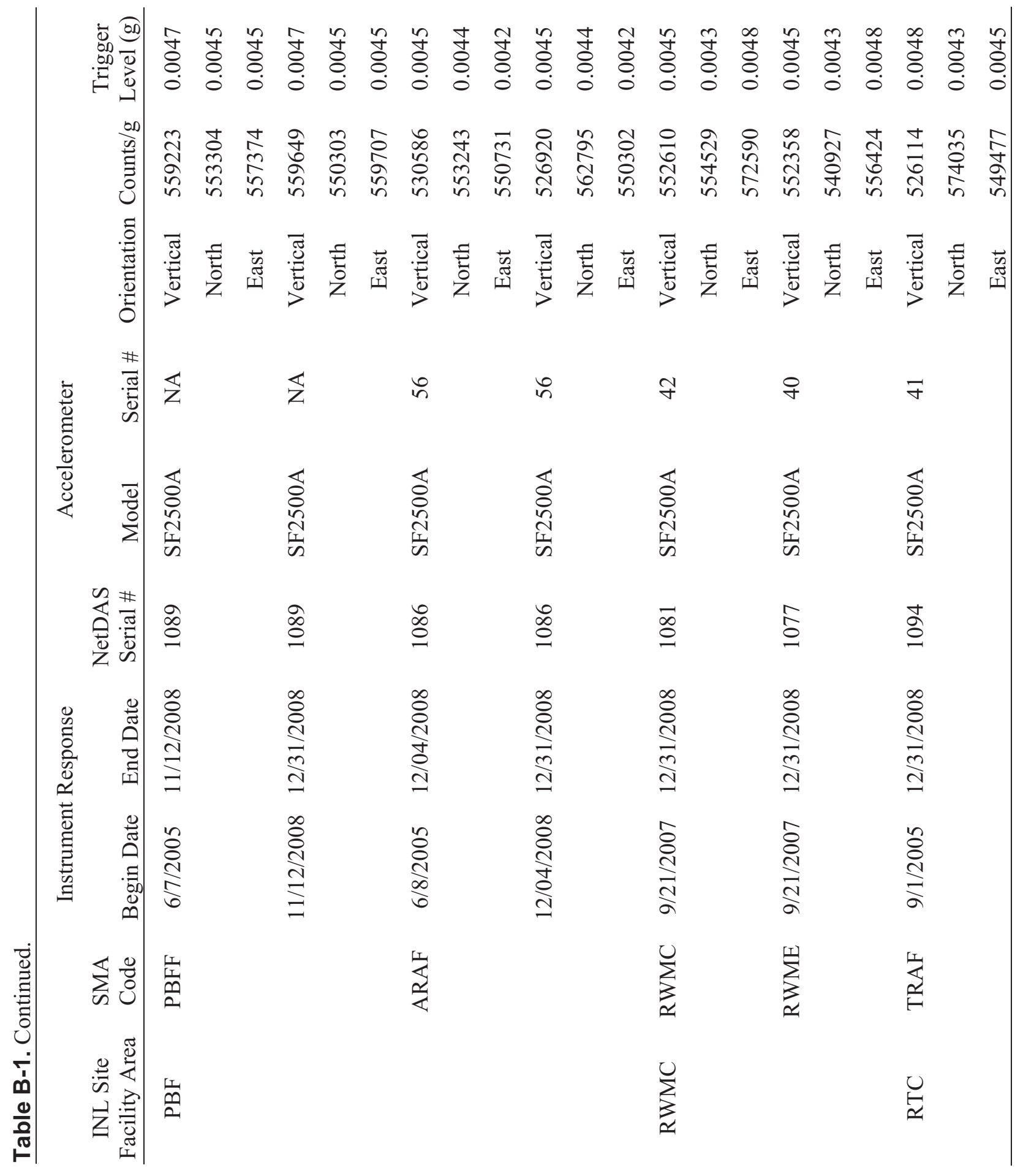




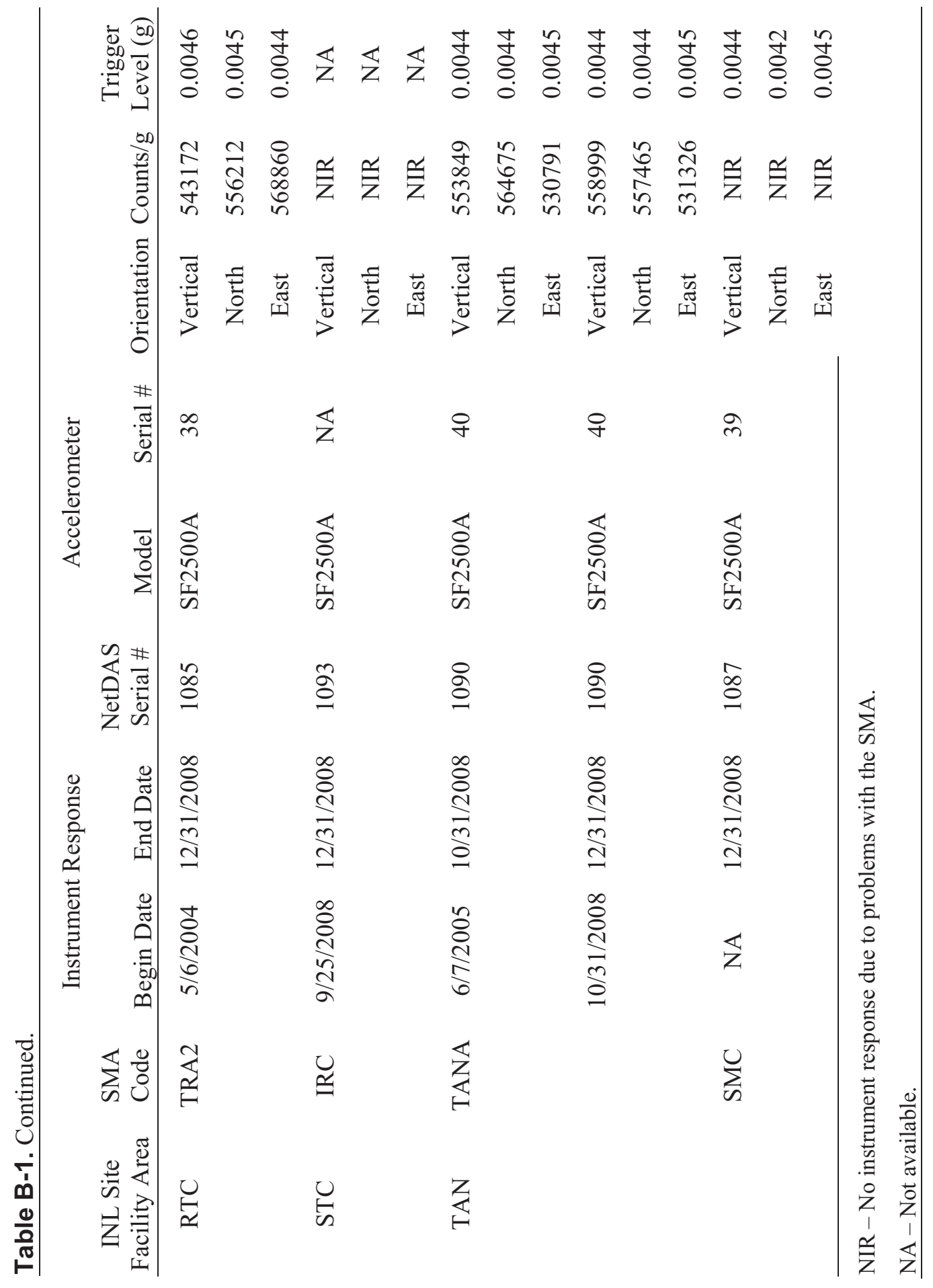




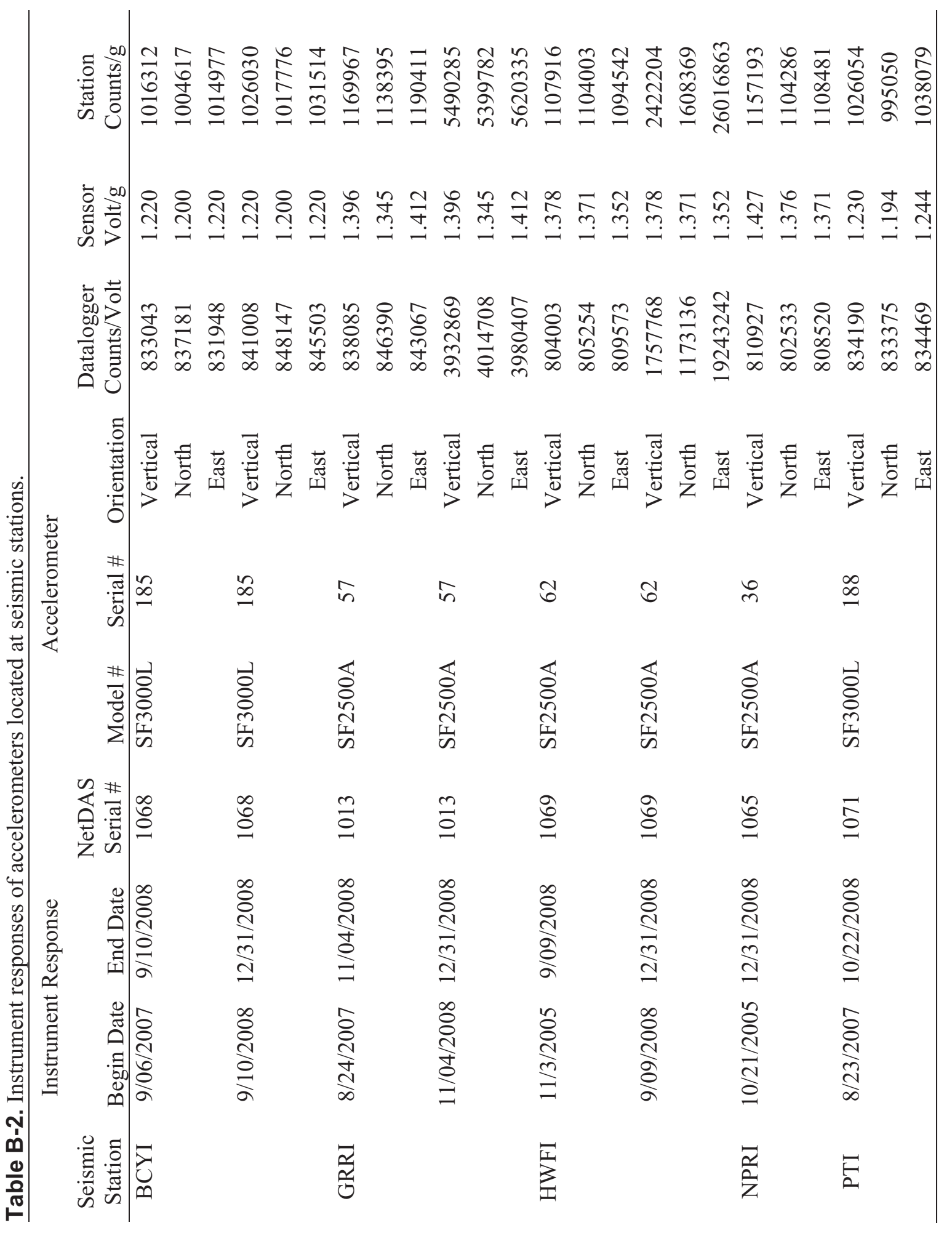




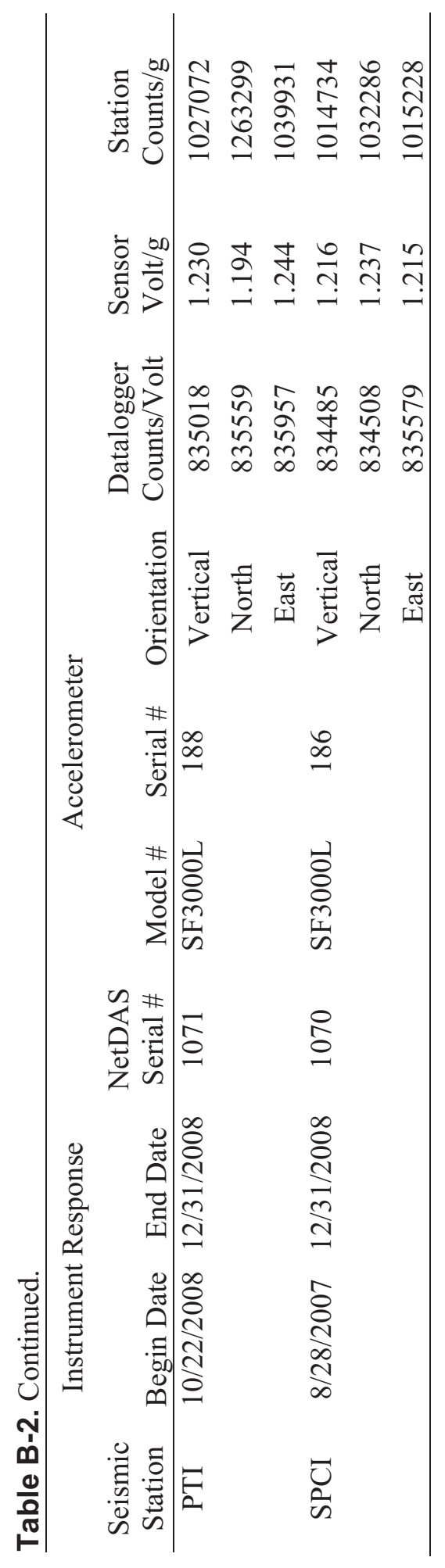


(Intentionally Blank) 
Appendix C

Instrument Response of Seismic Stations 
(Intentionally Blank) 


\section{Appendix C}

\section{Instrument Response of Seismic Stations}

\section{C.1 Method for Determining Amplitude Response}

The INL determines instrument responses for both the four $(4 \mathrm{CH})$ and eight channel $(8 \mathrm{CH})$ NetDAS units. The INL establishes a DC counts/volt level by measuring a known voltage level for a specified duration of time for each channel on the NetDAS units and recording the mean and standard deviation in counts for this duration. The input voltage polarity is often reversed in order to obtain a greater measurement range. The mean provides the method to produce the DC counts/volt level (Equation C-1a and C-1b) and the standard deviation provides an idea of the measurement uncertainty and system noise.

Single ended:

$$
\text { Counts } / \text { Volt }=\mu / \mathrm{v}_{\mathrm{i}}
$$

Reversed Polarity:

$$
\text { Counts } / \text { Volt }=\left(\mu+-\mu^{-}\right) /\left(v_{i}+-v_{i}^{-}\right)
$$

Where:

$$
\begin{aligned}
& \mu \text { is mean counts } \\
& \mathrm{V}_{\mathrm{i}} \text { is input voltage } \\
& \text { Subscript "+" is positive polarity } \\
& \text { Subscript "_- " is negative polarity }
\end{aligned}
$$

\section{C.2 NetDAS-4CH Frequency Response}

The response of the Symmetric Research PAR4CH (4CH) digitizer used in the NetDAS-4CH was calculated at the INL to establish the instrument response of NetDAS units. The DAQSystems, Inc., manufacturer of the NetDAS units, reviewed INL's frequency response results and methods, which is discussed in the following steps.

The NetDAS-4CH frequency response was determined empirically by measuring the output counts resulting from a known input signal. Trials were conducted using a constant-amplitude sine wave with frequencies varying between $0.1,5,10,15,20,25,30$, and $35 \mathrm{~Hz}$. The frequency sweep was performed twice and the averages of the measured counts at each frequency were then converted into decibel responses relative to the average response at $0.1 \mathrm{~Hz}$, because the vendor data sheets list a gain of 1 at this frequency. A $2^{\text {nd }}$ order polynomial was then fit to the data creating a simple amplitude response in frequency. The perfectly matched response (R-squared of one) is shown here in Equations C-2 and C-3 (conversion to decibels).

$$
\begin{aligned}
& Y_{d B}=-0.0045 f^{2}+0.0074 f-0.014 \\
& d B=20 \log \left(E_{2} / E_{1}\right)
\end{aligned}
$$


Where:

$$
\begin{aligned}
& f-\text { frequency }(\mathrm{Hz}) \\
& E_{1}-\text { original signal level } \\
& E_{2}-\text { modified signal level } \\
& E_{2} / E_{1}-\text { commonly referred to as gain }
\end{aligned}
$$

This relationship was then used to calculate the gains out to the Nyquist frequency $(1 / 2$ the sample rate - the INL samples all data at 100 samples per second or $0.01 \mathrm{~Hz}$ ). The information was then entered into MATLAB, which has a function to determine poles and zeros. Poles-and-zeros notations are the form that many seismic applications use to remove the instrument response. The NetDAS-4CH frequency response in $\mathrm{dB}$ and poles and zeros are shown in Figure $\mathrm{C}-1$.

Equations C-2 and C-3 can be used in conjunction with the DC counts/volt measurement to generate a count based frequency response for short hand calculations or spectral deconvolution to remove the frequency response.

$$
\text { Ycounts }=\text { Counts } / \text { Volt } \times 10^{\wedge}\left(\left(-0.0045 f^{2}+0.0074 f-0.014\right) / 20\right)
$$

Where:

$10^{\wedge}$ - Indicates 10 to the power of the number calculated in parentheses.

However, the preferred method for removing the frequency response from a recorded waveform is to use a seismic analysis package, such as SEISAN. This program uses the poles-and-zeros representation of instrument response, which quickly and accurately corrects recorded waveforms to actual ground motions.

\section{C.3 NetDAS-8CH Frequency Response}

The response of the Symmetric Research PAR24B $(8 \mathrm{CH})$ digitizer used in the NetDAS-8CH was based on vendor provided information, and calculated in the same method as described above for the PAR4CH. A $2^{\text {nd }}$ order polynomial was fit to the data creating a simple amplitude response in frequency that matched the amplitude response (R-squared of 0.999). Equation C-5, listed below, is similar to Equation C-3 used for the response of the NetDAS-4CH. The NetDAS-8CH frequency response in $\mathrm{dB}$ and poles and zeros are shown in Figure $\mathrm{C}-2$.

$$
Y_{\mathrm{dB}}=-0.0045 f^{2}+0.0071 f-0.0158
$$

\section{C.4 Short-period high-gain seismic stations}

In the fall of 2002, INL seismic personnel began recording instrument response of the seismic stations. These response values, in combination with the instrument frequency responses (see C.2 and C.3), are used to create site- and date-specific system response files for the INL seismic stations. These response files are used in SEISAN to correct waveforms for further analyses such as calculating local magnitudes by measuring amplitudes. Table $\mathrm{C}-1$ lists the measured responses (including any system amplification) for the seismic stations that have been measured for instrument responses (in counts/volt). 


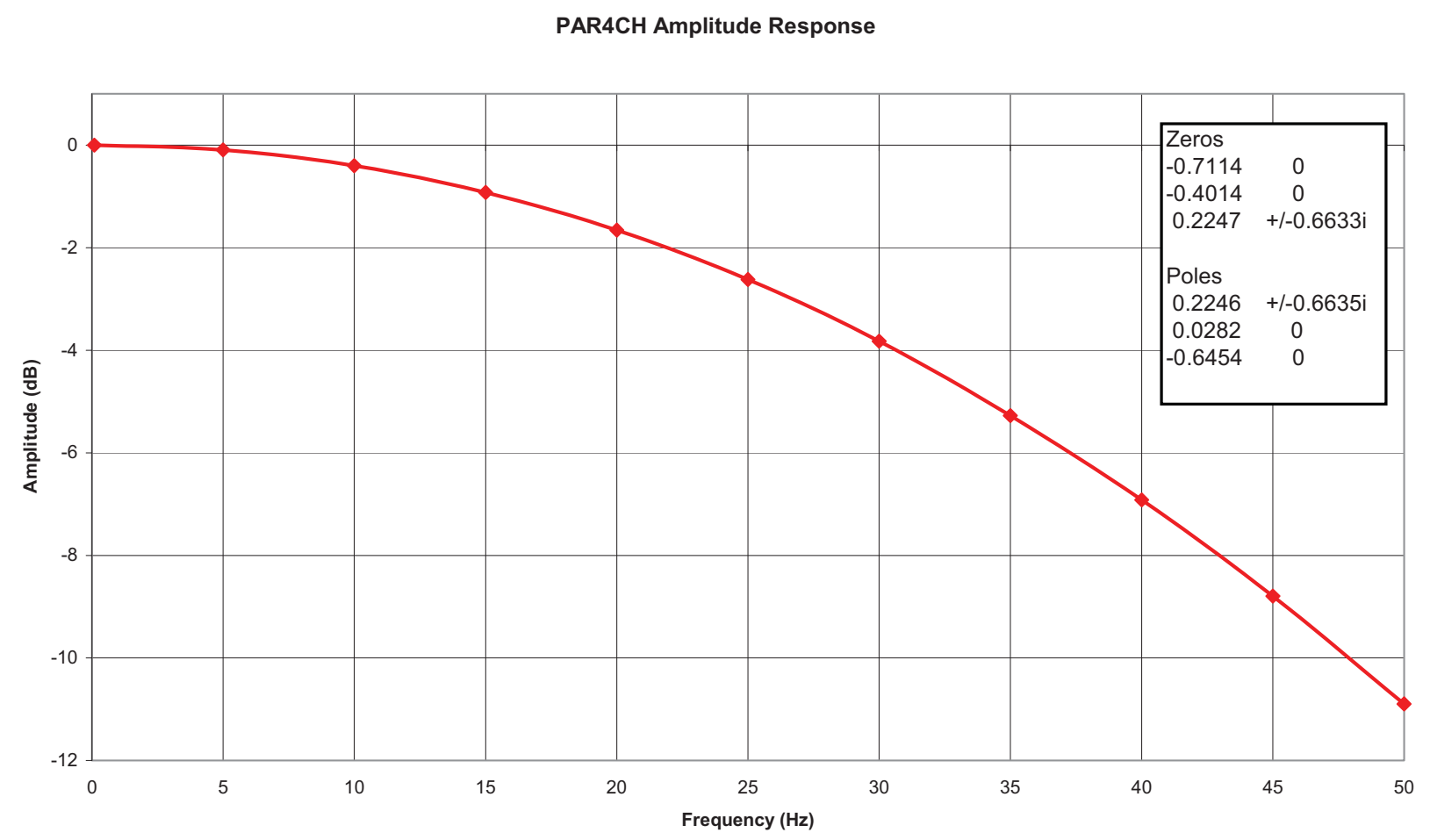

Figure C-1. Amplitude verses frequency system response of the Symmetric Research PAR4CH digitizer used in the NetDAS-4CH. 


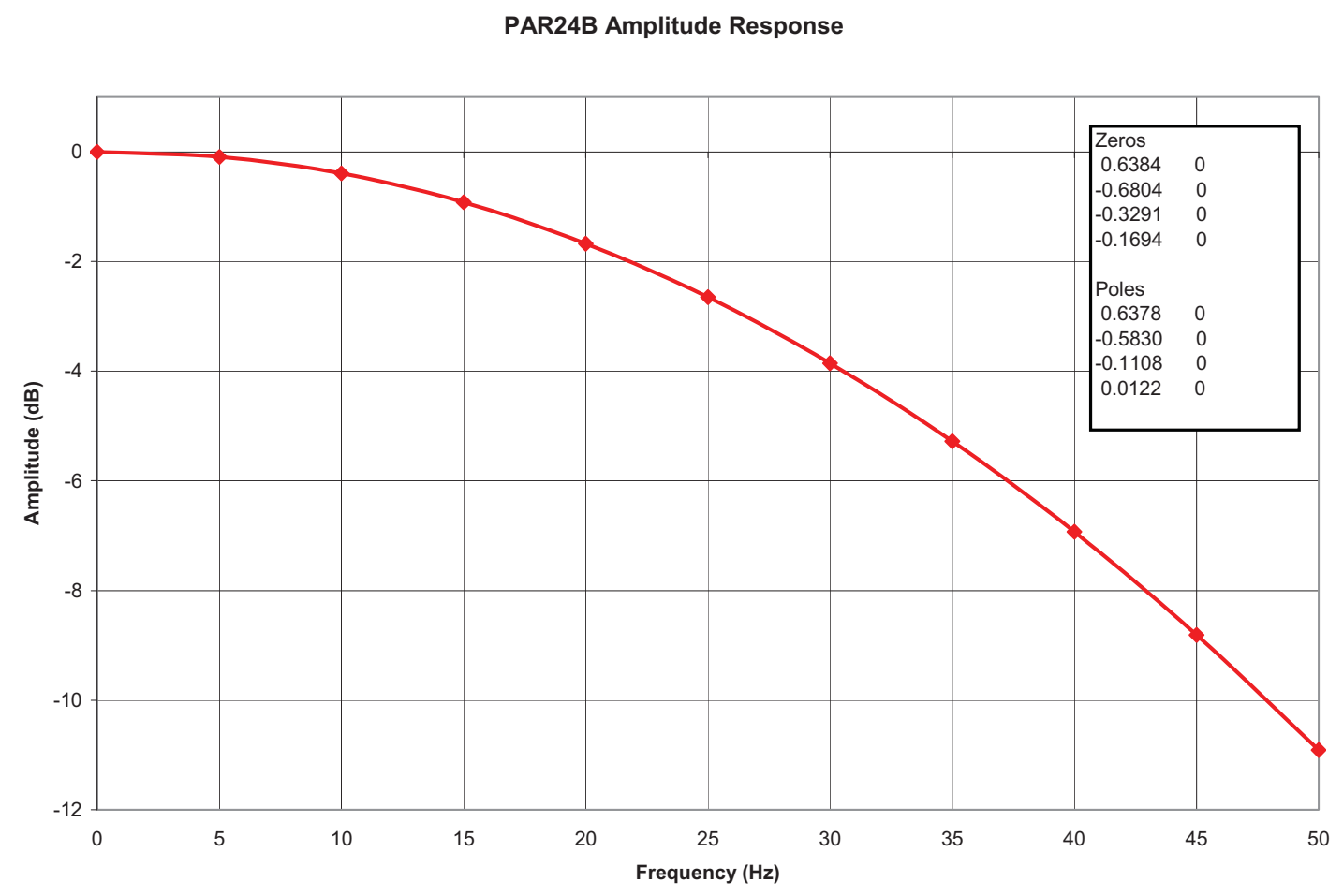

Figure C-2. Amplitude verses frequency system response of the Symmetric Research PAR24B digitizer used in the NetDAS- $8 \mathrm{CH}$. 


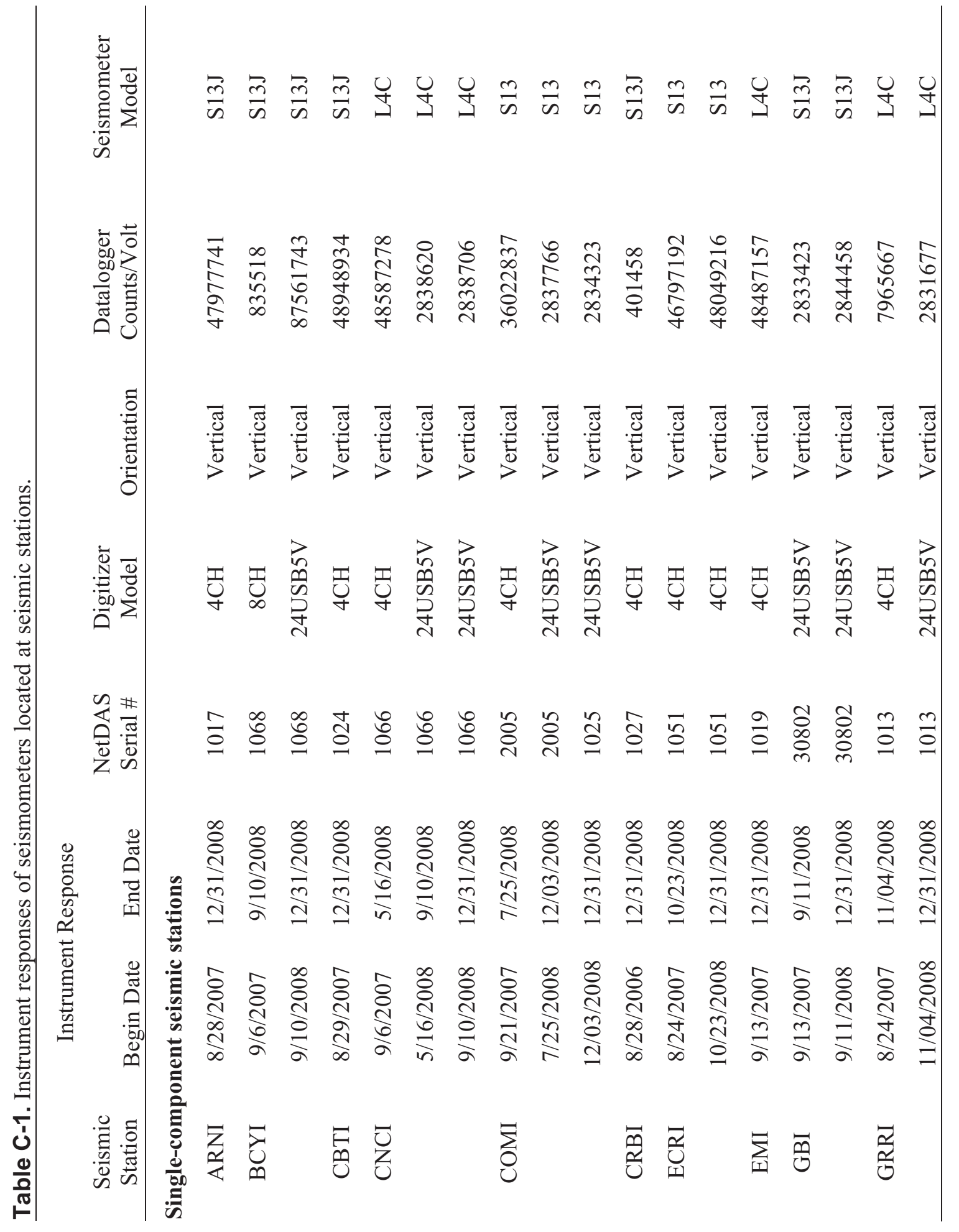




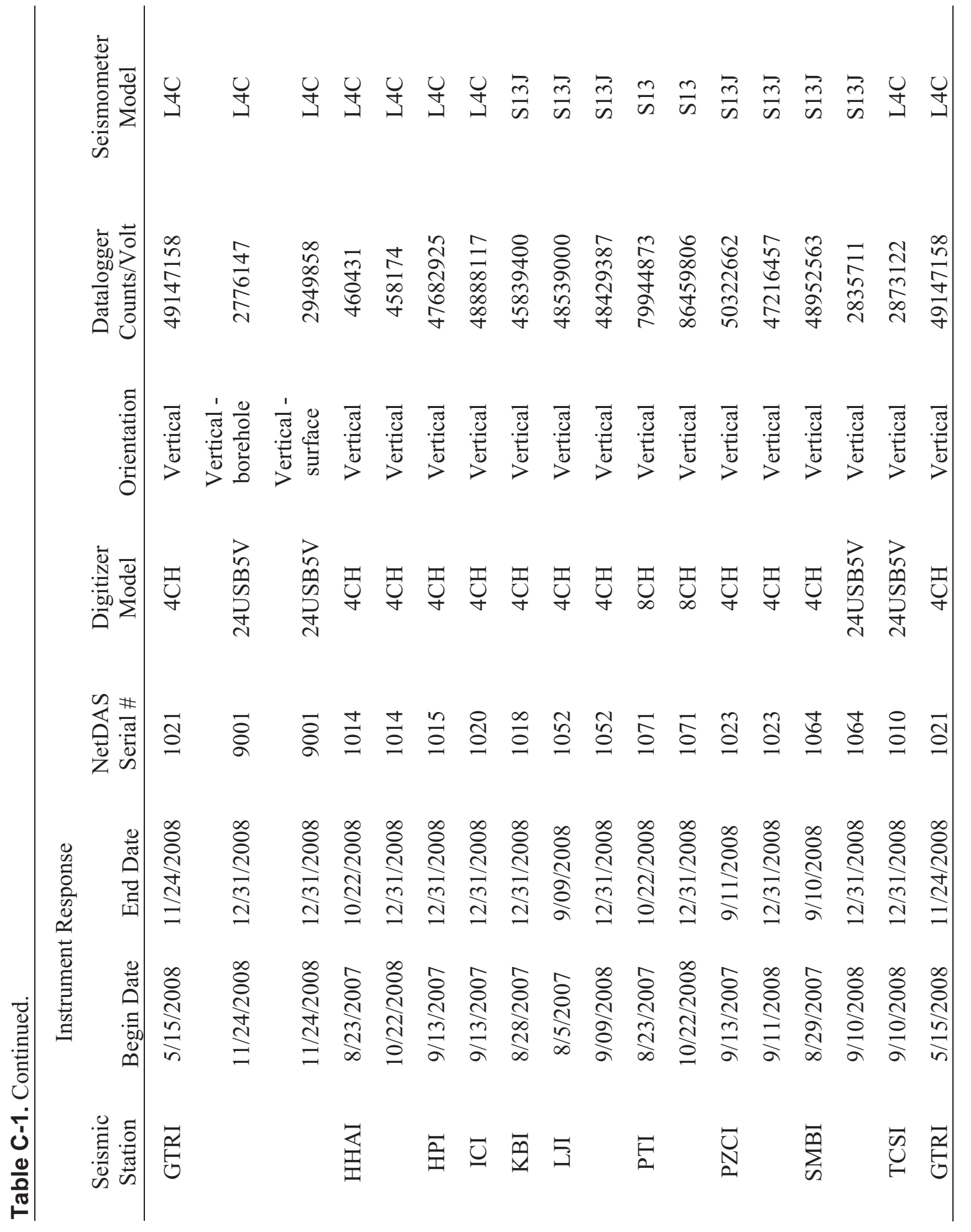




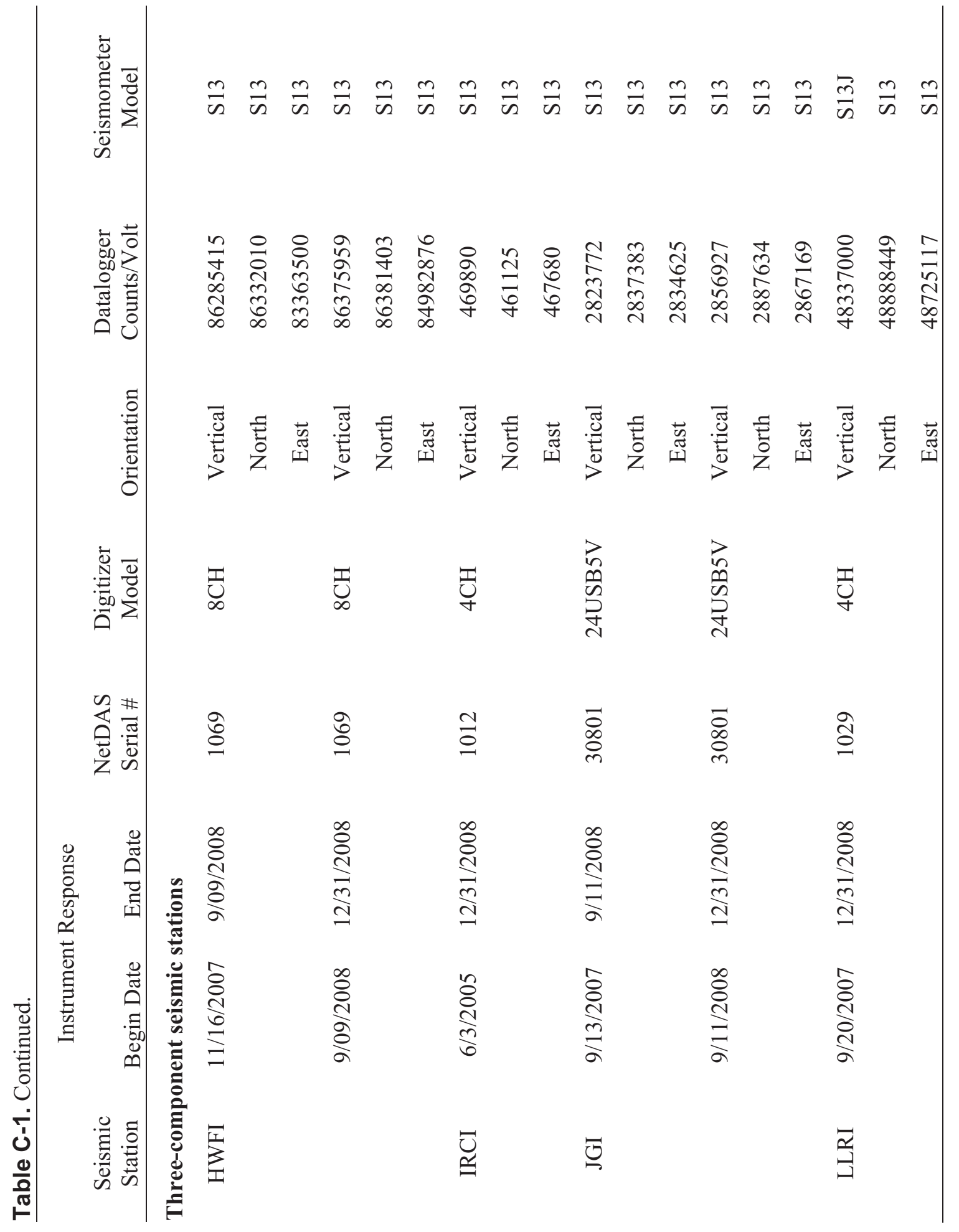




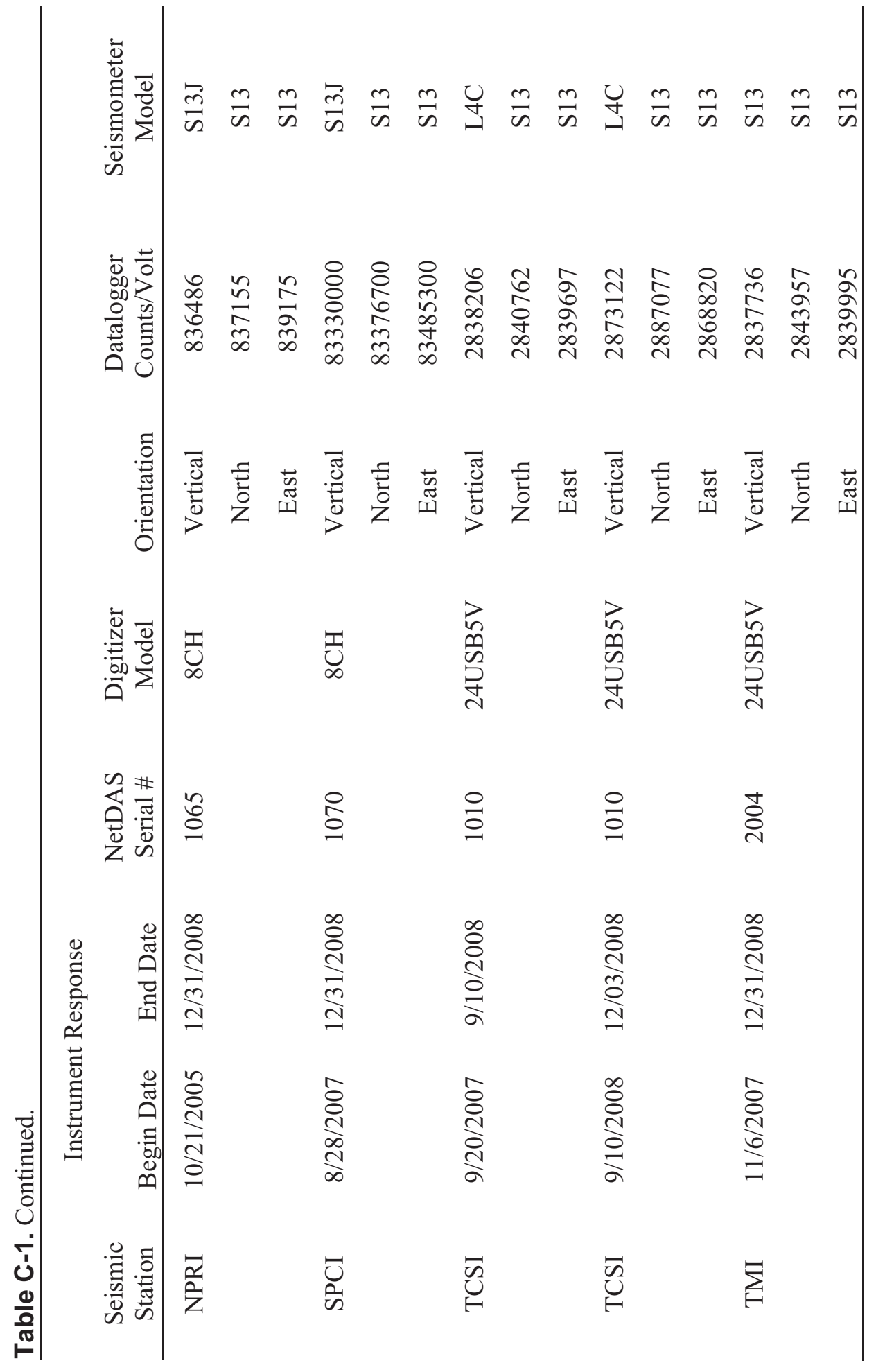


Appendix D

2008 Earthquake List 
(Intentionally Blank) 


\section{Appendix D}

\section{Earthquake List}

The summary list of earthquakes includes those located within a $161-\mathrm{km}(100-$ mile) radius of the INL centered at $43.0^{\circ} 39.00^{\prime} \mathrm{N}, 112^{\circ} 47.00^{\prime} \mathrm{W}$. Table D-1 provides an explanation of the headings listed in Table D-2 for the earthquake list. The format for this table has been modified from previous years. The earthquake identification number is no longer reported since the SEISAN analysis package identification number is simply the origin data and time. The listing also includes the distance of the earthquake epicenter from the center of INL. 
Table D-1. Explanation of the earthquake summary table headings.

\begin{tabular}{|c|c|c|}
\hline Heading & Example & Explanation \\
\hline ORIGIN & 1/3/2008 5:02 & $\begin{array}{l}\text { Date of the earthquake: month/day/year }(1 / 3 / 2008) \text {; origin } \\
\text { time of the earthquake: hour and minute in UTC }(5: 02)\end{array}$ \\
\hline LAT N & 44.3655 & Latitude of epicenter in degrees North \\
\hline LONG W & -113.9947 & Longitude of epicenter in degrees West \\
\hline MAG & 1.1 & Magnitude of the earthquake. \\
\hline TYPE & Mc IE & $\begin{array}{l}\text { Type of magnitude reported and reporting agency. Magnitude } \\
\text { types: Coda magnitude (Mc); Local magnitude (ML); } \\
\text { Moment magnitude (Mw); and Body wave magnitude (mb). } \\
\text { Reporting agencies include: Idaho National Laboratory (IE); } \\
\text { NEIC (US); University of Utah (UU); and Montana Bureau } \\
\text { of Mines and Geology (MB). NM with a magnitude of } 0.00 \\
\text { indicates that no magnitude was calculated as a result of } \\
\text { multiple earthquakes, which obscures the coda of the first } \\
\text { event or the record length was insufficient to include the full } \\
\text { coda of the earthquake. }\end{array}$ \\
\hline DIST & 125.6 & $\begin{array}{l}\text { Distance in km from center of INL at: } 43^{\circ} 39.00^{\prime} \mathrm{N} \text {, } \\
112^{\circ} 47.00^{\prime} \mathrm{W} \text {. }\end{array}$ \\
\hline $\mathrm{Z}$ & 6.15 & $\begin{array}{l}\text { Calculated focal depth in } \mathrm{km} \text {. Not all earthquakes have } \\
\text { appropriate seismic station geometry for calculating a reliable } \\
\text { focal depth, thus the errors (ERZ) are typically large. }\end{array}$ \\
\hline NO & 16 & Number of station readings used in locating the earthquakes. \\
\hline GAP & 95 & Largest azimuthal separation in degrees between stations. \\
\hline DMIN & 30.2 & Distance in $\mathrm{km}$ from the epicenter to the nearest station. \\
\hline \multirow[t]{2}{*}{ RMS } & 0.09 & $\begin{array}{l}\text { Root mean square error of arrival time residuals in second } \\
\text { using all weights as calculated by: } \mathrm{RMS}=\operatorname{SQRT}\left(\Sigma \mathrm{R}_{\mathrm{i}}^{2} / \mathrm{N}\right)\end{array}$ \\
\hline & & $\begin{array}{l}\text { Where: } \mathrm{SQRT} \text { is the square root; } \Sigma \mathrm{R}_{\mathrm{i}} \text { is the sum of the time } \\
\text { residuals for the } \mathrm{i}^{\text {th }} \text { station; and } \mathrm{N} \text { is the number of residuals. }\end{array}$ \\
\hline ERH & 0.4 & Standard horizontal error of the epicenter in $\mathrm{km}$. \\
\hline ERZ & 14.6 & Standard vertical error of the focal depth in $\mathrm{km}$. \\
\hline
\end{tabular}


Table D-2. Earthquakes located within 161-km radius of INL in 2008.

\begin{tabular}{|c|c|c|c|c|c|c|c|c|c|c|c|c|}
\hline ORIGIN TIME & LAT N & LONG W & MAG & -TYPE & DIST & $Z$ & NO & GAP & DMIN & RMS & ERH & ERZ \\
\hline 1/3/2008 5:02 & 44.3655 & -113.9947 & 1.1 & Mc IE & 125.6 & 6.15 & 16 & 95 & 30.2 & 0.09 & 0.4 & 14.6 \\
\hline $1 / 13 / 200822: 38$ & 44.3950 & -114.0470 & 1.6 & Mc IE & 130.9 & 0.49 & 17 & 88 & 53.7 & 0.14 & 0.5 & 17.0 \\
\hline 1/13/2008 23:05 & 42.7280 & -111.3045 & 2.0 & ML IE & 158.0 & 2.04 & 14 & 91 & 17.2 & 0.11 & 0.6 & 15.7 \\
\hline 1/15/2008 9:05 & 44.3970 & -114.0362 & 1.6 & Mc IE & 130.4 & 6.76 & 16 & 87 & 54.0 & 0.22 & 0.5 & 3.2 \\
\hline 1/18/2008 1:40 & 43.5475 & -111.0708 & 2.0 & Mc IE & 138.7 & 12.65 & 24 & 57 & 10.6 & 0.19 & 0.4 & 1.1 \\
\hline 1/19/2008 5:55 & 42.6197 & -112.0338 & 2.2 & Mc IE & 129.8 & 8.84 & 28 & 63 & 41.4 & 0.11 & 0.3 & 2.1 \\
\hline 1/20/2008 1:59 & 44.6360 & -112.0857 & 1.2 & Mc IE & 123.1 & 6.36 & 8 & 110 & 25.0 & 0.06 & 0.6 & 11.1 \\
\hline 1/21/2008 15:35 & 42.7427 & -111.3058 & 2.0 & ML IE & 156.8 & 6.44 & 11 & 100 & 17.0 & 0.13 & 0.6 & 3.1 \\
\hline $1 / 23 / 20083: 48$ & 42.7520 & -111.3272 & 2.4 & Mc IE & 154.8 & 11.39 & 39 & 138 & 23.1 & 0.16 & 0.3 & 0.8 \\
\hline 1/23/2008 23:46 & 42.7350 & -111.3083 & 0.0 & Mc IE & 157.2 & 2.11 & 15 & 89 & 17.4 & 0.09 & 0.3 & 11.4 \\
\hline 1/28/2008 20:30 & 44.3345 & -113.8848 & 2.0 & Mc IE & 116.6 & 4.10 & 9 & 287 & 38.4 & 0.09 & 4.0 & 8.2 \\
\hline 1/29/2008 22:42 & 44.3675 & -113.9957 & 2.2 & Mc IE & 125.8 & 5.25 & 27 & 96 & 30.0 & 0.11 & 0.3 & 1.0 \\
\hline 1/31/2008 23:26 & 42.7322 & -111.3133 & 1.9 & ML IE & 157.1 & 1.88 & 11 & 89 & 17.8 & 0.10 & 0.5 & 15.0 \\
\hline 2/4/2008 0:30 & 44.8947 & -112.7090 & 1.5 & Mc IE & 138.6 & 7.09 & 15 & 108 & 31.2 & 0.07 & 0.7 & 2.7 \\
\hline 2/4/2008 21:31 & 44.7897 & -112.4077 & 1.8 & ML IE & 130.3 & 6.63 & 11 & 82 & 21.8 & 0.12 & 0.6 & 13.7 \\
\hline 2/6/2008 2:07 & 44.7665 & -111.9578 & 2.5 & ML IE & 140.6 & 16.17 & 25 & 83 & 23.5 & 0.07 & 0.4 & 0.9 \\
\hline 2/9/2008 6:47 & 44.5533 & -112.3152 & 2.3 & Mc IE & 107.2 & 9.59 & 28 & 72 & 7.7 & 0.12 & 0.5 & 0.5 \\
\hline 2/10/2008 9:25 & 44.5238 & -114.2825 & 1.2 & Mc IE & 154.5 & 6.69 & 13 & 99 & 45.6 & 0.26 & 0.6 & 3.6 \\
\hline 2/14/2008 9:17 & 43.7708 & -111.0813 & 2.2 & ML IE & 137.7 & 11.49 & 17 & 93 & 21.3 & 0.05 & 0.3 & 2.2 \\
\hline 2/14/2008 22:42 & 44.2685 & -114.3188 & 2.1 & Mc IE & 141.1 & 0.04 & 18 & 84 & 42.5 & 0.26 & 0.6 & 6.3 \\
\hline 2/17/2008 21:28 & 44.7403 & -112.5067 & 1.7 & ML IE & 123.3 & 5.07 & 13 & 94 & 17.5 & 0.14 & 0.6 & 1.8 \\
\hline 2/21/2008 18:29 & 44.6787 & -111.9207 & 1.3 & Mc IE & 133.6 & 8.83 & 8 & 106 & 21.0 & 0.08 & 0.6 & 3.5 \\
\hline $2 / 22 / 2008$ 13:17 & 44.6300 & -112.0870 & 1.4 & Mc IE & 122.4 & 4.59 & 16 & 55 & 24.7 & 0.15 & 0.6 & 1.0 \\
\hline 2/22/2008 21:57 & 44.6327 & -112.0958 & 3.1 & ML MB & 122.4 & 13.69 & 48 & 73 & 24.1 & 0.11 & 0.3 & 0.8 \\
\hline 2/22/2008 22:01 & 44.6385 & -112.0983 & 2.0 & Mc IE & 122.9 & 11.99 & 19 & 57 & 24.0 & 0.12 & 0.5 & 2.3 \\
\hline 2/23/2008 5:01 & 44.6442 & -112.0978 & 2.5 & Mc IE & 123.4 & 13.50 & 39 & 64 & 24.2 & 0.14 & 0.4 & 1.1 \\
\hline 2/23/2008 5:13 & 44.6285 & -112.0918 & 3.0 & ML MB & 122.1 & 13.54 & 46 & 53 & 24.3 & 0.14 & 0.4 & 0.9 \\
\hline $2 / 23 / 20085: 50$ & 43.2998 & -110.8705 & 1.5 & Mc IE & 159.5 & 12.99 & 17 & 207 & 14.6 & 0.10 & 0.7 & 0.9 \\
\hline 2/23/2008 21:27 & 43.0477 & -111.4023 & 1.9 & Mc IE & 130.4 & 13.63 & 37 & 72 & 28.4 & 0.10 & 0.3 & 0.7 \\
\hline $2 / 24 / 2008$ 0:21 & 43.0582 & -111.4037 & 1.4 & Mc IE & 129.7 & 8.71 & 18 & 84 & 40.9 & 0.08 & 0.3 & 0.9 \\
\hline 2/26/2008 16:34 & 44.6347 & -112.0840 & 1.3 & Mc IE & 123.0 & 6.40 & 14 & 110 & 25.1 & 0.10 & 0.6 & 12.0 \\
\hline 2/27/2008 1:26 & 43.2693 & -111.4102 & 1.1 & Mc IE & 118.9 & 16.76 & 6 & 132 & 11.3 & 0.12 & 1.0 & 1.9 \\
\hline $2 / 28 / 20088: 10$ & 42.6155 & -111.4295 & 1.8 & Mc IE & 159.3 & 8.47 & 28 & 97 & 27.4 & 0.11 & 0.3 & 1.9 \\
\hline 2/28/2008 9:26 & 42.5238 & -111.8190 & 1.0 & Mc IE & 147.8 & 4.87 & 8 & 336 & 56.3 & 0.06 & 12.1 & 12.5 \\
\hline 3/1/2008 9:04 & 44.6268 & -112.5177 & 1.1 & Mc IE & 110.7 & 2.75 & 6 & 159 & 10.5 & 0.08 & 5.1 & 9.3 \\
\hline $3 / 3 / 200812: 54$ & 44.5998 & -112.5230 & 2.0 & Mc IE & 107.7 & 10.27 & 31 & 47 & 9.8 & 0.10 & 0.2 & 0.4 \\
\hline $3 / 4 / 20082: 13$ & 44.7077 & -111.8745 & 2.7 & Mc IE & 138.3 & 11.02 & 28 & 160 & 16.7 & 0.06 & 0.6 & 1.1 \\
\hline $3 / 4 / 2008$ 12:43 & 44.7008 & -111.8670 & 2.0 & Mc IE & 137.9 & 11.91 & 19 & 121 & 16.3 & 0.12 & 0.6 & 0.9 \\
\hline $3 / 4 / 2008$ 15:44 & 44.7057 & -111.8752 & 2.1 & Mc IE & 138.1 & 11.33 & 22 & 75 & 16.8 & 0.12 & 0.5 & 1.2 \\
\hline $3 / 4 / 2008$ 17:20 & 44.7930 & -112.9068 & 1.2 & ML IE & 127.5 & 10.86 & 9 & 193 & 6.0 & 0.05 & 1.2 & 0.6 \\
\hline 3/7/2008 2:52 & 44.6197 & -114.1040 & 2.5 & Mc IE & 151.0 & 5.83 & 33 & 86 & 13.4 & 0.09 & 0.3 & 0.6 \\
\hline 3/7/2008 8:41 & 44.6993 & -111.8862 & 1.7 & Mc IE & 137.0 & 13.86 & 9 & 94 & 17.8 & 0.11 & 0.9 & 1.5 \\
\hline $3 / 7 / 2008$ 15:14 & 43.1150 & -111.3620 & 2.2 & Mc IE & 129.6 & 1.86 & 39 & 76 & 6.9 & 0.11 & 0.3 & 0.8 \\
\hline 3/7/2008 15:55 & 42.4528 & -111.6727 & 1.2 & Mc IE & 161.0 & 13.23 & 15 & 93 & 38.4 & 0.10 & 0.5 & 1.0 \\
\hline 3/8/2008 3:19 & 43.2572 & -111.4078 & 1.1 & Mc IE & 119.5 & 3.09 & 11 & 113 & 12.3 & 0.04 & 0.5 & 7.0 \\
\hline $3 / 8 / 2008$ 16:12 & 44.2817 & -113.2133 & 0.7 & Mc IE & 78.3 & 4.40 & 8 & 154 & 15.7 & 0.06 & 3.4 & 5.8 \\
\hline $3 / 10 / 2008$ 2:14 & 42.8232 & -111.6527 & 1.2 & ML IE & 129.9 & 8.56 & 8 & 284 & 5.4 & 0.08 & 1.1 & 0.9 \\
\hline $3 / 11 / 20084: 39$ & 44.4395 & -114.0260 & 1.7 & Mc IE & 132.8 & 6.15 & 16 & 76 & 22.8 & 0.17 & 0.7 & 1.9 \\
\hline $3 / 12 / 2008$ 1:27 & 42.8770 & -111.6473 & 1.0 & Mc IE & 126.1 & 10.80 & 7 & 154 & 6.9 & 0.21 & 1.3 & 1.9 \\
\hline $3 / 12 / 2008$ 1:39 & 42.8797 & -111.6052 & 0.7 & Mc IE & 128.4 & 8.75 & 6 & 239 & 5.5 & 0.17 & 1.9 & 2.9 \\
\hline
\end{tabular}




\begin{tabular}{|c|c|c|c|c|c|c|c|c|c|c|c|c|}
\hline ORIGIN TIME & LAT N & LONG W & MAG & -TYPE & DIST & $Z$ & $\mathrm{NO}$ & GAP & DMIN & RMS & $\mathrm{ERH}$ & ERZ \\
\hline $3 / 13 / 20083: 17$ & 44.4773 & -112.8255 & 0.7 & Mc IE & 92.1 & 9.84 & 12 & 122 & 18.8 & 0.06 & 0.6 & 2.9 \\
\hline $3 / 14 / 20084: 04$ & 3.3412 & -110.8780 & 1.5 & Mc IE & 157.8 & 12.54 & 17 & 117 & 13.7 & 0.16 & 0.4 & 1.0 \\
\hline $3 / 14 / 20084: 18$ & 43.3395 & -110.8758 & 1.8 & Mc IE & 158.0 & 12.24 & 23 & 119 & 13.6 & 0.10 & 0.4 & 0.8 \\
\hline $3 / 14 / 2008$ 14:46 & 44.3655 & -113.9925 & 1.9 & Mc IE & 125.4 & 6.82 & 28 & 86 & 30.4 & 0.24 & 0.4 & 1.9 \\
\hline 3/15/2008 9:30 & 42.6573 & -111.4323 & 0.8 & Mc IE & 155.7 & 13.58 & 9 & 252 & 23.2 & 0.23 & 2.6 & 2.7 \\
\hline 3/15/2008 11:50 & 44.2062 & -114.0615 & 1.9 & Mc IE & 119.8 & 1.72 & 25 & 100 & 32.7 & 0.15 & 0.4 & 1.2 \\
\hline $3 / 15 / 2008$ 16:33 & 44.7052 & -111.8617 & 2.3 & Mc IE & 138.6 & 14.28 & 33 & 75 & 15.8 & 0.08 & 0.3 & 0.7 \\
\hline 3/15/2008 23:05 & 44.7015 & -111.8660 & 1.8 & Mc IE & 138.0 & 12.19 & 16 & 105 & 16.2 & 0.07 & 0.4 & 1.1 \\
\hline 3/16/2008 17:17 & 44.3582 & -114.0095 & 1.5 & Mc IE & 126.0 & 7.39 & 20 & 98 & 30.1 & 0.30 & 0.6 & 10.9 \\
\hline 3/16/2008 18:47 & 44.7007 & -111.8615 & 1.7 & Mc IE & 138.2 & 13.84 & 16 & 94 & 15.8 & 0.09 & 0.5 & 0.9 \\
\hline 3/16/2008 20:11 & 42.8785 & -111.5263 & 1.8 & ML IE & 133.3 & 11.23 & 11 & 116 & 7.2 & 0.11 & 0.6 & 0.9 \\
\hline 3/16/2008 20:38 & 44.7017 & -111.8680 & 1.5 & ML IE & 138.0 & 11.27 & 11 & 177 & 16.3 & 0.11 & 0.9 & 1.5 \\
\hline 3/17/2008 21:32 & 44.2402 & -114.3188 & 1.6 & Mc IE & 139.6 & 0.04 & 8 & 234 & 73.4 & 0.23 & 3.0 & 3.3 \\
\hline 3/19/2008 9:00 & 44.3760 & -113.9940 & 1.7 & Mc IE & 126.3 & 6.71 & 19 & 74 & 29.4 & 0.17 & 0.4 & 2.3 \\
\hline $3 / 20 / 20081: 10$ & 44.6973 & -111. & 1.2 & Mc IE & 137.9 & 13.25 & 11 & 72 & 15.9 & 0.08 & 0.5 & 1.1 \\
\hline $3 / 20 / 20081: 47$ & 44.7052 & -111.8813 & 1.9 & Mc IE & 137.8 & 10.58 & 23 & 75 & 17.3 & 0.09 & 0.4 & 1.4 \\
\hline $3 / 20 / 20084: 33$ & 42.9607 & -111.3005 & 1.3 & $\mathrm{~N}$ & 6 & 8.12 & 16 & 97 & 2 & 0.11 & 0.4 & 1.2 \\
\hline $3 / 20 / 2008$ 23:38 & 43.2250 & -110.8945 & 1.4 & Mc IE & 160.0 & 19.39 & 14 & 155 & 21.3 & 0.12 & 0.8 & 2.8 \\
\hline $3 / 21 / 20084: 50$ & 43.2222 & -110.9210 & 2.4 & Mc IE & 158.0 & 11.18 & 45 & 132 & 23.1 & 0.12 & 0.3 & 1.3 \\
\hline $3 / 22 / 20084: 15$ & 44.6945 & -111.8698 & 1.4 & ML IE & 137.2 & 13.39 & 14 & 73 & 16.6 & 0.05 & 0.4 & 1.0 \\
\hline $3 / 23 / 20083: 13$ & 43.0087 & -111.5235 & 2.1 & Mc IE & 124.6 & 8.33 & 28 & 60 & 11.4 & 0.08 & 0.3 & 0.8 \\
\hline $3 / 24 / 2008$ 2:04 & 42.3 & -112 & 2.2 & IE & 151.0 & 3.50 & 27 & 72 & 37.3 & 0.09 & 0.3 & 7.1 \\
\hline $3 / 25 / 20086: 58$ & 44.1 & -11 & 1.7 & $\mathrm{~N}$ & 0 & 9 & 24 & 93 & 2 & 0 & 3 & 0.9 \\
\hline $3 / 25 / 2008$ 19:10 & 44.2135 & -114.0447 & 1.1 & Mc IE & 119.1 & 6.93 & 16 & 94 & 33.7 & 0.09 & 0.7 & 14.7 \\
\hline $3 / 26 / 2008$ 12:40 & 44.6247 & -112.2767 & 2.3 & Mc IE & 115.8 & 4.59 & 45 & 75 & 29.2 & 0.12 & 0.3 & 1.4 \\
\hline 3/26/2008 13:00 & 44.6285 & -112.2783 & 2.2 & Mc IE & 116.1 & 5.10 & 30 & 54 & 29.0 & 0.19 & 0.4 & 1.6 \\
\hline 3/26/2008 13:18 & 44.6277 & -112.2733 & 1.9 & $\mathrm{Mc}$ IE & 116.2 & 4.40 & 20 & 77 & 29.4 & 0.09 & 0.4 & 2.1 \\
\hline 3/26/2008 13:24 & 44.6195 & -112.2578 & 1.6 & Mc IE & 115.8 & 2.95 & 13 & 182 & 30.6 & 0.02 & 0.6 & 1.3 \\
\hline 3/26/2008 13:41 & 44.6302 & & 1.9 & & & & 23 & 77 & & & & 13.4 \\
\hline $3 / 26 / 2008$ 15:03 & 44.6258 & -112.2762 & 1.6 & Mc IE & 115.9 & 4.85 & 17 & 77 & 29.2 & 0.12 & 0.5 & 1.9 \\
\hline $3 / 26 / 2008$ 15:32 & 44.6252 & -112.2785 & 2.3 & Mc IE & 115.8 & 3.96 & 36 & 59 & 29.0 & 0.14 & 0.3 & 0.8 \\
\hline 3/27/2008 11:01 & 44.7002 & -111.8752 & 1.9 & Mc IE & 137.5 & 7.74 & 14 & 79 & 49.7 & 0.11 & 0.5 & 5.6 \\
\hline $3 / 27 / 2008$ 23:53 & 44.4747 & -114.1398 & 1.3 & Mc IE & 142.2 & 6.26 & 11 & 253 & 61.3 & 0.05 & 1.8 & 3.5 \\
\hline $3 / 28 / 20084: 41$ & 44.7183 & -111.8593 & 1.3 & Mc IE & 139.9 & 13.89 & 15 & 129 & 15.4 & 0.09 & 0.6 & 1.4 \\
\hline 3/28/2008 17:48 & 44.6918 & -111.8747 & 1.9 & Mc IE & 136.8 & 9.85 & 23 & 70 & 17.1 & 0.12 & 0.4 & 1.3 \\
\hline 3/28/2008 22:01 & 44.6220 & -112.2870 & 2.4 & $\mathrm{Mc}$ IE & 115.2 & 10.49 & 46 & 47 & 9.1 & 0.16 & 0.3 & 0.6 \\
\hline $3 / 29 / 20081: 11$ & 44.6217 & -112.2798 & 0.7 & Mc IE & 115.4 & 7.42 & 6 & 271 & 9.6 & 0.07 & 1.5 & 1.5 \\
\hline $3 / 29 / 2008$ 2:35 & 44.6252 & -112.2563 & 2.1 & Mc IE & 116.4 & 9.53 & 33 & 76 & 11.5 & 0.07 & 0.4 & 0.7 \\
\hline $3 / 29 / 20084: 55$ & 44.6255 & -112.2722 & 2.5 & Mc IE & 116.0 & 10.47 & 51 & 91 & 10.3 & 0.11 & 0.2 & 0.5 \\
\hline $3 / 29 / 20087: 27$ & 44.6222 & -112.2665 & 2.2 & Mc IE & 115.8 & 9.13 & 37 & 167 & 10.6 & 0.15 & 0.4 & 0.9 \\
\hline $3 / 29 / 2008$ 13:42 & 44.6248 & -112.2667 & 0.6 & $\mathrm{Mc}$ IE & 116.0 & 6.51 & 5 & 223 & 10.7 & 0.04 & 2.0 & 3.9 \\
\hline $3 / 30 / 2008$ 1:24 & 44.6315 & -112.2892 & 1.5 & Mc IE & 116.1 & 7.43 & 18 & 123 & 9.4 & 0.09 & 0.4 & 1.2 \\
\hline $3 / 30 / 2008$ 1:45 & 44.6208 & -112.2753 & 0.7 & Mc IE & 115.4 & 8.25 & 15 & 180 & 9.9 & 0.09 & 0.4 & 1.0 \\
\hline 3/30/2008 3:08 & 43.9900 & -113.8863 & 1.7 & Mc IE & 96.4 & 6.99 & 29 & 100 & 20.3 & 0.11 & 0.4 & 14.3 \\
\hline 3/30/2008 11:54 & 44.6328 & -112.2705 & 1.2 & Mc IE & 116.8 & 5.36 & 14 & 115 & 10.8 & 0.13 & 0.5 & 0.6 \\
\hline $3 / 30 / 2008$ 18:33 & 44.6277 & -112.2718 & 1.7 & Mc IE & 116.2 & 7.82 & 24 & 114 & 10.4 & 0.13 & 0.5 & 1.3 \\
\hline $3 / 31 / 2008$ 2:09 & 44.6285 & -112.2742 & 1.5 & Mc IE & 116.2 & 8.53 & 23 & 114 & 10.3 & 0.12 & 0.5 & 1.2 \\
\hline $3 / 31 / 20088: 33$ & 42.9903 & -111.5317 & 1.1 & Mc IE & 125.2 & 0.03 & 12 & 89 & 10.7 & 0.08 & 0.4 & 0.8 \\
\hline $3 / 31 / 2008$ 14:52 & 44.3708 & -113.9965 & 1.6 & Mc IE & 126.1 & 6.90 & 15 & 116 & 29.7 & 0.10 & 0.4 & 14.9 \\
\hline $3 / 31 / 2008$ 16:51 & 44.4998 & -114.0650 & 2.0 & Mc IE & 139.5 & 4.97 & 25 & 81 & 16.7 & 0.13 & 0.4 & 1.1 \\
\hline $3 / 31 / 2008$ 16:58 & 43.2412 & -111.3933 & 1.5 & ML IE & 121.3 & 7.32 & 11 & 103 & 13.2 & 0.12 & 0.4 & 2.2 \\
\hline
\end{tabular}




\begin{tabular}{|c|c|c|c|c|c|c|c|c|c|c|c|c|}
\hline ORIGIN TIME & LAT N & LONG W & MAG & -TYPE & DIST & $Z$ & $\mathrm{NO}$ & GAP & DMIN & RMS & ERH & ERZ \\
\hline $3 / 31 / 2008$ 17:12 & 44.5608 & -112.3003 & 2.1 & Mc IE & 108.4 & 5.88 & 23 & 85 & 28.0 & 0.18 & 0.5 & 18.5 \\
\hline $3 / 31 / 2008$ 20:16 & 42.8050 & -111.1780 & 1.5 & Mc IE & 160.7 & 10.27 & 19 & 78 & 7.7 & 0.06 & 0.4 & 0.7 \\
\hline $3 / 31 / 200820: 25$ & 42.7918 & -111.2057 & 0.9 & Mc IE & 159.8 & 7.72 & 8 & 171 & 9.1 & 0.08 & 1.0 & 1.3 \\
\hline 4/1/2008 8:13 & 44.8813 & -112.0282 & 1.9 & Mc IE & 149.6 & 2.08 & 21 & 75 & 33.3 & 0.15 & 0.4 & 1.8 \\
\hline 4/1/2008 11:32 & 44.8807 & -112.0255 & 1.9 & Mc IE & 149.7 & 6.68 & 26 & 147 & 33.0 & 0.09 & 0.3 & 10.5 \\
\hline 4/1/2008 22:39 & 42.5802 & -111.8710 & 0.9 & Mc IE & 140.2 & 3.37 & 14 & 100 & 36.3 & 0.15 & 0.4 & 15.1 \\
\hline $4 / 2 / 2008$ 2:47 & 44.3713 & -113.9877 & 2.1 & Mc IE & 125.6 & 6.96 & 33 & 51 & 30.2 & 0.23 & 0.3 & 15.1 \\
\hline 4/2/2008 3:56 & 44.6277 & -112.2840 & 2.5 & Mc IE & 115.9 & 3.94 & 52 & 59 & 28.6 & 0.09 & 0.2 & 0.6 \\
\hline $4 / 2 / 20084: 52$ & 44.6280 & -112.2787 & 2.4 & Mc IE & 116.0 & 3.55 & 43 & 59 & 29.0 & 0.10 & 0.3 & 0.9 \\
\hline $4 / 2 / 20086: 48$ & 44.6235 & -112.2702 & 1.8 & Mc IE & 115.8 & 4.14 & 24 & 76 & 29.7 & 0.11 & 0.3 & 0.9 \\
\hline $4 / 2 / 20087: 45$ & 44.6292 & -112.2803 & 1.4 & $\mathrm{Mc}$ IE & 116.1 & 10.29 & 17 & 113 & 28.9 & 0.18 & 0.5 & 2.5 \\
\hline $4 / 2 / 2008$ 8:38 & 44.6230 & -112.2683 & 2.2 & Mc IE & 115.8 & 4.49 & 35 & 53 & 29.8 & 0.06 & 0.3 & 1.4 \\
\hline 4/2/2008 18:06 & 44.2708 & -114.3162 & 1.6 & Mc IE & 141.1 & 6.52 & 18 & 132 & 33.0 & 0.10 & 0.4 & 2.2 \\
\hline 4/2/2008 18:08 & 43.0775 & -111.2877 & 0.4 & Mc IE & 136.9 & 1.97 & 5 & 266 & 7.3 & 0.18 & 3.0 & 3.8 \\
\hline 4/2/2008 23:25 & 43.3563 & -110.9035 & 1.3 & ML IE & 155.4 & 13.37 & 14 & 182 & 15.3 & 0.08 & 0.6 & 1.0 \\
\hline 4/3/2008 0:26 & 44.2005 & -112.9635 & 0.8 & Mc IE & 62.9 & 3.08 & 10 & 110 & 14.4 & 0.10 & 0.4 & 1.5 \\
\hline 4/3/2008 15:46 & 44.1753 & -113.0248 & 1.6 & Mc IE & 61.6 & 10.51 & 25 & 87 & 18.4 & 0.21 & 0.5 & 3.1 \\
\hline 4/4/2008 7:20 & 44.6325 & -112.2972 & 1.5 & Mc IE & 116.0 & 5.72 & 18 & 112 & 32.4 & 0.09 & 0.7 & 2.4 \\
\hline $4 / 5 / 2008$ 7:23 & 43.5585 & -111.2435 & 1.8 & Mc IE & 124.7 & 12.74 & 34 & 75 & 24.3 & 0.18 & 0.3 & 1.2 \\
\hline 4/6/2008 2:02 & 44.6258 & -112.2783 & 2.5 & Mc IE & 115.8 & 13.91 & 45 & 103 & 29.0 & 0.10 & 0.2 & 0.6 \\
\hline 4/6/2008 2:12 & 44.6452 & -112.2737 & 1.5 & Mc IE & 118.0 & 6.27 & 13 & 159 & 29.5 & 0.25 & 0.8 & 19.2 \\
\hline $4 / 6 / 20082: 53$ & 44.6305 & -112.2848 & 1.8 & Mc IE & 116.1 & 5.97 & 31 & 75 & 28.5 & 0.13 & 0.3 & 16.3 \\
\hline 4/6/2008 21:57 & 44.6273 & -112.2833 & 2.3 & Mc IE & 115.8 & 5.26 & 47 & 75 & 28.6 & 0.14 & 0.2 & 1.3 \\
\hline 4/6/2008 22:02 & 42.7388 & -111.2952 & 1.4 & Mc IE & 157.8 & 2.50 & 7 & 181 & 16.2 & 0.12 & 1.5 & 15.0 \\
\hline 4/7/2008 2:19 & 44.6297 & -112.2883 & 1.8 & Mc IE & 116.0 & 8.74 & 25 & 54 & 28.2 & 0.11 & 0.3 & 3.0 \\
\hline 4/8/2008 16:30 & 43.3013 & -110.8892 & 1.3 & Mc IE & 158.0 & 12.33 & 14 & 164 & 15.9 & 0.13 & 0.6 & 1.3 \\
\hline 4/8/2008 18:06 & 43.5520 & -111.2002 & 1.4 & Mc IE & 128.2 & 12.34 & 18 & 124 & 21.3 & 0.15 & 0.4 & 2.1 \\
\hline 4/8/2008 21:16 & 44.6928 & -111.9298 & 1.5 & $\mathrm{Mc}$ IE & 13 & 3.21 & 14 & 87 & 8 & 0 & 0.4 & 1.8 \\
\hline $4 / 9 / 2008$ 2:03 & 44.6295 & -112.2792 & 2.2 & Mc IE & 116.2 & 4.24 & 30 & 75 & 29.0 & 0.15 & 0.4 & 1.2 \\
\hline 4/10/2008 9:11 & 43.5730 & -111.2685 & 1.8 & Mc IE & 122.5 & 4.79 & 18 & 144 & 7.2 & 0.31 & 0.8 & 10.0 \\
\hline 4/10/2008 9:19 & 44.7615 & -111.7273 & 1.8 & Mc IE & 149.7 & 5.65 & 17 & 95 & 52.3 & 0.15 & 0.4 & 2.9 \\
\hline 4/11/2008 3:49 & 44.6307 & -112.2783 & 1.5 & Mc IE & 116.3 & 4.26 & 12 & 113 & 29.0 & 0.10 & 0.8 & 1.7 \\
\hline 4/11/2008 9:08 & 44.6023 & -111.3997 & 0.8 & ML IE & 153.2 & 5.05 & 5 & 247 & 16.5 & 0.11 & 6.8 & 13.7 \\
\hline 4/11/2008 10:44 & 44.3358 & -112.6368 & 1.1 & Mc IE & 77.2 & 3.11 & 16 & 89 & 24.3 & 0 & 0.3 & 1.2 \\
\hline 4/11/2008 16:58 & 44.7148 & -112.4462 & 1.0 & Mc IE & 121.5 & 5.39 & 10 & 198 & 19.1 & 0.07 & 1.0 & 1.1 \\
\hline 4/12/2008 6:22 & 44.6840 & -111.9312 & 1.5 & Mc IE & 133.7 & 0.03 & 15 & 78 & 48.9 & 0.11 & 0.5 & 2.1 \\
\hline 4/12/2008 8:22 & 44.6262 & -112.2795 & 1.9 & Mc IE & 115.8 & 10.75 & 30 & 59 & 28.9 & 0.11 & 0.3 & 2.0 \\
\hline 4/14/2008 14:00 & 44.6250 & -112.2837 & 1.5 & Mc IE & 115.6 & 4.91 & 14 & 120 & 28.6 & 0.16 & 0.6 & 2.6 \\
\hline 4/14/2008 23:12 & 42.9358 & -111.0863 & 0.5 & Mc IE & 158.9 & 4.90 & 7 & 168 & 19.0 & 0.05 & 1.0 & 10.6 \\
\hline 4/16/2008 5:46 & 42.6818 & -111.7385 & 1.7 & Mc IE & 137.1 & 5.89 & 19 & 73 & 20.7 & 0.17 & 0.5 & 3.6 \\
\hline 4/16/2008 16:13 & 44.6425 & -112.0938 & 0.6 & Mc IE & 123.4 & 6.21 & 7 & 199 & 24.5 & 0.06 & 1.3 & 12.9 \\
\hline 4/16/2008 18:03 & 44.6247 & -112.1050 & 2.9 & Mc IE & 121.2 & 14.18 & 74 & 45 & 23.2 & 0.16 & 0.3 & 0.7 \\
\hline 4/17/2008 9:24 & 44.3568 & -114.5232 & 2.0 & Mc IE & 160.1 & 1.98 & 25 & 91 & 31.4 & 0.11 & 0.5 & 1.9 \\
\hline 4/17/2008 21:31 & 42.7612 & -111.5410 & 1.7 & ML IE & 141.3 & 3.42 & 8 & 286 & 21.9 & 0.06 & 3.3 & 10.8 \\
\hline 4/18/2008 8:28 & 42.8613 & -111.5865 & 0.8 & Mc IE & 130.9 & 11.85 & 9 & 129 & 3.2 & 0.08 & 1.0 & 1.0 \\
\hline 4/18/2008 8:29 & 42.8950 & -111.6157 & 2.3 & Mc IE & 126.6 & 7.69 & 44 & 54 & 7.3 & 0.11 & 0.2 & 0.5 \\
\hline 4/18/2008 8:36 & 42.8945 & -111.6067 & 1.0 & Mc IE & 127.2 & 9.51 & 9 & 101 & 7.1 & 0.05 & 1.0 & 1.6 \\
\hline 4/18/2008 8:42 & 42.8783 & -111.6125 & 2.2 & Mc IE & 128.0 & 10.72 & 37 & 52 & 5.5 & 0.11 & 0.3 & 0.5 \\
\hline 4/18/2008 10:18 & 42.5382 & -111.6013 & 2.1 & Mc IE & 156.7 & 13.00 & 33 & 88 & 32.7 & 0.15 & 0.4 & 1.2 \\
\hline 4/19/2008 0:25 & 44.4425 & -112.7608 & 1.6 & Mc IE & 88.2 & 3.72 & 17 & 63 & 19.1 & 0.15 & 0.5 & 1.3 \\
\hline $4 / 19 / 2008$ 2:59 & 44.6298 & -112.2600 & 1.7 & Mc IE & 116.8 & 6.80 & 24 & 161 & 11.4 & 0.11 & 0.4 & 1.5 \\
\hline
\end{tabular}




\begin{tabular}{|c|c|c|c|c|c|c|c|c|c|c|c|c|}
\hline ORIGIN TIME & LAT N & LONG W & MAG & -TYPE & DIST & $Z$ & $\mathrm{NO}$ & GAP & DMIN & RMS & ERH & ERZ \\
\hline $4 / 19 / 20084: 26$ & 44.1407 & -114.0002 & 1.5 & Mc IE & 112.0 & 5.21 & 24 & 96 & 26.8 & 0.10 & 0.3 & 0.8 \\
\hline 4/19/2008 11:46 & 42.6197 & -111.4152 & 1.3 & Mc IE & 159.7 & 8.81 & 14 & 125 & 27.5 & 0.16 & 0.7 & 2.2 \\
\hline 4/24/2008 22:55 & 44.3308 & -114.3533 & 2.2 & Mc IE & 146.9 & 3.40 & 33 & 75 & 27.1 & 0.10 & 0.3 & 0.9 \\
\hline 4/24/2008 23:04 & 42.9150 & -111.2892 & 1.4 & ML IE & 146.2 & 16.33 & 11 & 147 & 11.1 & 0.05 & 1.3 & 0.9 \\
\hline 4/25/2008 9:25 & 44.1717 & -113.9872 & 2.1 & Mc IE & 112.8 & 1.98 & 33 & 56 & 30.4 & 0.14 & 0.3 & 1.0 \\
\hline 4/26/2008 7:10 & 44.5788 & -112.5962 & 1.3 & Mc IE & 104.4 & 14.62 & 15 & 63 & 5.7 & 0.10 & 0.6 & 0.4 \\
\hline 4/27/2008 23:49 & 42.6360 & -111.3783 & 1.7 & Mc IE & 160.5 & 2.48 & 7 & 297 & 26.9 & 0.10 & 2.9 & 14.4 \\
\hline 4/28/2008 9:02 & 44.1065 & -114.4848 & 1.4 & ML IE & 145.8 & 6.77 & 6 & 260 & 60.8 & 0.14 & 9.4 & 12.8 \\
\hline 4/28/2008 17:44 & 42.9128 & -111.3188 & 0.6 & ML IE & 144.4 & 8.42 & 5 & 157 & 8.8 & 0.06 & 2.0 & 4.6 \\
\hline 4/28/2008 23:12 & 42.8568 & -111.2743 & & NM & 150.9 & 3.67 & 9 & 93 & 15.0 & 0.06 & 1.2 & 10.8 \\
\hline 4/28/2008 23:16 & 42.8365 & -111.3055 & 1.0 & ML IE & 150.3 & 9.76 & 5 & 205 & 14.7 & 0.05 & 1.7 & 2.5 \\
\hline 4/29/2008 8:49 & 44.7645 & -112.3730 & 2.4 & Mc IE & 128.2 & 4.99 & 40 & 110 & 27.0 & 0.17 & 0.4 & 1.8 \\
\hline 4/30/2008 22:04 & 42.6542 & -111.3888 & 0.0 & Mc IE & 158.5 & 4.98 & 4 & 294 & 26.7 & 0.08 & 9.2 & 11.4 \\
\hline $5 / 2 / 2008$ 10:46 & 44.4817 & -112.9943 & 1.7 & Mc IE & 94.1 & 6.02 & 25 & 70 & 17.4 & 0.10 & 0.2 & 0.6 \\
\hline $5 / 3 / 2008$ 12:17 & 44.7012 & -111.8742 & 2.0 & $\mathrm{Mc}$ IE & 137.7 & 12.31 & 36 & 83 & 16.8 & 0.12 & 0.4 & 1.0 \\
\hline $5 / 4 / 20085: 48$ & 42.8007 & -111.4750 & 1.2 & Mc IE & 142.2 & 12.81 & 10 & 194 & 9.9 & 0.14 & 1.1 & 1.4 \\
\hline 5/4/2008 9:02 & 44.6333 & -112.2445 & 1.0 & ML IE & 117.6 & 9.57 & 8 & 184 & 12.7 & 0.07 & 1.1 & 1.4 \\
\hline $5 / 4 / 200821: 56$ & 44.6560 & -114.1643 & 1.7 & Mc IE & 157.2 & 6.71 & 19 & 99 & 48.9 & 0.12 & 0.4 & 3.6 \\
\hline $5 / 5 / 20080: 54$ & 43.2673 & -111.6015 & 1.1 & Mc IE & 104.6 & 8.93 & 9 & 239 & 24.5 & 0.11 & 1.5 & 4.0 \\
\hline $5 / 5 / 20080: 54$ & 43.2493 & -111.5420 & 1.4 & Mc IE & 109.9 & 0.23 & 11 & 120 & 21.0 & 0.08 & 0.6 & 1.6 \\
\hline $5 / 5 / 20080: 57$ & 42.7347 & -111 & 0.0 & $\mathrm{Mc}$ IE & 157.2 & 2.35 & 8 & 210 & 17.4 & 0.07 & 1.2 & 13.3 \\
\hline $5 / 5 / 20082: 41$ & 42.7 & -111 & 0.7 & IE & $1<$ & 0.13 & $t$ & 292 & 14.7 & 0.09 & 5.0 & 6.6 \\
\hline 5/5/2008 20:06 & 44.2678 & -11 & 1 & $\mathrm{~N}$ & 1 & 30 & 26 & 75 & 5 & 0 & 3 & .3 \\
\hline 5/7/2008 0:22 & 42.7252 & -111.3940 & 0.1 & Mc IE & 152.7 & 5.10 & 4 & 276 & 23.7 & 0.04 & 2.0 & 9.7 \\
\hline 5/8/2008 10:21 & 42.9092 & -111.1628 & 0.9 & Mc IE & 155.1 & 13.23 & 10 & 127 & 16.8 & 0.10 & 1.1 & 3.5 \\
\hline 5/8/2008 10:34 & 42.9285 & -111.1568 & 0.7 & Mc IE & 154.4 & 6.64 & 10 & 105 & 18.7 & 0.06 & 0.5 & 3.7 \\
\hline $5 / 8 / 200814: 10$ & 44.6860 & -112.5550 & 2.0 & $\mathrm{Mc}$ IE & 116.7 & 14.32 & 16 & 126 & 10.4 & 0.10 & 1.4 & 0.6 \\
\hline 5/8/2008 20:12 & 43.0182 & -111.0185 & 0.5 & Mc IE & 159.4 & 5.00 & 6 & 197 & 29.0 & 0.08 & 1.2 & 12.9 \\
\hline 5/11/2008 19:53 & & & 0.8 & & & & 6 & & & & & 2.4 \\
\hline $5 / 12 / 2008$ 21:26 & 44.4513 & -113.0107 & 1.3 & Mc IE & 91.0 & 8.14 & 5 & 133 & 14.6 & 0.06 & 0.9 & 2.5 \\
\hline $5 / 13 / 20084: 44$ & 42.7377 & -111.5488 & 2.4 & Mc IE & 142.7 & 8.02 & 41 & 75 & 11.0 & 0.13 & 0.3 & 0.8 \\
\hline $5 / 13 / 20084: 58$ & 42.7112 & -111.5372 & 0.8 & Mc IE & 145.5 & 3.17 & 8 & 259 & 14.1 & 0.07 & 1.4 & 7.8 \\
\hline $5 / 13 / 20087: 27$ & 42.7060 & -111.5410 & 0.8 & Mc IE & 145.7 & 2.71 & 5 & 325 & 14.5 & 0.12 & 1.8 & 15.1 \\
\hline $5 / 13 / 2008$ 10:50 & 44.1110 & -114.6453 & 2.5 & Mc IE & 158.1 & 7.13 & 46 & 43 & 47.7 & 0.20 & 0.3 & 7.1 \\
\hline $5 / 13 / 2008$ 14:08 & 42.7197 & -111.5682 & 1.7 & ML IE & 143.0 & 8.40 & 9 & 271 & 12.6 & 0.12 & 1.2 & 1.2 \\
\hline 5/13/2008 17:42 & 42.7820 & -111.5035 & 1.5 & ML IE & 141.9 & 6.80 & 7 & 280 & 18.6 & 0.08 & 9.1 & 4.7 \\
\hline 5/13/2008 18:21 & 44.8232 & -111.6563 & 2.1 & Mc IE & 158.5 & 8.37 & 17 & 186 & 10.4 & 0.05 & 0.6 & 0.7 \\
\hline $5 / 13 / 200821: 39$ & 42.6608 & -111.5463 & 0.9 & Mc IE & 149.1 & 10.22 & 9 & 278 & 19.3 & 0.09 & 1.3 & 1.7 \\
\hline $5 / 14 / 20083: 55$ & 42.8327 & -111.2425 & 2.5 & Mc IE & 154.6 & 11.30 & 44 & 72 & 13.8 & 0.10 & 0.3 & 0.6 \\
\hline 5/14/2008 6:03 & 42.8562 & -111.2320 & 1.1 & ML IE & 153.8 & 5.02 & 8 & 132 & 14.8 & 0.09 & 0.8 & 4.7 \\
\hline $5 / 14 / 20086: 12$ & 42.8328 & -111.2487 & 1.1 & $\mathrm{Mc}$ IE & 154.2 & 8.56 & 15 & 149 & 14.3 & 0.09 & 0.9 & 1.6 \\
\hline $5 / 14 / 20086: 42$ & 42.8263 & -111.2358 & 3.0 & ML IE & 155.5 & 11.19 & 52 & 72 & 13.0 & 0.13 & 0.3 & 0.5 \\
\hline $5 / 14 / 20086: 42$ & 42.8245 & -111.2488 & 2.8 & ML IE & 154.8 & 9.55 & 9 & 154 & 13.8 & 0.06 & 0.7 & 1.3 \\
\hline $5 / 14 / 20086: 47$ & 44.4520 & -114.1105 & 1.3 & Mc IE & 138.8 & 4.26 & 14 & 79 & 16.9 & 0.05 & 0.5 & 1.2 \\
\hline $5 / 14 / 20086: 49$ & 42.8317 & -111.2048 & 0.3 & Mc IE & 157.2 & 16.58 & 6 & 174 & 11.3 & 0.01 & 3.2 & 1.3 \\
\hline $5 / 14 / 20086: 53$ & 42.7957 & -111.2802 & 0.6 & Mc IE & 154.7 & 8.44 & 5 & 222 & 15.1 & 0.09 & 1.5 & 2.3 \\
\hline 5/14/2008 6:56 & 42.8417 & -111.2445 & 1.5 & ML IE & 153.9 & 5.49 & 7 & 133 & 14.5 & 0.11 & 1.3 & 4.0 \\
\hline $5 / 14 / 20086: 56$ & 42.8005 & -111.2730 & 0.6 & Mc IE & 154.8 & 9.87 & 6 & 217 & 14.7 & 0.01 & 2.4 & 1.6 \\
\hline $5 / 14 / 20087: 00$ & 42.8275 & -111.2500 & 0.8 & $\mathrm{Mc}$ IE & 154.5 & 10.27 & 8 & 153 & 14.1 & 0.06 & 1.0 & 1.1 \\
\hline $5 / 14 / 2008$ 7:01 & 42.8307 & -111.2400 & 2.0 & Mc IE & 154.9 & 9.97 & 32 & 73 & 13.5 & 0.09 & 0.3 & 0.7 \\
\hline $5 / 14 / 20087: 45$ & 42.8357 & -111.2423 & 1.4 & Mc IE & 154.4 & 9.90 & 18 & 80 & 14.0 & 0.10 & 0.5 & 1.2 \\
\hline
\end{tabular}




\begin{tabular}{|c|c|c|c|c|c|c|c|c|c|c|c|c|}
\hline ORIGIN TIME & LAT N & LONG W & MAG & -TYPE & DIST & $Z$ & $\mathrm{NO}$ & GAP & DMIN & RMS & ERH & ERZ \\
\hline $5 / 14 / 20087: 52$ & 42.8412 & -111.2300 & 0.8 & Mc IE & 154.9 & 9.90 & 5 & 177 & 13.5 & 0.02 & 2.4 & 1.7 \\
\hline $5 / 14 / 2008$ 12:51 & 2.8297 & -111.2505 & 0.7 & Mc IE & 154.3 & 8.49 & 10 & 151 & 14.2 & 0.07 & 0.8 & 1.9 \\
\hline 5/14/2008 16:40 & 42.9457 & -111.4162 & 1.0 & Mc IE & 135.8 & 7.20 & 8 & 110 & 1.0 & 0.07 & 0.5 & 1.1 \\
\hline 5/14/2008 17:39 & 42.8257 & -111.2505 & 0.9 & Mc IE & 154.6 & 10.62 & 5 & 194 & 14.0 & 0.02 & 1.6 & 2.2 \\
\hline 5/14/2008 18:58 & 42.8427 & -111.5755 & 0.9 & ML IE & 132.9 & 12.19 & 4 & 173 & 1.6 & 0.00 & 4.9 & 2.4 \\
\hline $5 / 16 / 2008$ 0:14 & 43.1120 & -111.3942 & 1.2 & $\mathrm{Mc}$ IE & 127.4 & 2.35 & 4 & 185 & 6.8 & 0.03 & 2.5 & 11.2 \\
\hline $5 / 16 / 20087: 25$ & 43.1965 & -111.2482 & 2.1 & Mc IE & 134.1 & 11.94 & 17 & 128 & 17.7 & 0.11 & 0.8 & 2.3 \\
\hline 5/16/2008 22:32 & 42.8665 & -111.1992 & 1.3 & Mc IE & 155.3 & 0.02 & 9 & 154 & 13.8 & 0.13 & 0.9 & 1.6 \\
\hline $5 / 17 / 20080: 47$ & 42.8220 & -111.2438 & 0.8 & Mc IE & 155.2 & 9.64 & 5 & 194 & 13.3 & 0.04 & 1.4 & 2.1 \\
\hline $5 / 17 / 20083: 40$ & 42.8363 & -111.2267 & 0.5 & Mc IE & 155.4 & 9.91 & 7 & 179 & 13.0 & 0.04 & 1.0 & 2.0 \\
\hline $5 / 17 / 20084: 54$ & 42.8133 & -111.2875 & 0.9 & ML IE & 153.0 & 3.08 & 6 & 213 & 16.2 & 0.07 & 1.1 & 10.9 \\
\hline $5 / 17 / 20085: 23$ & 42.8408 & -111.2198 & 1.4 & ML IE & 155.6 & 10.49 & 7 & 174 & 12.9 & 0.06 & 0.9 & 1.6 \\
\hline $5 / 17 / 20085: 23$ & 42.8282 & -111.2322 & 1.3 & Mc IE & 155.6 & 10.87 & 7 & 187 & 12.8 & 0.08 & 1.0 & 1.7 \\
\hline $5 / 17 / 20085: 24$ & 42.8437 & -111.2165 & 1.0 & Mc IE & 155.6 & 11.07 & 7 & 171 & 12.9 & 0.08 & 1.1 & 2.0 \\
\hline $5 / 17 / 20086: 41$ & 44.7093 & -111. & 1.1 & $\mathrm{Mc}$ IE & 137.6 & 5.00 & 6 & 206 & 18.2 & 0.28 & 10.1 & 11.7 \\
\hline 5/17/2008 12:03 & 42.8568 & -111.2060 & 2.2 & Mc IE & 155.5 & 6.78 & 16 & 170 & 13.3 & 0.11 & 0.7 & 2.4 \\
\hline 5/18/2008 23:15 & 42.9078 & -111.2048 & 0.4 & $\mathrm{~N}$ & 152.4 & 5.00 & 4 & 190 & 0 & 0.04 & .3 & 10.7 \\
\hline 5/18/2008 23:16 & 42.8832 & -111.2312 & 0.9 & Mc IE & 152.1 & 18.70 & 6 & 152 & 16.7 & 0.08 & 1.8 & 3.2 \\
\hline 5/21/2008 13:51 & 42.9033 & -111.2108 & 1.2 & Mc IE & 152.2 & 10.99 & 11 & 132 & 17.6 & 0.14 & 0.6 & 2.3 \\
\hline 5/21/2008 18:23 & 43.3143 & -110.8870 & 1.0 & Mc IE & 157.8 & 9.84 & 9 & 197 & 15.2 & 0.28 & 1.3 & 3.6 \\
\hline 5/21/2008 18:25 & 43.3163 & -110 & 1.0 & $\mathrm{Mc}$ IE & 157.3 & 15.96 & 7 & 196 & 15.5 & 0.04 & 1.0 & 1.7 \\
\hline 5/21/2008 18:28 & 43. & -111 & 0.8 & IE & 13 & 4.99 & 7 & 249 & 22.8 & 0.04 & 2.0 & 12.8 \\
\hline $5 / 21 / 2008$ 18:31 & 43 & -11 & 1. & $\mathrm{~N}$ & 1 & 12 & 11 & 2 & & 11 & .7 & 5 \\
\hline 5/21/2008 19:30 & 43.3093 & -110.8958 & 0.7 & Mc IE & 157.2 & 12.28 & 8 & 210 & 16.1 & 0.08 & 0.6 & 1.7 \\
\hline 5/21/2008 19:41 & 43.3133 & -110.9048 & 0.8 & $\mathrm{Mc}$ IE & 156.4 & 13.65 & 9 & 196 & 16.6 & 0.33 & 1.5 & 3.0 \\
\hline 5/22/2008 20:56 & 43.1692 & -111.2618 & 0.8 & Mc IE & 134.3 & 11.13 & 8 & 172 & 20.4 & 0.12 & 0.9 & 3.1 \\
\hline 5/23/2008 18:19 & 42.7067 & -111.6582 & 2.2 & $\mathrm{Mc}$ IE & 139.2 & 5.04 & 13 & 163 & 15.1 & 0.07 & 0.8 & 3.4 \\
\hline 5/23/2008 21:51 & 44.1980 & -114 & 1.1 & $\mathrm{Mc}$ IE & 115.3 & 4.02 & 6 & 230 & 32.8 & 0.11 & 1.9 & 2.6 \\
\hline 5/24/2008 13:25 & & & 1.6 & & & & 15 & 81 & & & & 3.0 \\
\hline $5 / 24 / 2008$ 13:31 & 43.5745 & -111.2225 & 1.0 & Mc IE & 126.2 & 6.08 & 7 & 194 & 3.8 & 0.21 & 1.7 & 2.7 \\
\hline 5/24/2008 14:57 & 44.2005 & -114.0340 & 0.8 & Mc IE & 117.6 & 7.41 & 10 & 145 & 32.5 & 0.04 & 0.8 & 12.9 \\
\hline 5/24/2008 19:14 & 42.5508 & -111.5612 & 1.6 & ML IE & 157.6 & 5.00 & 6 & 290 & 31.3 & 0.06 & 1.4 & 13.1 \\
\hline 5/24/2008 22:17 & 42.6862 & -111.3237 & 1.7 & Mc IE & 159.9 & 2.57 & 6 & 268 & 20.3 & 0.13 & 5.4 & 15.4 \\
\hline 5/25/2008 13:32 & 42.8278 & -111.2318 & 1.2 & Mc IE & 155.6 & 11.18 & 8 & 187 & 12.8 & 0.05 & 1.0 & 1.6 \\
\hline 5/25/2008 14:35 & 43.4907 & -111.1047 & 0.9 & $\mathrm{Mc}$ IE & 136.7 & 13.57 & 8 & 148 & 12.5 & 0.03 & 0.9 & 1.8 \\
\hline 5/25/2008 14:52 & 42.8338 & -111.2202 & 0.9 & Mc IE & 156.0 & 11.96 & 6 & 179 & 12.4 & 0.07 & 1.1 & 2.0 \\
\hline 5/26/2008 15:07 & 44.4898 & -114.2602 & 2.0 & Mc IE & 150.7 & 11.14 & 26 & 92 & 8.3 & 0.08 & 0.3 & 0.4 \\
\hline 5/26/2008 17:01 & 44.4100 & -112.8762 & 1.2 & $\mathrm{Mc}$ IE & 84.9 & 6.16 & 5 & 151 & 10.3 & 0.02 & 1.7 & 1.0 \\
\hline $5 / 28 / 20082: 35$ & 44.4510 & -114.1193 & 2.1 & $\mathrm{Mc}$ IE & 139.3 & 4.83 & 26 & 52 & 16.5 & 0.07 & 0.4 & 0.8 \\
\hline 5/28/2008 12:26 & 44.1633 & -113.9863 & 2.1 & Mc IE & 112.2 & 6.05 & 25 & 88 & 29.5 & 0.13 & 0.4 & 2.1 \\
\hline $5 / 28 / 2008$ 12:33 & 42.8513 & -111.6162 & 0.9 & $\mathrm{Mc}$ IE & 129.9 & 18.58 & 6 & 227 & 3.1 & 0.10 & 2.8 & 2.5 \\
\hline 5/30/2008 14:45 & 43.9393 & -114.3232 & 1.4 & $\mathrm{Mc}$ IE & 128.0 & 5.91 & 15 & 91 & 16.8 & 0.07 & 0.4 & 0.7 \\
\hline 5/30/2008 22:44 & 42.7005 & -111.3332 & 1.6 & ML IE & 158.2 & 5.03 & 7 & 232 & 20.4 & 0.01 & 3.6 & 7.5 \\
\hline $5 / 31 / 20088: 36$ & 44.3873 & -113.0093 & 1.1 & Mc IE & 84.0 & 14.48 & 10 & 114 & 8.4 & 0.10 & 0.8 & 1.1 \\
\hline 5/31/2008 13:01 & 44.6880 & -111.9055 & 2.8 & MI MB & 135.1 & 4.07 & 33 & 153 & 19.6 & 0.14 & 0.6 & 1.2 \\
\hline 5/31/2008 20:59 & 43.4267 & -110.9553 & 1.4 & Mc IE & 149.7 & 9.73 & 10 & 201 & 7.1 & 0.13 & 1.1 & 0.8 \\
\hline 6/1/2008 14:55 & 44.7070 & -111.8915 & 2.2 & Mc IE & 137.5 & 12.85 & 29 & 75 & 18.1 & 0.07 & 0.2 & 0.7 \\
\hline 6/1/2008 16:29 & 42.9043 & -111.2548 & 1.3 & Mc IE & 149.2 & 2.49 & 8 & 114 & 20.0 & 0.10 & 0.5 & 14.9 \\
\hline 6/2/2008 18:31 & 42.9040 & -111.2395 & 1.3 & $\mathrm{Mc}$ IE & 150.2 & 11.98 & 13 & 112 & 19.1 & 0.05 & 0.4 & 1.9 \\
\hline 6/3/2008 17:46 & 42.9272 & -111.2368 & 0.7 & Mc IE & 149.0 & 5.00 & 5 & 156 & 21.2 & 0.07 & 1.2 & 10.2 \\
\hline 6/4/2008 4:09 & 44.7225 & -113.0308 & 2.5 & MI MB & 121.0 & 7.81 & 37 & 106 & 18.6 & 0.10 & 0.3 & 2.3 \\
\hline
\end{tabular}




\begin{tabular}{|c|c|c|c|c|c|c|c|c|c|c|c|c|}
\hline ORIGIN TIME & LAT N & LONG W & MAG & -TYPE & DIST & $Z$ & $\mathrm{NO}$ & GAP & DMIN & RMS & ERH & ERZ \\
\hline 6/4/2008 9:24 & 44.1233 & -113.9458 & 1.5 & Mc IE & 107.2 & 0.43 & 11 & 240 & 26.9 & 0.12 & 2.7 & 3.3 \\
\hline 6/4/2008 11:35 & 43.0042 & -111.2817 & 1.4 & Mc IE & 141.3 & 10.49 & 14 & 84 & 30.4 & 0.09 & 0.4 & 2.7 \\
\hline 6/4/2008 14:07 & 43.8112 & -114.0057 & 1.0 & ML IE & 100.1 & 7.04 & 8 & 172 & 14.6 & 0.09 & 0.7 & 13.0 \\
\hline 6/5/2008 21:14 & 42.8597 & -111.3712 & 1.7 & ML IE & 144.4 & 2.43 & 7 & 146 & 9.6 & 0.14 & 0.8 & 14.0 \\
\hline 6/6/2008 9:21 & 42.9050 & -111.2562 & 1.6 & $\mathrm{Mc}$ IE & 149.0 & 7.89 & 8 & 127 & 14.0 & 0.11 & 0.8 & 3.1 \\
\hline 6/6/2008 18:57 & 42.9012 & -111.2602 & 1.6 & Mc IE & 149.0 & 2.21 & 12 & 116 & 13.8 & 0.11 & 0.6 & 14.8 \\
\hline 6/8/2008 1:19 & 43.2530 & -110.9330 & 1.0 & ML IE & 156.1 & 15.56 & 6 & 174 & 21.7 & 0.12 & 1.4 & 3.1 \\
\hline 6/8/2008 3:20 & 43.9132 & -114.2820 & 2.3 & Mc IE & 124.1 & 7.87 & 33 & 68 & 13.3 & 0.14 & 0.3 & 1.6 \\
\hline 6/8/2008 6:55 & 43.8817 & -114.2710 & 0.7 & Mc IE & 122.5 & 2.80 & 8 & 235 & 12.9 & 0.08 & 1.5 & 1.5 \\
\hline 6/8/2008 9:02 & 42.8855 & -111.2792 & 1.9 & Mc IE & 148.7 & 13.80 & 14 & 165 & 13.0 & 0.05 & 0.8 & 1.2 \\
\hline 6/8/2008 10:08 & 44.5705 & -112.0537 & 2.2 & ML IE & 117.9 & 5.16 & 34 & 60 & 27.2 & 0.15 & 0.3 & 3.0 \\
\hline 6/8/2008 13:36 & 44.3877 & -114.3263 & 2.3 & Mc IE & 148.4 & 6.18 & 34 & 71 & 20.4 & 0.09 & 0.3 & 0.7 \\
\hline 6/8/2008 13:39 & 44.3908 & -114.3187 & 1.9 & Mc IE & 148.1 & 7.14 & 20 & 8 & 19.9 & 0.08 & 0.4 & 4.8 \\
\hline 6/9/2008 8:43 & 44.8325 & -111. & 2.0 & Mc IE & 160.4 & 7.82 & 23 & 69 & 11.7 & 0.11 & 0.3 & 1.4 \\
\hline 6/9/2008 12:10 & 43.7973 & -114.0202 & 1.4 & Mc IE & 101.0 & 5.48 & 7 & 102 & 15.2 & 0.10 & 1.3 & 3.2 \\
\hline 6/9/2008 12:45 & 43.2013 & -111.4995 & 1.0 & Mc IE & 115.3 & 4.95 & 6 & 114 & 19.5 & 0.05 & 0.8 & 10.8 \\
\hline 6/9/2008 18:00 & 42.8972 & -111.3957 & 0.6 & Mc IE & 140.3 & 2.13 & 4 & 240 & 5.0 & 0.22 & 4.6 & 20.7 \\
\hline 6/9/2008 22:32 & 44.3177 & -114.5445 & 2.2 & Mc IE & 159.6 & 0.03 & 19 & 71 & 35.7 & 0.21 & 0.8 & 10.1 \\
\hline $6 / 10 / 2008$ 2:34 & 44.4118 & -114.0253 & 1.5 & Mc IE & 130.7 & 4.41 & 12 & 186 & 24.9 & 0.10 & 1.1 & 1.8 \\
\hline 6/10/2008 7:41 & 43.0380 & -111.4552 & 1.1 & Mc IE & 127.3 & 6.73 & 6 & 171 & 7.1 & 0.01 & 1.1 & 1.9 \\
\hline $6 / 12 / 2008$ 15:46 & 42.7110 & -111. & 1.5 & Mc IE & 147.7 & 12.83 & 10 & 232 & 15.4 & 0.10 & 1.3 & 1.6 \\
\hline 6/14/2008 6:05 & 44.7217 & -112.5737 & 1.0 & Mc IE & 120.4 & 6.55 & 7 & 0 & 12.9 & 0.07 & 1.3 & 2.6 \\
\hline 6/14/2008 8:04 & 44.7003 & -111.9033 & 1.1 & MI MB & 136.4 & 4.25 & 9 & 134 & 40.7 & 0.06 & 0.6 & 2.9 \\
\hline $6 / 14 / 2008$ 10:25 & 44.7927 & -112.5628 & 1.0 & Mc IE & 128.3 & 7.79 & 6 & 149 & 20.5 & 0.02 & 1.6 & 11.6 \\
\hline 6/14/2008 19:56 & 42.9382 & -111.4493 & 1.3 & ML IE & 134.1 & 7.41 & 4 & 161 & 2.3 & 0.17 & 8.4 & 4.9 \\
\hline 6/15/2008 8:39 & 44.1148 & -114.6570 & 2.3 & Mc IE & 159.2 & 6.83 & 31 & 71 & 48.7 & 0.11 & 0.3 & 1.6 \\
\hline 6/15/2008 17:37 & 44.4190 & -112 & 1.4 & Mc IE & 85.8 & 13.97 & 13 & 141 & 11.5 & 0.10 & 0.6 & 1.3 \\
\hline 6/16/2008 18:38 & 44.0 & -114.1062 & 0.9 & Mc IE & 115.4 & 14.31 & 8 & 259 & 3 & 0.08 & 1.6 & 1.0 \\
\hline 6/17/2008 11:04 & 44.4950 & -112.6980 & 1.6 & Mc IE & 94.3 & 6.91 & 19 & 58 & 14.2 & 0.09 & 0.5 & 12.6 \\
\hline 6/19/2008 4:58 & 42.6823 & -111.4463 & 0.9 & Mc IE & 153.0 & 12.50 & 8 & 247 & 20.3 & 0.10 & 1.5 & 2.2 \\
\hline 6/20/2008 21:11 & 43.2770 & -111.4097 & 1.7 & Mc IE & 118.6 & 6.74 & 12 & 115 & 10.7 & 0.11 & 0.5 & 1.7 \\
\hline 6/21/2008 9:14 & 44.6120 & -114.0453 & 1.4 & Mc IE & 147.1 & 5.54 & 14 & 104 & 17.4 & 0.07 & 0.4 & 1.0 \\
\hline $6 / 22 / 200820: 12$ & 42.8435 & -111.2777 & 0.9 & ML IE & 151.6 & 10.39 & 4 & 192 & 15.8 & 0.00 & 2.8 & 3.1 \\
\hline 6/23/2008 3:22 & 44.4615 & -114.1223 & 1.8 & Mc IE & 140.2 & 6.40 & 19 & 80 & 15.5 & 0.07 & 0.3 & 0.5 \\
\hline 6/23/2008 11:24 & 44.4532 & -114.1165 & 1.7 & Mc IE & 139.3 & 4.57 & 16 & 79 & 16.5 & 0.04 & 0.4 & 1.0 \\
\hline 6/23/2008 18:37 & 43.8810 & -110.9738 & 1.8 & ML IE & 147.9 & 9.40 & 9 & 77 & 3.3 & 0.07 & 0.6 & 0.7 \\
\hline 6/24/2008 6:52 & 44.1508 & -114.5163 & 0.8 & Mc IE & 149.9 & 6.98 & 10 & 152 & 41.4 & 0.09 & 0.4 & 12.6 \\
\hline 6/24/2008 7:12 & 44.1595 & -114.5295 & 2.5 & Mc IE & 151.3 & 6.69 & 28 & 99 & 42.8 & 0.13 & 0.4 & 2.2 \\
\hline 6/24/2008 13:03 & 44.4582 & -114.1412 & 1.3 & Mc IE & 141.1 & 9.16 & 11 & 103 & 14.8 & 0.11 & 0.6 & 1.9 \\
\hline 6/24/2008 13:09 & 43.2747 & -110.8807 & 0.9 & ML IE & 159.4 & 5.06 & 5 & 229 & 16.8 & 0.15 & 1.7 & 12.7 \\
\hline 6/24/2008 13:45 & 44.4522 & -114.1063 & 1.1 & Mc IE & 138.6 & 0.67 & 12 & 123 & 17.1 & 0.15 & 0.8 & 2.0 \\
\hline 6/24/2008 16:16 & 44.4482 & -114.1377 & 1.9 & Mc IE & 140.2 & 8.63 & 17 & 89 & 15.9 & 0.12 & 0.5 & 1.9 \\
\hline 6/24/2008 19:28 & 44.1617 & -114.5275 & 1.8 & Mc IE & 151.2 & 6.96 & 14 & 98 & 42.9 & 0.17 & 0.6 & 6.2 \\
\hline $6 / 24 / 200820: 13$ & 44.5058 & -114.0087 & 1.1 & Mc IE & 136.7 & 7.80 & 6 & 157 & 52.4 & 0.05 & 1.1 & 12.7 \\
\hline 6/25/2008 5:03 & 43.3007 & -110.8682 & 1.9 & Mc IE & 159.7 & 12.70 & 17 & 176 & 14.4 & 0.09 & 0.4 & 1.1 \\
\hline 6/25/2008 5:09 & 43.3303 & -110.8422 & 1.0 & Mc IE & 160.9 & 16.37 & 10 & 194 & 11.2 & 0.07 & 0.9 & 0.9 \\
\hline 6/26/2008 21:13 & 42.9000 & -111.4492 & 1.6 & Mc IE & 136.7 & 1.15 & 5 & 209 & 4.8 & 0.04 & 10.6 & 1.3 \\
\hline $7 / 5 / 200822: 09$ & 43.1553 & -110.9355 & 1.3 & Mc IE & 159.4 & 14.88 & 11 & 140 & 29.4 & 0.12 & 0.6 & 2.7 \\
\hline $7 / 6 / 2008$ 7:20 & 43.1695 & -110.9667 & 0.8 & $\mathrm{Mc}$ IE & 156.5 & 5.00 & 7 & 234 & 34.8 & 0.12 & 1.3 & 13.5 \\
\hline 7/6/2008 13:58 & 45.0278 & -113.0530 & 2.4 & Mc IE & 154.8 & 7.11 & 16 & 155 & 27.5 & 0.08 & 0.6 & 11.4 \\
\hline $7 / 6 / 2008$ 14:04 & 45.0307 & -113.0568 & 2.3 & Mc IE & 155.2 & 7.08 & 16 & 156 & 27.9 & 0.07 & 0.7 & 13.9 \\
\hline
\end{tabular}




\begin{tabular}{|c|c|c|c|c|c|c|c|c|c|c|c|c|}
\hline ORIGIN TIME & LAT N & LONG W & MAG & -TYPE & DIST & $Z$ & $\mathrm{NO}$ & GAP & DMIN & RMS & ERH & ERZ \\
\hline $7 / 6 / 2008$ 15:02 & 44.1947 & -114.5652 & 1.3 & Mc IE & 155.4 & 7.29 & 9 & 164 & 47.5 & 0.10 & 1.0 & 14.3 \\
\hline $7 / 8 / 20080: 21$ & 44.1723 & -114.5242 & 2.7 & Mc IE & 151.4 & 7.46 & 34 & 71 & 43.4 & 0.16 & 0.4 & 8.5 \\
\hline $7 / 8 / 20080: 59$ & 43.4725 & -110.8985 & 1.8 & Mc IE & 153.5 & 10.47 & 21 & 88 & 4.7 & 0.21 & 0.6 & 0.7 \\
\hline $7 / 8 / 2008$ 7:24 & 43.3153 & -111.5432 & 1.3 & Mc IE & 106.9 & 7.00 & 12 & 118 & 7.2 & 0.11 & 0.6 & 1.2 \\
\hline 7/9/2008 4:15 & 43.6980 & -111.2898 & 1.3 & ML IE & 120.5 & 11.53 & 12 & 112 & 14.3 & 0.13 & 0.5 & 2.4 \\
\hline $7 / 9 / 20084: 15$ & 43.7032 & -111.3070 & 1.0 & Mc IE & 119.1 & 12.20 & 14 & 76 & 24.0 & 0.19 & 0.5 & 1.6 \\
\hline $7 / 9 / 20084: 22$ & 43.6887 & -111.2823 & 2.0 & Mc IE & 121.1 & 11.23 & 25 & 80 & 13.1 & 0.10 & 0.3 & 1.3 \\
\hline $7 / 9 / 20084: 23$ & 43.6823 & -111.2898 & 2.1 & Mc IE & 120.4 & 13.17 & 26 & 54 & 12.9 & 0.06 & 0.3 & 0.9 \\
\hline $7 / 9 / 20084: 27$ & 43.7080 & -111.3177 & 0.6 & Mc IE & 118.3 & 2.51 & 10 & 234 & 16.6 & 0.04 & 1.5 & 12.7 \\
\hline $7 / 9 / 20084: 33$ & 43.7067 & -111.3055 & 1.1 & ML IE & 119.3 & 2.50 & 9 & 189 & 36.3 & 0.33 & 2.0 & 29.7 \\
\hline $7 / 9 / 20084: 36$ & 43.7112 & -111.3140 & 1.2 & Mc IE & 118.6 & 2.50 & 14 & 208 & 16.7 & 0.13 & 0.7 & 15.7 \\
\hline $7 / 9 / 20084: 44$ & 43.6958 & -111.2843 & 1.0 & Mc IE & 120.9 & 11.93 & 9 & 136 & 13.8 & 0.09 & 0.6 & 2.7 \\
\hline $7 / 9 / 20084: 47$ & 43.6985 & -111.2878 & 1.4 & ML IE & 120.6 & 6.85 & 12 & 111 & 14.2 & 0.07 & 0.4 & 3.3 \\
\hline $7 / 9 / 20084: 50$ & 43.6885 & -111.2707 & 1.2 & ML IE & 122.0 & 11.45 & 11 & 134 & 12.6 & 0.08 & 0.5 & 2.3 \\
\hline 7/9/2008 5:06 & 43.6890 & -111.2770 & 1.0 & Mc IE & 121.5 & 12.16 & 12 & 110 & 12.9 & 0.09 & 0.5 & 2.6 \\
\hline 7/9/2008 5:10 & 43.6880 & -111.2783 & 1.7 & Mc IE & 121.4 & 10.38 & 22 & 111 & 12.9 & 0.12 & 0.5 & 2.8 \\
\hline 7/9/2008 5:18 & 43.6968 & -111.3032 & 1.1 & Mc IE & 119.4 & 12.69 & 15 & 73 & 14.9 & 0.10 & 0.4 & 2.0 \\
\hline $7 / 9 / 200814: 27$ & 43.2647 & -111.2897 & 1.8 & Mc IE & 128.2 & 7.65 & 23 & 110 & 9.5 & 0.10 & 0.4 & 1.2 \\
\hline $7 / 9 / 200822: 10$ & 42.9467 & -111.2903 & 1.3 & Mc IE & 144.2 & 5.43 & 9 & 145 & 10.8 & 0.09 & 0.7 & 3.0 \\
\hline 7/9/2008 23:18 & 42.9480 & -111.2892 & 1.0 & Mc IE & 144.1 & 7.30 & 8 & 145 & 10.9 & 0.11 & 0.7 & 3.0 \\
\hline 7/10/2008 3:15 & 44.5807 & -112 & 0.7 & $\mathrm{Mc} M B$ & 104.4 & 7.45 & 12 & 100 & 24.7 & 0.16 & 0.5 & 13.5 \\
\hline 7/10/2008 3:15 & 44.5835 & -112.9472 & 0.7 & ML IE & 104.7 & 7.42 & 7 & 99 & 24.4 & 0.11 & 0.7 & 14.0 \\
\hline 7/12/2008 13:18 & 44.6997 & -113.1795 & 1.1 & Mc IE & 121.0 & 0.80 & 5 & 162 & 17.5 & 0.01 & 1.2 & 1.6 \\
\hline $7 / 12 / 2008$ 16:34 & 44.7093 & -113.2065 & 1.3 & $\mathrm{Mc} M B$ & 122.6 & 10.65 & 14 & 108 & 16.4 & 0.08 & 0.9 & 1.6 \\
\hline $7 / 12 / 2008$ 16:41 & 44.6745 & -112.1188 & 1.6 & $\mathrm{Mc} M B$ & 125.7 & 6.07 & 18 & 116 & 40.3 & 0.12 & 0.5 & 14.2 \\
\hline 7/12/2008 19:11 & 44.6955 & -113.2005 & 2.1 & Mc IE & 121.0 & 11.72 & 19 & 161 & 15.9 & 0.08 & 0.6 & 0.6 \\
\hline $7 / 13 / 2008$ 1:47 & 44.6 & -113.1660 & 1.0 & Mc IE & 120.4 & 0.55 & 5 & 164 & 18.3 & 0.03 & 1.4 & 1.3 \\
\hline 7/13/2008 9:55 & 44.7213 & -113.2033 & 1.1 & Mc IE & 123.8 & 6.10 & 11 & 149 & 17.5 & 0.06 & 0.8 & 1.6 \\
\hline 7/13/2008 10:02 & 44.7182 & -113.1812 & 1.2 & Mc IE & 123.0 & 1.64 & 6 & 174 & 18.6 & 0.02 & 1.4 & 5.7 \\
\hline $7 / 13 / 2008$ 12:15 & 44.5575 & -114.2808 & 1.7 & Mc IE & 156.7 & 5.42 & 11 & 93 & 2.2 & 0.09 & 0.7 & 0.3 \\
\hline $7 / 13 / 2008$ 14:28 & 44.5067 & -111.1638 & 1.3 & ML IE & 160.9 & 5.21 & 7 & 161 & 22.9 & 0.07 & 1.1 & 4.0 \\
\hline 7/13/2008 23:39 & 44.6725 & -112.1188 & 1.5 & $\mathrm{Mc} M B$ & 125.5 & 2.42 & 20 & 66 & 40.1 & 0.07 & 0.4 & 2.7 \\
\hline $7 / 14 / 2008$ 0:03 & 44.6777 & -112.1155 & 2.0 & ML IE & 126.2 & 7.06 & 20 & 66 & 40.7 & 0.11 & 0.4 & 12.1 \\
\hline $7 / 14 / 2008$ 14:47 & 44.5805 & -112.3368 & 1.9 & ML IE & 109.5 & 2.94 & 27 & 96 & 24.7 & 0.12 & 0.4 & 0.7 \\
\hline 7/14/2008 15:05 & 44.6362 & -114.0997 & 1.6 & $\mathrm{Mc} I \mathrm{E}$ & 152.1 & 6.03 & 14 & 102 & 14.7 & 0.23 & 0.7 & 1.3 \\
\hline $7 / 14 / 200820: 37$ & 44.5135 & -114.2815 & 2.8 & ML IE & 153.7 & 6.74 & 40 & 87 & 45.8 & 0.14 & 0.3 & 2.5 \\
\hline 7/15/2008 8:14 & 42.8983 & -111.5363 & 1.6 & Mc IE & 131.2 & 9.87 & 10 & 147 & 8.5 & 0.13 & 0.8 & 1.9 \\
\hline $7 / 15 / 2008$ 12:53 & 44.3873 & -114.0690 & 1.0 & Mc IE & 131.7 & 7.37 & 6 & 139 & 24.6 & 0.09 & 0.9 & 14.6 \\
\hline 7/16/2008 9:42 & 43.5708 & -111.1710 & 1.2 & Mc IE & 130.4 & 8.71 & 8 & 132 & 2.8 & 0.09 & 0.7 & 2.1 \\
\hline 7/17/2008 2:08 & 42.9838 & -111.4093 & 0.3 & Mc IE & 133.8 & 7.58 & 7 & 170 & 5.2 & 0.08 & 1.7 & 1.8 \\
\hline 7/17/2008 2:18 & 42.9277 & -111.2707 & 0.6 & Mc IE & 146.7 & 9.86 & 5 & 252 & 12.4 & 0.02 & 3.9 & 3.6 \\
\hline $7 / 17 / 2008$ 2:27 & 42.9335 & -111.2785 & 0.5 & ML IE & 145.8 & 13.66 & 5 & 276 & 11.7 & 0.01 & 3.1 & 2.8 \\
\hline $7 / 17 / 2008$ 2:49 & 42.9542 & -111.3303 & 0.5 & ML IE & 141.0 & 8.41 & 5 & 237 & 7.7 & 0.05 & 3.7 & 1.6 \\
\hline $7 / 17 / 2008$ 2:56 & 43.0035 & -111.4417 & 0.4 & Mc IE & 130.4 & 2.23 & 6 & 123 & 7.5 & 0.16 & 0.9 & 17.0 \\
\hline 7/17/2008 3:21 & 42.9977 & -111.4075 & 0.8 & Mc IE & 133.1 & 7.02 & 8 & 165 & 6.7 & 0.19 & 1.7 & 2.6 \\
\hline 7/17/2008 5:02 & 44.9020 & -113.5922 & 1.3 & Mc IE & 153.5 & 1.97 & 8 & 195 & 36.4 & 0.04 & 0.7 & 2.2 \\
\hline 7/19/2008 8:59 & 44.1802 & -112.9737 & 0.9 & Mc IE & 60.9 & 0.02 & 7 & 303 & 12.4 & 0.02 & 4.3 & 5.4 \\
\hline 7/19/2008 9:58 & 44.6187 & -112.0790 & 1.5 & ML IE & 121.6 & 5.72 & 15 & 122 & 25.2 & 0.14 & 0.5 & 3.0 \\
\hline 7/19/2008 16:38 & 43.0842 & -111.3065 & 1.7 & Mc IE & 135.2 & 5.81 & 20 & 107 & 6.2 & 0.09 & 0.3 & 0.8 \\
\hline 7/20/2008 9:48 & 44.6272 & -112.0840 & 1.8 & ML IE & 122.3 & 4.84 & 32 & 55 & 24.9 & 0.11 & 0.3 & 0.7 \\
\hline $7 / 21 / 2008$ 16:43 & 44.1615 & -114.5217 & 0.8 & Mc IE & 150.8 & 7.06 & 7 & 105 & 42.5 & 0.09 & 0.6 & 14.8 \\
\hline
\end{tabular}




\begin{tabular}{|c|c|c|c|c|c|c|c|c|c|c|c|c|}
\hline ORIGIN TIME & LAT N & LONG W & MAG & -TYPE & DIST & $Z$ & $\mathrm{NO}$ & GAP & DMIN & RMS & $\mathrm{ERH}$ & ERZ \\
\hline $7 / 21 / 2008$ 23:14 & 42.8985 & -111.2610 & 1.5 & Mc IE & 149.1 & 8.72 & 10 & 117 & 13.8 & 0.12 & 0.6 & 1.9 \\
\hline 7/22/2008 9:32 & 2.9043 & -111.2523 & 3.2 & MLUS & 149.4 & 10.49 & 67 & 82 & 14.3 & 0.12 & 0.3 & 0.5 \\
\hline 7/22/2008 9:37 & 42.8928 & -111.2612 & 1.0 & Mc IE & 149.5 & 11.59 & 12 & 119 & 14.0 & 0.17 & 0.7 & 1.5 \\
\hline 7/22/2008 9:39 & 42.9013 & -111.2512 & 1.1 & Mc IE & 149.6 & 7.08 & 13 & 120 & 14.5 & 0.16 & 0.6 & 1.8 \\
\hline 7/22/2008 9:45 & 42.8958 & -111.2553 & 0.9 & Mc IE & 149.7 & 0.03 & 9 & 118 & 14.4 & 0.08 & 0.8 & 2.0 \\
\hline 7/22/2008 9:46 & 42.8893 & -111.2243 & 0.4 & Mc IE & 152.2 & 5.01 & 3 & 292 & 17.0 & 0.08 & 2.8 & 12.0 \\
\hline 7/22/2008 9:51 & 42.9082 & -111.2630 & 0.8 & ML IE & 148.4 & 2.98 & 5 & 118 & 13.4 & 0.02 & 0.9 & 9.6 \\
\hline 7/22/2008 9:52 & 42.9058 & -111.2522 & 0.6 & Mc IE & 149.3 & 7.20 & 9 & 121 & 14.3 & 0.11 & 0.5 & 2.6 \\
\hline $7 / 22 / 20089: 53$ & 42.9082 & -111.2552 & 2.0 & Mc IE & 148.9 & 3.35 & 27 & 81 & 14.0 & 0.10 & 0.3 & 4.9 \\
\hline 7/22/2008 9:56 & 42.9110 & -111.2533 & 1.0 & Mc IE & 148.9 & 3.08 & 8 & 122 & 14.1 & 0.09 & 0.6 & 10.8 \\
\hline 7/22/2008 10:00 & 42.8972 & -111.2743 & 1.2 & ML IE & 148.3 & 2.99 & 6 & 120 & 12.9 & 0.07 & 0.7 & 10.7 \\
\hline 7/22/2008 10:02 & 42.9025 & -111.2597 & 0.9 & Mc IE & 149.0 & 3.84 & 8 & 119 & 13.8 & 0.08 & 0.6 & 5.7 \\
\hline $7 / 22 / 2008$ 10:06 & 42.9028 & -111.2610 & 0.8 & Mc IE & 148.9 & 4.94 & 7 & 118 & 13.7 & 0.08 & 0.8 & 5.5 \\
\hline 7/22/2008 10:07 & 42.9025 & -111.2745 & 0.7 & Mc IE & 148.0 & 0.03 & 6 & 118 & 12.7 & 0.18 & 1.2 & 4.9 \\
\hline 7/22/2008 10:08 & 42.9093 & -111.2593 & 1.1 & Mc IE & 148.6 & 4.92 & 9 & 119 & 13.6 & 0.08 & 0.5 & 3.3 \\
\hline $7 / 22 / 2008$ 10:30 & 42.9068 & -111.2512 & 1.5 & Mc IE & 149.3 & 2.51 & 15 & 113 & 14.3 & 0.11 & 0.5 & 12.3 \\
\hline 7/22/2008 10:45 & 42.9065 & -111.2580 & 1.5 & $\mathrm{~N}$ & 14 & 6.99 & 18 & 114 & 13.8 & 1 & 0.4 & 2.0 \\
\hline 7/22/2008 11:09 & 42.9013 & -111.2603 & 0.4 & Mc IE & 149.0 & 9.05 & 6 & 144 & 13.8 & 0.13 & 1.0 & 3.5 \\
\hline 7/22/2008 11:19 & 42.9002 & -111.2575 & 0.8 & Mc IE & 149.3 & 2.18 & 5 & 167 & 14.0 & 0.07 & 0.8 & 13.4 \\
\hline 7/22/2008 11:53 & 42.9038 & -111.2513 & 0.5 & Mc IE & 149.5 & 2.50 & 5 & 171 & 14.4 & 0.08 & 1.2 & 13.2 \\
\hline 7/22/2008 13:48 & 42.9003 & -111.2535 & 1.2 & Mc IE & 149.5 & 8.07 & 7 & 120 & 14.4 & 0.11 & 0.8 & 2.5 \\
\hline $7 / 22 / 2008$ 15:57 & 42.9013 & -111 & 0.9 & M & $1<$ & 3.06 & 6 & 166 & 13.8 & 0.05 & 0.7 & 9.9 \\
\hline 7/22/2008 16:12 & 42. & -11 & 0.3 & $\mathrm{~N}$ & 1 & 6 & 5 & 1 & 4 & 8 & 6 & 3.8 \\
\hline $7 / 22 / 2008$ 16:29 & 42.8997 & -111.2575 & 1.0 & Mc IE & 149.3 & 7.99 & 8 & 144 & 14.1 & 0.12 & 0.6 & 2.4 \\
\hline 7/22/2008 16:47 & 42.8957 & -111.2612 & 1.1 & Mc IE & 149.3 & 6.77 & 7 & 119 & 13.9 & 0.09 & 0.7 & 2.9 \\
\hline $7 / 22 / 2008$ 18:47 & 42.8955 & -111.2667 & 0.3 & Mc IE & 148.9 & 5.84 & 5 & 161 & 13.5 & 0.08 & 0.9 & 4.3 \\
\hline 7/22/2008 19:48 & 44.3897 & -112.5973 & 1.3 & $\mathrm{Mc} M B$ & 83.6 & 12.98 & 22 & 72 & 23.0 & 0.06 & 0.3 & 1.1 \\
\hline $7 / 23 / 20085: 14$ & 42.8925 & -111.2605 & 0.9 & Mc IE & 149.5 & 8.98 & 8 & 120 & 14.1 & 0.17 & 0.8 & 3.3 \\
\hline 7/23/2008 7:17 & & & 0.7 & & & & 7 & & & & & 10.0 \\
\hline 7/24/2008 19:46 & 42.8983 & -111.2553 & 1.2 & ML IE & 149.5 & 6.12 & 6 & 145 & 14.3 & 0.10 & 0.8 & 4.1 \\
\hline $7 / 25 / 20080: 21$ & 43.9615 & -114.3572 & 1.1 & ML IE & 131.3 & 7.32 & 10 & 153 & 20.0 & 0.12 & 0.7 & 14.0 \\
\hline 7/25/2008 1:10 & 42.9177 & -111.2663 & 0.6 & Mc IE & 147.6 & 5.91 & 5 & 280 & 12.9 & 0.07 & 5.6 & 9.0 \\
\hline 7/25/2008 2:08 & 44.2695 & -114.4572 & 1.9 & ML IE & 151.0 & 7.04 & 18 & 89 & 44.4 & 0.15 & 0.5 & 11.0 \\
\hline 7/25/2008 2:09 & 44.2822 & -114.4652 & 1.5 & ML IE & 152.2 & 0.02 & 8 & 89 & 43.0 & 0.13 & 0.7 & 2.5 \\
\hline 7/25/2008 7:20 & 43.8665 & -111.0348 & 1.0 & ML IE & 142.8 & 5.37 & 5 & 256 & 8.4 & 0.03 & 2.4 & 1.7 \\
\hline 7/25/2008 10:18 & 43.6270 & -113.7507 & 0.9 & Mc IE & 78.1 & 0.37 & 16 & 84 & 22.0 & 0.06 & 0.3 & 2.1 \\
\hline 7/25/2008 10:58 & 43.8422 & -110.9947 & 0.9 & Mc IE & 145.6 & 2.19 & 7 & 120 & 7.6 & 0.16 & 0.9 & 15.9 \\
\hline 7/25/2008 12:02 & 43.8688 & -110.9903 & 1.3 & Mc IE & 146.3 & 7.57 & 16 & 65 & 5.2 & 0.29 & 0.6 & 1.2 \\
\hline 7/26/2008 1:55 & 44.6348 & -112.0958 & 2.0 & ML IE & 122.6 & 6.07 & 20 & 60 & 24.1 & 0.12 & 0.4 & 13.9 \\
\hline 7/26/2008 7:17 & 42.8962 & -111.2633 & 1.2 & Mc IE & & 6.32 & 12 & 119 & 13.7 & 0.11 & 0.5 & 2.5 \\
\hline 7/26/2008 7:19 & 42.9110 & -111.2463 & 0.9 & Mc IE & 149.3 & 2.43 & 8 & 123 & 14.6 & 0.12 & 0.8 & 14.3 \\
\hline 7/26/2008 7:23 & 42.9020 & -111.2555 & 0.8 & Mc IE & 149.3 & 2.48 & 7 & 120 & 14.2 & 0.09 & 0.7 & 13.0 \\
\hline 7/26/2008 7:52 & 42.9093 & -111.2565 & 1.7 & Mc IE & 148.8 & 0.07 & 20 & 81 & 13.9 & 0.21 & 0.4 & 1.8 \\
\hline $7 / 26 / 2008$ 11:11 & 42.9030 & -111.2547 & 1.0 & Mc IE & 149.3 & 0.03 & 8 & 115 & 14.2 & 0.09 & 0.6 & 3.3 \\
\hline 7/26/2008 12:11 & 43.5692 & -110.7953 & 0.3 & Mc IE & 160.6 & 2.49 & 5 & 107 & 15.3 & 0.17 & 1.2 & 18.2 \\
\hline $7 / 26 / 2008$ 12:29 & 43.1390 & -111.4333 & 0.6 & Mc IE & 123.2 & 4.21 & 3 & 204 & 10.8 & 0.02 & 4.5 & 11.8 \\
\hline 7/26/2008 12:58 & 42.9083 & -111.2542 & 1.6 & Mc IE & 149.0 & 6.69 & 18 & 112 & 14.1 & 0.14 & 0.5 & 2.7 \\
\hline $7 / 26 / 2008$ 14:23 & 42.9057 & -111.2512 & 1.2 & Mc IE & 149.3 & 4.98 & 9 & 121 & 14.4 & 0.12 & 0.6 & 5.2 \\
\hline 7/26/2008 15:46 & 42.9032 & -111.2598 & 0.8 & ML IE & 148.9 & 0.02 & 5 & 167 & 13.8 & 0.09 & 0.8 & 3.7 \\
\hline 7/26/2008 16:02 & 44.1063 & -113.9340 & 1.0 & Mc IE & 105.5 & 8.12 & 7 & 142 & 25.9 & 0.04 & 0.7 & 11.8 \\
\hline $7 / 26 / 200821: 23$ & 43.1747 & -111.4413 & 1.2 & ML IE & 120.8 & 13.07 & 6 & 133 & 14.6 & 0.12 & 0.9 & 3.1 \\
\hline
\end{tabular}




\begin{tabular}{|c|c|c|c|c|c|c|c|c|c|c|c|c|}
\hline ORIGIN TIME & LAT N & LONG W & MAG & -TYPE & DIST & $Z$ & $\mathrm{NO}$ & GAP & DMIN & RMS & $\mathrm{ERH}$ & ERZ \\
\hline $7 / 26 / 200822: 46$ & 44.0507 & -114.4967 & 1.5 & Mc IE & 144.8 & 6.95 & 11 & 125 & 34.0 & 0.10 & 0.5 & 14.0 \\
\hline $7 / 27 / 20087: 48$ & 42.8947 & -111.2670 & 0.8 & Mc IE & 149.0 & 4.74 & 5 & 155 & 13.5 & 0.08 & 1.0 & 6.6 \\
\hline $7 / 27 / 2008$ 12:23 & 42.9057 & -111.2563 & 0.8 & Mc IE & 149.0 & 3.62 & 8 & 127 & 14.0 & 0.08 & 0.7 & 6.0 \\
\hline 7/27/2008 14:15 & 42.9005 & -111.2587 & 1.0 & Mc IE & 149.2 & 5.81 & 9 & 116 & 13.9 & 0.08 & 0.5 & 2.5 \\
\hline $7 / 27 / 2008$ 15:03 & 42.8992 & -111.2520 & 0.6 & Mc IE & 149.7 & 2.44 & 6 & 115 & 14.5 & 0.06 & 0.7 & 12.0 \\
\hline 7/27/2008 19:14 & 42.8993 & -111.2610 & 1.2 & Mc IE & 149.1 & 6.77 & 10 & 117 & 13.8 & 0.10 & 0.6 & 2.6 \\
\hline $7 / 27 / 200820: 10$ & 42.9025 & -111.2548 & 1.6 & Mc IE & 149.3 & 6.52 & 11 & 115 & 14.2 & 0.08 & 0.5 & 2.6 \\
\hline $7 / 28 / 20085: 26$ & 42.9117 & -111.2565 & 0.5 & Mc IE & 148.6 & 4.30 & 5 & 171 & 13.8 & 0.13 & 1.6 & 9.2 \\
\hline 7/30/2008 5:59 & 44.6787 & -113.9792 & 2.0 & Mc IE & 149.1 & 0.31 & 10 & 243 & 61.3 & 0.11 & 1.5 & 7.3 \\
\hline 7/30/2008 23:34 & 42.8813 & -111.2803 & 0.9 & Mc IE & 148.9 & 11.27 & 5 & 168 & 13.1 & 0.05 & 1.7 & 4.0 \\
\hline $8 / 1 / 20086: 13$ & 43.3217 & -111.0890 & 0.4 & Mc IE & 141.8 & 11.21 & 5 & 229 & 19.0 & 0.06 & 1.3 & 2.0 \\
\hline 8/1/2008 20:06 & 44.0958 & -113.9137 & 2.3 & ML IE & 103.5 & 6.81 & 21 & 191 & 41.4 & 0.28 & 0.7 & 3.1 \\
\hline 8/2/2008 8:20 & 43.9213 & -113.8087 & 1.4 & Mc IE & 87.9 & 7.19 & 11 & 276 & 28.6 & 0.10 & 0.9 & 14.4 \\
\hline 8/2/2008 18:00 & 42.8930 & -111.1997 & 0.7 & Mc IE & 153.6 & 15.15 & 5 & 136 & 16.3 & 0.04 & 1.4 & 1.8 \\
\hline 8/3/2008 22:02 & 42.8750 & -111.2945 & 0.9 & Mc IE & 148.4 & 14.20 & 9 & 178 & 12.5 & 0.06 & 0.9 & 0.9 \\
\hline 8/3/2008 22:07 & 42.8732 & -111.2898 & 1.1 & Mc IE & 148.8 & 12.62 & 12 & 144 & 13.0 & 0.08 & 0.5 & 0.6 \\
\hline 8/3/2008 23:05 & 42.8737 & -111.2885 & 0.7 & $\mathrm{~N}$ & 14 & 15.44 & 5 & 177 & 13.0 & 0.04 & 1.8 & 2.0 \\
\hline $8 / 4 / 2008$ 0:25 & 42.8727 & -111.2923 & 0.5 & Mc IE & 148.7 & 15.56 & 4 & 178 & 12.8 & 0.05 & 1.4 & 2.0 \\
\hline $8 / 4 / 2008$ 0:27 & 42.8750 & -111.2945 & 0.5 & Mc IE & 148.4 & 14.51 & 4 & 177 & 12.5 & 0.05 & 1.1 & 1.8 \\
\hline 8/4/2008 1:07 & 42.8823 & -111.2812 & 0.7 & Mc IE & 148.8 & 12.89 & 4 & 168 & 13.0 & 0.04 & 1.0 & 1.7 \\
\hline $8 / 4 / 2008$ 1:40 & 42.8838 & -111.2798 & 0.9 & Mc IE & 148.8 & 11.93 & 9 & 167 & 13.0 & 0.05 & 1.0 & 1.9 \\
\hline $8 / 4 / 2008$ 2:45 & 42.8718 & -111.2925 & 0.7 & Mc IE & 14 & 14.64 & 6 & 179 & 12.9 & 0.06 & 1.2 & 1.0 \\
\hline $8 / 4 / 2008$ 2:57 & 42.8720 & -111.2 & & NM & 1 & 0 & 9 & 0 & 7 & 4 & 0.8 & 0.8 \\
\hline 8/4/2008 15:03 & 42.8705 & -111.3032 & & NM & 148.1 & 14.02 & 7 & 183 & 12.2 & 0.08 & 1.3 & 1.0 \\
\hline 8/6/2008 11:53 & 42.5065 & -111.5935 & 1.7 & Mc IE & 159.9 & 7.60 & 25 & 90 & 36.2 & 0.18 & 0.4 & 4.9 \\
\hline 8/6/2008 21:11 & 42.8597 & -111.3717 & 1.4 & Mc IE & 144.4 & 15.15 & 6 & 146 & 9.6 & 0.21 & 1.1 & 2.2 \\
\hline $8 / 7 / 20086: 25$ & 43.3293 & -110.8643 & 0.4 & Mc IE & 159.2 & 11.32 & 11 & 266 & 12.9 & 0.07 & 1.7 & 1.1 \\
\hline 8/7/2008 6:34 & 43.3317 & -110.8570 & 0.8 & Mc IE & 159.7 & 12.81 & 11 & 264 & 12.3 & 0.07 & 0.8 & 1.0 \\
\hline 8/7/2008 17:50 & & & 1.2 & & & & 7 & 177 & & & & 2.4 \\
\hline 8/8/2008 10:46 & 42.5985 & -111.5910 & 1.1 & Mc IE & 151.9 & 12.91 & 14 & 85 & 26.0 & 0.16 & 0.5 & 1.1 \\
\hline 8/8/2008 16:16 & 44.3128 & -114.5673 & 1.1 & Mc IE & 161.0 & 6.91 & 16 & 149 & 34.9 & 0.07 & 0.4 & 13.7 \\
\hline 8/9/2008 12:04 & 44.3098 & -112.7000 & 1.1 & Mc IE & 73.7 & 3.46 & 8 & 132 & 24.2 & 0.13 & 0.8 & 1.7 \\
\hline 8/9/2008 18:22 & 42.8995 & -111.2598 & 1.6 & Mc IE & 149.1 & 7.02 & 19 & 87 & 13.9 & 0.11 & 0.3 & 1.4 \\
\hline 8/9/2008 19:52 & 43.5728 & -111.2010 & 1.4 & Mc IE & 127.9 & 6.40 & 13 & 117 & 2.0 & 0 & 0.5 & 2.4 \\
\hline 8/10/2008 14:49 & 44.3590 & -112.9983 & 1.3 & Mc IE & 80.7 & 11.28 & 7 & 267 & 5.6 & 0.07 & 1.0 & 0.9 \\
\hline 8/10/2008 15:42 & 44.1603 & -114.5432 & 1.9 & Mc IE & 152.3 & 7.19 & 21 & 101 & 43.7 & 0.10 & 0.4 & 13.7 \\
\hline 8/12/2008 19:11 & 43.4403 & -113.5565 & 1.2 & ML IE & 66.7 & 25.33 & 19 & 109 & 13.4 & 0.27 & 1.3 & 2.5 \\
\hline 8/12/2008 22:36 & 42.9180 & -111.2567 & 0.5 & Mc IE & 148.2 & 2.47 & 5 & 222 & 13.7 & 0.02 & 2.4 & 12.3 \\
\hline 8/13/2008 7:44 & 44.6377 & -112.0655 & 0.8 & Mc IE & 124.0 & 6.34 & 12 & 129 & 38.6 & 0.16 & 0.5 & 17.7 \\
\hline 8/13/2008 13:37 & 42.9055 & -111.2557 & 1.6 & Mc IE & 149.0 & 5.08 & 24 & 114 & 14.0 & 0.14 & 0.3 & 2.8 \\
\hline 8/14/2008 8:03 & 44.6733 & -112.1130 & 1.4 & Mc IE & 125.8 & 5.86 & 18 & 94 & 24.0 & 0.12 & 0.4 & 13.9 \\
\hline 8/14/2008 8:26 & 44.9108 & -112.6880 & 1.5 & Mc IE & 140.5 & 1.83 & 10 & 168 & 15.7 & 0.03 & 0.5 & 1.5 \\
\hline $8 / 14 / 2008$ 11:27 & 42.8993 & -111.2600 & 1.5 & Mc IE & 149.1 & 2.08 & 14 & 117 & 13.9 & 0.12 & 0.4 & 16.1 \\
\hline 8/14/2008 16:15 & 44.9117 & -112.6887 & 1.5 & Mc IE & 140.6 & 3.12 & 12 & 183 & 15.7 & 0.04 & 0.4 & 1.2 \\
\hline 8/14/2008 17:09 & 42.6910 & -111.6492 & 2.0 & Mc IE & 141.0 & 2.50 & 10 & 113 & 16.5 & 0.10 & 0.9 & 12.1 \\
\hline $8 / 14 / 200820: 37$ & 42.9070 & -111.2578 & 1.1 & ML IE & 148.8 & 0.03 & 8 & 145 & 13.8 & 0.11 & 0.6 & 3.1 \\
\hline 8/15/2008 15:06 & 42.8917 & -111.2608 & 1.6 & ML IE & 149.6 & 12.09 & 9 & 121 & 14.1 & 0.17 & 0.9 & 1.8 \\
\hline $8 / 15 / 2008$ 20:46 & 44.7045 & -111.8483 & 1.6 & Mc MB & 139.1 & 13.05 & 16 & 83 & 14.7 & 0.10 & 0.5 & 1.1 \\
\hline 8/15/2008 20:49 & 44.6170 & -112.1372 & 0.8 & Mc IE & 119.3 & 13.76 & 5 & 273 & 20.6 & 0.01 & 2.0 & 2.8 \\
\hline 8/16/2008 3:03 & 42.7848 & -111.1967 & 1.1 & Mc IE & 160.8 & 6.29 & 11 & 175 & 8.2 & 0.10 & 1.0 & 1.7 \\
\hline 8/16/2008 3:16 & 42.7807 & -111.2012 & 1.0 & Mc IE & 160.8 & 6.36 & 10 & 180 & 8.4 & 0.13 & 1.2 & 2.0 \\
\hline
\end{tabular}




\begin{tabular}{|c|c|c|c|c|c|c|c|c|c|c|c|c|}
\hline ORIGIN TIME & LAT N & LONG W & MAG & -TYPE & DIST & $Z$ & $\mathrm{NO}$ & GAP & DMIN & RMS & ERH & ERZ \\
\hline $8 / 16 / 2008$ 15:33 & 43.4203 & -111.0817 & 1.8 & Mc IE & 139.8 & 11.11 & 22 & 148 & 13.1 & 0.09 & 0.5 & 0.8 \\
\hline 8/17/2008 5:13 & 44.6620 & -112.9572 & 0.9 & Mc IE & 113.4 & 13.94 & 5 & 161 & 20.3 & 0.05 & 0.8 & 2.5 \\
\hline 8/17/2008 11:07 & 44.3660 & -114.0760 & 1.1 & Mc IE & 130.7 & 4.64 & 12 & 71 & 26.2 & 0.26 & 0.9 & 2.3 \\
\hline 8/17/2008 11:22 & 44.4617 & -111.2720 & 0.8 & Mc IE & 151.0 & 35.86 & 6 & 198 & 27.0 & 0.08 & 2.0 & 2.5 \\
\hline 8/17/2008 21:32 & 44.6442 & -112.1685 & 1.1 & Mc IE & 121.0 & 13.75 & 15 & 53 & 18.8 & 0.07 & 0.4 & 1.2 \\
\hline 8/18/2008 13:44 & 44.7627 & -111.5202 & 1.0 & Mc IE & 159.7 & 13.39 & 7 & 197 & 12.1 & 0.04 & 1.0 & 1.6 \\
\hline 8/19/2008 7:46 & 42.9007 & -111.2632 & 0.8 & Mc IE & 148.8 & 2.29 & 10 & 117 & 13.6 & 0.10 & 0.6 & 13.5 \\
\hline 8/19/2008 8:05 & 42.8960 & -111.2508 & 2.8 & Mc IE & 150.0 & 13.03 & 57 & 117 & 14.7 & 0.16 & 0.4 & 0.7 \\
\hline 8/19/2008 8:24 & 42.8942 & -111.2598 & 0.8 & Mc IE & 149.5 & 4.62 & 14 & 119 & 14.1 & 0.14 & 0.6 & 4.5 \\
\hline 8/19/2008 8:25 & 42.9022 & -111.2567 & 1.0 & Mc IE & 149.2 & 2.71 & 9 & 144 & 14.0 & 0.10 & 0.8 & 11.6 \\
\hline 8/19/2008 13:09 & 42.8985 & -111.2542 & 1.4 & Mc IE & 149.6 & 1.23 & 11 & 117 & 14.4 & 0.09 & 0.5 & 1.8 \\
\hline 8/19/2008 17:03 & 42.9720 & -111.5293 & 1.2 & Mc IE & 126.6 & 3.73 & 10 & 106 & 9.6 & 0.09 & 0.6 & 5.0 \\
\hline 8/20/2008 17:40 & 44.1573 & -113.9888 & 1.3 & Mc IE & 112.1 & 10.28 & 9 & 145 & 28.9 & 0.10 & 0.5 & 3.1 \\
\hline 8/21/2008 6:26 & 44.5707 & -114.3070 & 0.8 & ML IE & 159.3 & 5.67 & 6 & 241 & 4.2 & 0.07 & 3.4 & 2.3 \\
\hline 8/21/2008 18:44 & 44.3207 & -114.5512 & 2.0 & Mc IE & 160.2 & 5.01 & 12 & 101 & 35.1 & 0.08 & 0.6 & 14.2 \\
\hline 8/22/2008 3:10 & 44.0022 & -113.8790 & 2.0 & Mc IE & 96.4 & 6.52 & 25 & 65 & 21.4 & 0.15 & 0.4 & 1.9 \\
\hline 8/23/2008 6:27 & 42.7998 & -111.1932 & 0.7 & Mc IE & 160.0 & 11.04 & 6 & 194 & 8.5 & 0.04 & 1.3 & 2.5 \\
\hline 8/23/2008 10:12 & 44.4842 & -114.1765 & 1.4 & Mc IE & 145.1 & 5.18 & 9 & 202 & 10.8 & 0.10 & 0.8 & 0.9 \\
\hline 8/23/2008 19:22 & 42.7157 & -111.5433 & 1.2 & ML IE & 144.7 & 3.08 & 7 & 324 & 13.5 & 0.08 & 1.5 & 12.8 \\
\hline 8/24/2008 22:24 & 42.9050 & -111.2548 & 0.9 & Mc IE & 149.1 & 6.79 & 7 & 146 & 14.1 & 0.10 & 0.6 & 2.5 \\
\hline 8/25/2008 18:28 & 42.8765 & -111. & 0.7 & Mc IE & 148.8 & 12.92 & 8 & 131 & 13.0 & 0.05 & 0.7 & 1.9 \\
\hline $8 / 25 / 200820: 39$ & 43.0718 & -111.2985 & 0.5 & ML IE & 136.4 & 3.53 & 4 & 263 & 6.2 & 0.05 & 1.7 & 4.7 \\
\hline 8/27/2008 3:49 & 44.5770 & -114.2868 & 1.4 & ML IE & 158.5 & 5.62 & 9 & 115 & 2.9 & 0.06 & 0.6 & 0.5 \\
\hline $8 / 27 / 20086: 40$ & 43.4058 & -110.8567 & 1.3 & Mc IE & 158.0 & 14.30 & 10 & 209 & 12.1 & 0.10 & 0.7 & 1.3 \\
\hline 8/29/2008 1:16 & 43.5552 & -111.0840 & 1.4 & ML IE & 137.5 & 6.51 & 8 & 157 & 13.0 & 0.02 & 1.1 & 4.0 \\
\hline $8 / 29 / 20087: 28$ & 44.2723 & -114.0457 & 0.7 & Mc IE & 122.7 & 7.13 & 8 & 93 & 36.5 & 0.17 & 0.8 & 14.0 \\
\hline 8/29/2008 10:46 & 42.8570 & -111.1702 & 0.8 & Mc IE & 157.9 & 6.60 & 6 & 162 & 11.7 & 0.07 & 0.9 & 5.0 \\
\hline 8/30/2008 11:44 & 44.1797 & -113.1142 & 0.7 & Mc IE & 64.7 & 6.10 & 10 & 4 & 1 & 0.20 & 0.9 & 1.2 \\
\hline 8/30/2008 18:56 & 43.1968 & -111.2637 & 1.0 & Mc IE & 132.9 & 9.83 & 9 & 127 & 17.3 & 0.15 & 1.0 & 2.8 \\
\hline 8/30/2008 19:40 & 44.6135 & -114.1677 & 2.0 & Mc IE & 154.1 & 5.22 & 18 & 92 & 8.8 & 0.10 & 0.3 & 0.4 \\
\hline 8/31/2008 8:08 & 44.7068 & -111.8497 & 1.4 & Mc MB & 139.2 & 11.14 & 13 & 133 & 14.8 & 0.14 & 0.4 & 1.4 \\
\hline 8/31/2008 13:57 & 42.9068 & -111.2683 & 2.8 & Mc IE & 148.1 & 10.68 & 37 & 80 & 13.0 & 0.11 & 0.3 & 0.5 \\
\hline $8 / 31 / 2008$ 14:52 & 42.9100 & -111.2542 & 2.5 & Mc IE & 148.9 & 5.71 & 30 & 89 & 14.0 & 0.12 & 0.2 & 1.6 \\
\hline 9/1/2008 18:18 & 43.0558 & -111.3755 & 1.1 & Mc IE & 131.8 & 4.10 & 7 & 115 & 0.5 & 0.02 & 1.0 & 0.7 \\
\hline 9/2/2008 23:15 & 42.6203 & -111.4018 & 2.4 & $\mathrm{Mc} I \mathrm{E}$ & 160.4 & 15.02 & 25 & 100 & 28.1 & 0.17 & 0.5 & 0.9 \\
\hline 9/2/2008 23:24 & 42.6252 & -111.4065 & 2.3 & Mc IE & 159.8 & 14.83 & 21 & 99 & 27.4 & 0.22 & 0.7 & 1.1 \\
\hline 9/2/2008 23:32 & 42.6185 & -111.4108 & 1.5 & Mc IE & 160.1 & 13.05 & 12 & 99 & 27.8 & 0.29 & 1.1 & 1.8 \\
\hline 9/2/2008 23:33 & 42.5578 & -111.4988 & 1.8 & ML IE & 160.3 & 15.46 & 8 & 282 & 31.3 & 0.08 & 1.7 & 2.3 \\
\hline 9/3/2008 1:59 & 44.5887 & -112.4175 & 1.0 & Mc IE & 108.5 & 10.08 & 7 & 89 & 1.9 & 0.06 & 0.6 & 1.0 \\
\hline 9/3/2008 21:03 & 42.8588 & -111.3655 & 1.3 & Mc IE & 144.9 & 2.55 & 7 & 146 & 9.9 & 0.14 & 1.0 & 12.4 \\
\hline 9/5/2008 17:10 & 42.9833 & -111.3980 & 1.7 & Mc IE & 134.6 & 8.39 & 24 & 71 & 5.4 & 0.11 & 0.3 & 0.5 \\
\hline 9/6/2008 15:18 & 43.7922 & -110.9238 & 0.7 & Mc IE & 150.6 & 7.44 & 6 & 133 & 11.7 & 0.04 & 1.2 & 3.7 \\
\hline 9/6/2008 15:33 & 43.7822 & -110.9483 & 1.0 & Mc IE & 148.5 & 0.04 & 13 & 72 & 12.8 & 0.20 & 0.5 & 2.2 \\
\hline 9/6/2008 18:58 & 43.3462 & -110.9332 & 0.7 & Mc IE & 153.3 & 14.34 & 9 & 178 & 16.1 & 0.04 & 0.8 & 1.7 \\
\hline 9/7/2008 3:08 & 43.3423 & -110.9375 & 1.3 & ML IE & 153.1 & 12.40 & 10 & 140 & 16.5 & 0.11 & 0.7 & 1.8 \\
\hline 9/7/2008 4:32 & 44.6267 & -112.0067 & 1.4 & Mc IE & 125.1 & 13.43 & 11 & 86 & 29.4 & 0.08 & 0.6 & 2.1 \\
\hline 9/7/2008 5:05 & 42.8973 & -111.2665 & 2.0 & Mc IE & 148.8 & 10.03 & 31 & 118 & 13.5 & 0.16 & 0.4 & 1.0 \\
\hline 9/8/2008 5:42 & 44.4405 & -114.3278 & 1.8 & Mc IE & 151.8 & 4.29 & 20 & 78 & 14.9 & 0.18 & 0.5 & 1.3 \\
\hline 9/8/2008 16:37 & 44.1677 & -114.0103 & 1.2 & Mc IE & 114.1 & 7.83 & 9 & 129 & 29.4 & 0.04 & 0.5 & 11.5 \\
\hline 9/9/2008 8:10 & 42.9165 & -111.3697 & 0.4 & Mc IE & 140.7 & 9.48 & 6 & 243 & 4.9 & 0.13 & 3.6 & 1.0 \\
\hline 9/10/2008 1:13 & 44.2630 & -114.1493 & 0.7 & Mc IE & 129.1 & 15.67 & 7 & 180 & 34.5 & 0.05 & 5.0 & 1.4 \\
\hline
\end{tabular}




\begin{tabular}{|c|c|c|c|c|c|c|c|c|c|c|c|c|}
\hline ORIGIN TIME & LAT N & LONG W & MAG & -TYPE & DIST & $Z$ & $\mathrm{NO}$ & GAP & DMIN & RMS & $\mathrm{ERH}$ & ERZ \\
\hline 9/10/2008 17:18 & 44.2440 & -114.3103 & 1.0 & ML IE & 139.2 & 6.58 & 6 & 242 & 39.7 & 0.03 & 2.0 & 9.9 \\
\hline 9/10/2008 17:45 & 4.1618 & -114.5110 & 1.3 & Mc IE & 150.0 & 9.70 & 9 & 106 & 41.9 & 0.07 & 0.6 & 10.9 \\
\hline 9/12/2008 10:18 & 44.2808 & -112.4032 & 1.5 & Mc IE & 76.5 & 9.75 & 19 & 98 & 9.6 & 0.10 & 0.4 & 1.0 \\
\hline $9 / 13 / 20081: 13$ & 43.0215 & -111.4618 & 1.2 & ML IE & 127.9 & 10.63 & 6 & 130 & 8.3 & 0.04 & 1.4 & 2.5 \\
\hline 9/13/2008 4:06 & 44.1777 & -114.3408 & 1.5 & Mc IE & 138.2 & 3.29 & 11 & 101 & 34.3 & 0.14 & 0.7 & 2.5 \\
\hline 9/13/2008 18:42 & 44.0203 & -114.5928 & 1.5 & Mc IE & 151.2 & 10.65 & 16 & 100 & 40.0 & 0.08 & 0.4 & 3.6 \\
\hline 9/13/2008 18:50 & 44.0257 & -114.5950 & 1.3 & Mc IE & 151.5 & 12.26 & 6 & 227 & 40.3 & 0.03 & 0.8 & 7.2 \\
\hline 9/14/2008 6:36 & 44.6028 & -112.4725 & 0.5 & ML IE & 108.9 & 17.67 & 4 & 182 & 6.3 & 0.05 & 3.1 & 1.1 \\
\hline 9/14/2008 20:12 & 43.1762 & -111.0728 & 1.5 & Mc IE & 148.1 & 13.83 & 20 & 111 & 27.7 & 0.13 & 0.4 & 1.4 \\
\hline 9/14/2008 22:21 & 44.4448 & -114.1738 & 1.5 & Mc IE & 142.2 & 18.54 & 9 & 137 & 55.4 & 0.09 & 0.8 & 14.7 \\
\hline 9/16/2008 19:16 & 43.4865 & -110.8720 & 1.4 & ML IE & 155.4 & 11.67 & 8 & 112 & 6.4 & 0.10 & 1.0 & 1.3 \\
\hline 9/17/2008 21:50 & 43.2002 & -111.3562 & 1.2 & Mc IE & 125.9 & 8.53 & 6 & 140 & 16.3 & 0.07 & 0.7 & 3.4 \\
\hline $9 / 18 / 20081: 57$ & 43.6908 & -110.8350 & 0.9 & Mc IE & 157.1 & 12.55 & 7 & 134 & 20.6 & 0.03 & 0.6 & 2.8 \\
\hline 9/18/2008 11:22 & 44.0948 & -113.9170 & 1.1 & Mc IE & 103.7 & 2.88 & 9 & 114 & 25.6 & 0.11 & 0.7 & 1.1 \\
\hline 9/18/2008 16:44 & 42.7027 & -111. & 1.6 & Mc IE & 140.8 & 2.38 & 10 & 86 & 14.9 & 0.06 & 0.8 & 11.5 \\
\hline 9/19/2008 11:59 & 44.3645 & -113.9720 & 1.4 & Mc IE & 124.1 & 7.27 & 10 & 78 & 31.6 & 0.14 & 0.8 & 10.3 \\
\hline 9/19/2008 22:46 & 44.4615 & -112.6112 & 1.1 & Mc IE & 91.3 & 15.80 & 6 & 139 & 22.6 & 0.03 & 0.9 & 3.2 \\
\hline 9/20/2008 13:16 & 42.6432 & -111.4020 & 1.0 & ML IE & 158.6 & 12.38 & 10 & 157 & 26.0 & 0.07 & 1.2 & 1.7 \\
\hline 9/20/2008 15:42 & 44.0685 & -114.4770 & 1.4 & ML IE & 143.9 & 6.79 & 6 & 128 & 33.6 & 0.07 & 1.0 & 3.4 \\
\hline 9/20/2008 16:08 & 43.3438 & -113.6335 & 1.4 & Mc IE & 76.7 & 18.40 & 16 & 189 & 9.7 & 0.22 & 1.3 & 1.3 \\
\hline 9/20/2008 16:13 & 43.3648 & -113 & 2.0 & ML IE & 68.4 & 35.75 & 20 & 110 & 4.8 & 0.38 & 1.2 & 2.0 \\
\hline 9/20/2008 23:50 & 43.2 & -11 & 1.1 & Mc IE & 151.7 & 17.30 & 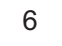 & 187 & 28.7 & 0.04 & 3.7 & 12.0 \\
\hline $9 / 21 / 20086: 28$ & 42.8 & -11 & 0.6 & $N$ & 1 & 5 & 6 & 206 & & 6 & 2.7 & 11.5 \\
\hline 9/21/2008 21:00 & 44.7825 & -112.8138 & 2.0 & ML MB & 126.0 & 11.43 & 32 & 68 & 5.7 & 0.09 & 0.3 & 0.6 \\
\hline $9 / 22 / 20086: 38$ & 44.5688 & -112.1445 & 2.1 & ML IE & 114.3 & 14.25 & 42 & 57 & 20.0 & 0.10 & 0.2 & 0.7 \\
\hline $9 / 22 / 20086: 42$ & 44.5612 & -112.1385 & 2.0 & ML IE & 113.7 & 13.77 & 16 & 66 & 20.6 & 0.12 & 0.5 & 1.5 \\
\hline 9/22/2008 8:34 & 43.2963 & -110.9543 & 0.7 & Mc IE & 153.0 & 2.05 & 7 & 212 & 21.0 & 0.26 & 1.4 & 24.8 \\
\hline 9/22/2008 12:07 & 43.5730 & -111.1 & 1.3 & ML IE & 133.1 & 8.70 & $y$ & 92 & 5 & 0.09 & 0.8 & 3.5 \\
\hline $9 / 23 / 20083: 42$ & & & 2.0 & & & & 18 & & & & & 10.9 \\
\hline 9/23/2008 8:02 & 44.7085 & -114.0672 & 1.7 & Mc IE & 156.2 & 4.90 & 11 & 116 & 21.9 & 0.13 & 0.8 & 2.1 \\
\hline 9/24/2008 2:19 & 44.0860 & -113.9240 & 2.1 & Mc IE & 103.7 & 6.94 & 27 & 86 & 24.5 & 0.16 & 0.3 & 11.2 \\
\hline 9/24/2008 6:26 & 44.1178 & -113.9293 & 1.6 & Mc IE & 105.8 & 6.94 & 24 & 53 & 27.1 & 0.27 & 0.6 & 17.0 \\
\hline 9/25/2008 12:16 & 44.3598 & -113.9708 & 1.5 & Mc IE & 123.7 & 6.19 & 13 & 79 & 32.0 & 0.08 & 0.7 & 5.1 \\
\hline 9/25/2008 17:42 & 43.3310 & -111.4888 & 1.6 & ML IE & 110.5 & 20.40 & 6 & 189 & 8 & 0.07 & 10.2 & 2.1 \\
\hline 9/25/2008 17:44 & 43.1858 & -111.4263 & 0.9 & Mc IE & 121.4 & 9.45 & 11 & 114 & 15.4 & 0.12 & 0.5 & 2.2 \\
\hline 9/28/2008 0:36 & 44.0718 & -114.5005 & 1.1 & Mc IE & 145.8 & 28.10 & 5 & 221 & 57.1 & 0.01 & 2.2 & 9.8 \\
\hline 9/28/2008 11:39 & 43.0338 & -111.3017 & 1.0 & Mc IE & 138.3 & 7.55 & 8 & 194 & 6.0 & 0.11 & 1.0 & 1.4 \\
\hline 9/28/2008 15:38 & 43.5463 & -111.0240 & 0.8 & Mc IE & 142.4 & 13.49 & 8 & 144 & 8.6 & 0.03 & 3.6 & 2.3 \\
\hline 9/29/2008 14:53 & 44.6987 & -111.8558 & 1.5 & Mc IE & 138.2 & 12.64 & 12 & 115 & 15.5 & 0.07 & 0.6 & 1.8 \\
\hline 9/30/2008 4:01 & 43.5600 & -111.1613 & 1.7 & Mc IE & 131.3 & 5.14 & 16 & 104 & & 0.22 & 0.6 & 4.6 \\
\hline 9/30/2008 6:23 & 44.8103 & -111.8820 & 1.5 & Mc IE & 147.8 & 13.37 & 5 & 153 & 19.3 & 0.01 & 1.6 & 2.9 \\
\hline 9/30/2008 21:42 & 43.3273 & -110.9543 & 1.4 & ML IE & 152.2 & 12.70 & 8 & 197 & 18.1 & 0.10 & 0.9 & 2.1 \\
\hline 9/30/2008 23:31 & 43.4903 & -114.6623 & 1.2 & Mc IE & 152.8 & 0.04 & 9 & 162 & 22.2 & 0.17 & 1.2 & 2.7 \\
\hline 10/1/2008 15:39 & 43.7132 & -110.8853 & 0.9 & Mc IE & 153.1 & 2.47 & 8 & 127 & 20.9 & 0.04 & 0.6 & 12.5 \\
\hline 10/1/2008 21:10 & 42.9057 & -111.4245 & 0.5 & Mc IE & 137.9 & 1.70 & 4 & 224 & 3.6 & 0.14 & 12.8 & 2.1 \\
\hline $10 / 2 / 20080: 26$ & 44.5537 & -112.3393 & 1.7 & Mc IE & 106.6 & 5.62 & 15 & 97 & 6.2 & 0.11 & 0.4 & 0.3 \\
\hline 10/2/2008 9:10 & 44.8385 & -111.7425 & 0.8 & Mc IE & 156.2 & 3.86 & 3 & 201 & 13.5 & 0.02 & 8.6 & 8.1 \\
\hline 10/2/2008 10:11 & 44.8988 & -112.6903 & 1.1 & Mc IE & 139.1 & 3.33 & 7 & 150 & 14.8 & 0.07 & 0.8 & 2.8 \\
\hline 10/2/2008 12:19 & 42.9377 & -111.6457 & 1.7 & Mc IE & 121.6 & 11.97 & 15 & 69 & 12.6 & 0.05 & 0.4 & 0.8 \\
\hline 10/2/2008 13:11 & 44.7175 & -111.9938 & 2.5 & Mc IE & 134.5 & 14.97 & 37 & 51 & 26.0 & 0.12 & 0.3 & 0.8 \\
\hline 10/2/2008 16:30 & 42.9218 & -111.6355 & 0.9 & Mc IE & 123.4 & 15.76 & 10 & 93 & 10.7 & 0.09 & 1.1 & 1.1 \\
\hline
\end{tabular}




\begin{tabular}{|c|c|c|c|c|c|c|c|c|c|c|c|c|}
\hline ORIGIN TIME & LAT N & LONG W & MAG & -TYPE & DIST & $Z$ & $\mathrm{NO}$ & GAP & DMIN & RMS & $\mathrm{ERH}$ & ERZ \\
\hline 10/2/2008 17:16 & 42.9285 & -111.6565 & 2.2 & ML IE & 121.6 & 13.37 & 14 & 112 & 12.1 & 0.10 & 0.5 & 1.0 \\
\hline 10/2/2008 17:17 & 2.9335 & -111.6503 & 1.1 & ML IE & 121.6 & 10.75 & 6 & 264 & 12.3 & 0.01 & 1.0 & 2.6 \\
\hline 10/2/2008 17:18 & 42.9393 & -111.6472 & 1.4 & ML IE & 121.4 & 12.82 & 10 & 196 & 18.4 & 0.07 & 1.1 & 1.8 \\
\hline 10/2/2008 17:19 & 42.9300 & -111.6583 & 2.3 & ML IE & 121.4 & 8.07 & 15 & 99 & 19.3 & 0.05 & 0.5 & 1.5 \\
\hline 10/2/2008 17:20 & 42.9357 & -111.6590 & 1.6 & ML IE & 120.9 & 12.41 & 8 & 198 & 19.4 & 0.06 & 1.6 & 2.3 \\
\hline 10/2/2008 17:24 & 42.9288 & -111.6623 & 0.6 & Mc IE & 121.3 & 12.98 & 7 & 216 & 12.3 & 0.06 & 1.4 & 2.5 \\
\hline 10/3/2008 3:06 & 43.3545 & -110.9633 & 0.7 & Mc IE & 150.7 & 11.80 & 7 & 182 & 20.4 & 0.02 & 0.6 & 3.6 \\
\hline 10/3/2008 3:18 & 43.2788 & -112.9932 & 1.1 & ML IE & 44.7 & 37.01 & 27 & 110 & 13.8 & 0.14 & 0.6 & 1.0 \\
\hline 10/3/2008 15:08 & 42.6872 & -111.4777 & 1.1 & Mc IE & 150.8 & 15.39 & 7 & 257 & 18.5 & 0.13 & 1.7 & 1.4 \\
\hline 10/4/2008 11:06 & 44.0385 & -114.5195 & 1.0 & Mc IE & 146.1 & 6.94 & 8 & 165 & 53.7 & 0.17 & 1.6 & 12.9 \\
\hline 10/4/2008 13:19 & 44.6410 & -112.0870 & 1.3 & Mc IE & 123.5 & 6.19 & 9 & 178 & 25.0 & 0.09 & 1.1 & 12.9 \\
\hline 10/4/2008 13:46 & 44.6605 & -112.1127 & 1.2 & Mc IE & 124.5 & 2.46 & 7 & 185 & 23.6 & 0.07 & 1.1 & 1.3 \\
\hline 10/4/2008 20:56 & 42.9343 & -111.6752 & 1.3 & Mc IE & 120.1 & 11.92 & 11 & 102 & 13.4 & 0.11 & 1.1 & 2.6 \\
\hline 10/5/2008 10:01 & 43.7727 & -111.0333 & 0.7 & Mc IE & 141.6 & 2.54 & 8 & 221 & 15.8 & 0.06 & 1.0 & 12.4 \\
\hline 10/5/2008 16:53 & 44.6268 & -112. & 1.4 & Mc IE & 121.8 & 16.63 & 16 & 134 & 24.0 & 0.10 & 0.5 & 0.4 \\
\hline 10/6/2008 9:53 & 44.6252 & -112.0993 & 2.2 & ML IE & 121.5 & 13.93 & 32 & 53 & 23.7 & 0.28 & 0.4 & 1.2 \\
\hline 10/6/2008 10:10 & 43.5565 & -111.1560 & 1.6 & M & 131.7 & 9.35 & 19 & 94 & 8 & & 0.4 & .9 \\
\hline 10/6/2008 15:11 & 44.3947 & -113.1198 & 0.7 & Mc IE & 87.1 & 7.15 & 7 & 154 & 16.0 & 0.28 & 1.9 & 20.8 \\
\hline 10/6/2008 22:12 & 44.6802 & -112.6755 & 1.1 & Mc IE & 114.9 & 2.49 & 4 & 127 & 7.4 & 0.01 & 2.9 & 4.4 \\
\hline 10/7/2008 1:23 & 44.6698 & -112.7073 & 1.2 & ML IE & 113.6 & 6.40 & 4 & 189 & 7.7 & 0. & 9.2 & 4.7 \\
\hline 10/7/2008 16:49 & 44.6820 & -112 & 1.2 & Mc IE & 115.3 & 1.10 & 4 & 214 & 7.3 & 0 & 3.6 & 10.2 \\
\hline 10/9/2008 8:07 & 43 & -11 & 1.5 & $\mathrm{~N}$ & 4 & 30 & 26 & 107 & & & 3 & 0.5 \\
\hline 10/11/2008 5:15 & 43 & -11 & 2.0 & $\mathrm{~N}$ & 7 & 4 & 26 & 85 & & & 3 & 0.9 \\
\hline 10/12/2008 3:01 & 44.6420 & -114.1203 & 2.0 & Mc IE & 153.7 & 5.78 & 24 & 89 & 13.7 & 0.14 & 0.3 & 0.6 \\
\hline 10/15/2008 23:53 & 44.6193 & -112.3757 & 0.9 & $\mathrm{Mc} M B$ & 112.7 & 5.90 & 5 & 278 & 21.3 & 0.03 & 1.7 & 12.7 \\
\hline 10/16/2008 7:56 & 43.1972 & -111.3585 & 1.3 & ML IE & 125.8 & 10.42 & 10 & 132 & 16.0 & 0.06 & 0.5 & 1.8 \\
\hline 10/16/2008 8:07 & 43.1935 & -111.3653 & 2.1 & Mc IE & 125.5 & 8.32 & 26 & 112 & 15.6 & 0.12 & 0.3 & 1.4 \\
\hline 10/16/2008 8:23 & 43.1988 & -111.3737 & 1.8 & Mc IE & 124.6 & 7.12 & 22 & 135 & 17.1 & 0.20 & 0.6 & 2.4 \\
\hline $10 / 16 / 200815: 50$ & & & 2.6 & & & & 38 & & & & & 0.5 \\
\hline $10 / 17 / 20082: 40$ & 43.1035 & -110.9583 & 0.5 & ML IE & 159.8 & 4.99 & 7 & 219 & 34.0 & 0.18 & 1.1 & 17.7 \\
\hline 10/17/2008 14:07 & 43.1863 & -111.4702 & 1.3 & Mc IE & 118.1 & 8.45 & 10 & 100 & 15.1 & 0.11 & 0.4 & 2.1 \\
\hline 10/17/2008 17:17 & 43.6682 & -111.1062 & 1.7 & ML IE & 135.2 & 9.17 & 12 & 90 & 10.3 & 0.19 & 0.6 & 3.5 \\
\hline 10/19/2008 2:10 & 43.2640 & -111.3073 & 1.4 & Mc IE & 126.9 & 0.98 & 17 & 138 & 9.3 & 0.09 & 0.4 & 1.5 \\
\hline $10 / 19 / 200811: 45$ & 43.4108 & -111.1030 & 1.5 & Mc IE & 138.3 & 11.04 & 15 & 108 & 10.1 & 0 & 0.6 & 1.1 \\
\hline 10/19/2008 12:08 & 43.4212 & -111.0863 & 0.5 & ML IE & 139.4 & 8.13 & 8 & 146 & 13.4 & 0.25 & 1.6 & 3.5 \\
\hline 10/19/2008 12:13 & 43.4077 & -111.0987 & 1.4 & Mc IE & 138.7 & 9.75 & 11 & 152 & 15.1 & 0.06 & 0.7 & 1.5 \\
\hline $10 / 19 / 200812: 46$ & 43.3973 & -111.0925 & 0.8 & ML IE & 139.5 & 11.20 & 5 & 206 & 15.4 & 0.01 & 2.7 & 1.6 \\
\hline $10 / 19 / 200815: 54$ & 43.4090 & -111.1100 & 1.0 & Mc IE & 137.8 & 9.11 & 9 & 151 & 15.7 & 0.04 & 0.8 & 1.5 \\
\hline 10/19/2008 16:51 & 43.3913 & -111.4910 & 0.9 & Mc IE & 108.3 & 4.81 & 5 & 218 & 14.7 & 0.03 & 4.3 & 11.8 \\
\hline 10/20/2008 10:11 & 43.4552 & -110.8095 & 0.9 & ML IE & 160.9 & 2.50 & 5 & 147 & 12.1 & 0.26 & 2.0 & 23.8 \\
\hline $10 / 21 / 200810: 29$ & 42.6068 & -111.4270 & 1.1 & Mc IE & 160.1 & 6.44 & 10 & 152 & 28.3 & 0.22 & 1.0 & 10.2 \\
\hline 10/21/2008 20:56 & 44.6975 & -111.8523 & 2.0 & Mc IE & 138.3 & 14.20 & 18 & 73 & 15.2 & 0.09 & 0.4 & 0.7 \\
\hline $10 / 21 / 2008$ 21:46 & 44.6742 & -111.8555 & 1.4 & Mc IE & 135.9 & 12.01 & 9 & 144 & 16.3 & 0.10 & 0.6 & 1.4 \\
\hline 10/22/2008 10:15 & 43.1272 & -111.4200 & 0.5 & Mc IE & 124.8 & 4.28 & 6 & 135 & 9.1 & 0.06 & 0.8 & 4.3 \\
\hline 10/23/2008 6:59 & 43.0338 & -111.3212 & 0.4 & ML IE & 136.9 & 3.42 & 6 & 218 & 4.6 & 0.06 & 2.4 & 1.6 \\
\hline 10/23/2008 7:00 & 43.0315 & -111.3153 & 0.4 & Mc IE & 137.4 & 2.79 & 5 & 220 & 5.1 & 0.01 & 1.7 & 3.5 \\
\hline 10/23/2008 8:35 & 44.0502 & -113.8943 & 1.4 & Mc IE & 99.8 & 6.91 & 15 & 138 & 23.4 & 0.18 & 1.0 & 19.7 \\
\hline 10/23/2008 9:47 & 42.6917 & -111.8863 & 1.6 & Mc IE & 129.1 & 4.41 & 12 & 125 & 29.0 & 0.11 & 0.9 & 8.6 \\
\hline $10 / 23 / 200820: 56$ & 43.0385 & -111.3368 & 0.7 & Mc le & 135.5 & 5.10 & 5 & 293 & 3.2 & 0.00 & 2.4 & 1.9 \\
\hline 10/24/2008 3:53 & 43.1940 & -111.0043 & 1.0 & Mc IE & 152.6 & 2.50 & 10 & 209 & 30.8 & 0.20 & 1.2 & 19.8 \\
\hline 10/24/2008 9:04 & 43.1035 & -111.4155 & 0.3 & Mc IE & 126.4 & 9.96 & 5 & 174 & 6.7 & 0.02 & 0.9 & 2.0 \\
\hline
\end{tabular}




\begin{tabular}{|c|c|c|c|c|c|c|c|c|c|c|c|c|}
\hline ORIGIN TIME & LAT N & LONG W & MAG & -TYPE & DIST & $Z$ & $\mathrm{NO}$ & GAP & DMIN & RMS & ERH & ERZ \\
\hline $10 / 24 / 200812: 48$ & 43.0665 & -111.3863 & 1.7 & Mc IE & 130.5 & 9.46 & 8 & 102 & 1.9 & 0.09 & 0.8 & 1.3 \\
\hline 10/27/2008 23:01 & 42.7040 & -111.3038 & 2.0 & ML IE & 159.8 & 2.92 & 8 & 222 & 18.0 & 0.06 & 1.2 & 11.6 \\
\hline $10 / 27 / 2008$ 23:40 & 44.3215 & -114.5533 & 1.8 & ML IE & 160.4 & 5.01 & 12 & 98 & 34.9 & 0.08 & 0.5 & 14.3 \\
\hline $10 / 27 / 2008$ 23:41 & 42.7017 & -111.6772 & 1.4 & Mc IE & 138.6 & 2.29 & 10 & 148 & 16.2 & 0.06 & 0.6 & 12.2 \\
\hline 10/28/2008 11:42 & 42.7297 & -111.6432 & 1.0 & Mc IE & 138.1 & 7.99 & 5 & 236 & 12.2 & 0.22 & 4.2 & 2.8 \\
\hline $10 / 28 / 200811: 51$ & 42.7380 & -111.6915 & 0.0 & Mc IE & 134.8 & 0.03 & 6 & 161 & 13.4 & 0.11 & 2.0 & 2.2 \\
\hline 10/28/2008 17:36 & 42.9243 & -111.2728 & 1.0 & Mc IE & 146.7 & 11.30 & 7 & 184 & 16.4 & 0.08 & 1.6 & 2.8 \\
\hline 10/28/2008 21:02 & 44.6592 & -112.9745 & 2.8 & Mc IE & 113.3 & 11.98 & 42 & 57 & 21.2 & 0.13 & 0.2 & 0.8 \\
\hline 10/30/2008 2:15 & 43.4055 & -110.9302 & 1.8 & Mc IE & 152.2 & 8.62 & 13 & 155 & 9.5 & 0.06 & 0.6 & 1.6 \\
\hline 10/30/2008 6:15 & 43.9075 & -114.5753 & 2.1 & Mc IE & 147.0 & 6.90 & 24 & 88 & 36.8 & 0.14 & 0.3 & 1.6 \\
\hline 10/30/2008 9:05 & 43.7315 & -110.9153 & 0.5 & ML IE & 150.8 & 2.50 & 6 & 168 & 18.5 & 0.15 & 1.0 & 17.3 \\
\hline 10/30/2008 9:25 & 43.7455 & -110.8955 & 2.6 & Mc IE & 152.5 & 2.17 & 38 & 81 & 17.2 & 0.20 & 0.4 & 19.9 \\
\hline $10 / 30 / 200811: 28$ & 43.7358 & -110.9168 & 0.7 & ML IE & 150.7 & 2.50 & 6 & 169 & 18.0 & 0.23 & 1.2 & 22.0 \\
\hline 10/30/2008 11:35 & 43.7387 & -110.9042 & 1.2 & Mc IE & 151.7 & 2.50 & 10 & 102 & 17.8 & 0.26 & 0.8 & 22.5 \\
\hline $10 / 30 / 200811: 40$ & 43.7352 & -110.9022 & 1.2 & Mc le & 151.9 & 2.50 & 11 & 101 & 18.2 & 0.24 & 0.7 & 20.6 \\
\hline $10 / 30 / 200812: 28$ & 43.7335 & -110.9247 & 0.7 & ML IE & 150.0 & 2.50 & 7 & 172 & 18.2 & 0.17 & 1.0 & 18.2 \\
\hline $10 / 30 / 200812: 59$ & 44.2012 & -114.0438 & 1.2 & Mc IE & 118.3 & 7.05 & 16 & 99 & 32.4 & 0.14 & 0.4 & 14.5 \\
\hline 10/30/2008 13:13 & 42.9578 & -111.3593 & 1.1 & Mc IE & 138.8 & 7.67 & 5 & 217 & 10.7 & 0.00 & 2.7 & 1.7 \\
\hline $10 / 30 / 2008$ 19:45 & 43.7463 & -110.8812 & 2.3 & Mc IE & 153.6 & 2.12 & 28 & 98 & 17.4 & 0.19 & 0.4 & 19.7 \\
\hline 10/30/2008 21:06 & 43.7315 & -110.9090 & 1.5 & Mc IE & 151.3 & 2.50 & 10 & 118 & 18.5 & 0.18 & 0.6 & 16.9 \\
\hline $10 / 31 / 2 C$ & 43.7 & -110 & 1.8 & Mc IE & 153.3 & 2.49 & 14 & ד & 17.9 & 0.25 & 0.5 & 19.4 \\
\hline 10/31/2008 10:12 & 43.7410 & -110.8842 & 1.4 & Mc IE & 153.3 & 2.49 & 11 & 71 & 17.9 & 0.24 & 0.7 & 19.5 \\
\hline $10 / 31 / 200811: 21$ & 43.7380 & -110.8892 & 1.9 & Mc IE & 152.9 & 2.30 & 19 & 70 & 18.1 & 0.25 & 0.5 & 21.9 \\
\hline 10/31/2008 12:16 & 43.7348 & -110.8865 & 1.2 & ML IE & 153.1 & 2.50 & 7 & 169 & 18.5 & 0.35 & 1.5 & 28.9 \\
\hline 10/31/2008 12:18 & 43.7580 & -110.8913 & 1.1 & ML IE & 152.9 & 2.49 & 6 & 162 & 15.9 & 0.11 & 0.8 & 14.2 \\
\hline 11/1/2008 2:34 & 42.9980 & -111.2978 & 1.3 & ML IE & 140.6 & 9.08 & 9 & 170 & 8.5 & 0.11 & 0.7 & 1.5 \\
\hline $11 / 1 / 20082: 48$ & 43.7260 & -110 & 0.5 & ML IE & 149.7 & 2.50 & 1 & 174 & 19.0 & 0.08 & 1.0 & 13.6 \\
\hline $11 / 1 / 20084: 32$ & 43.8573 & -110. & 2. & Mc IE & 14 & 1.92 & 28 & 0 & & 0.22 & 0.4 & 1.6 \\
\hline $11 / 1 / 20084: 41$ & 43.8685 & -111.0422 & 1.0 & ML IE & 142.2 & 2.36 & 5 & 259 & 8.9 & 0.13 & 2.8 & 12.7 \\
\hline 11/1/2008 5:07 & 43.3338 & -111.1100 & 1.4 & Mc IE & 139.8 & 8.54 & 11 & 177 & 17.1 & 0.09 & 0.9 & 2.3 \\
\hline 11/1/2008 5:42 & 43.4463 & -113.5473 & 2.3 & ML IE & 65.8 & 18.18 & 31 & 95 & 4.1 & 0.12 & 0.3 & 0.6 \\
\hline $11 / 1 / 20085: 43$ & 43.8527 & -110.9705 & 1.2 & ML IE & 147.6 & 5.00 & 8 & 159 & 39.8 & 0.09 & 0.9 & 12.0 \\
\hline 11/1/2008 9:51 & 44.6168 & -112.9857 & 1.2 & Mc IE & 108.8 & 5.97 & 7 & 115 & 25.8 & 0.15 & 1.3 & 2.3 \\
\hline 11/1/2008 9:53 & 43.6830 & -110.8485 & 0.5 & Mc IE & 156.0 & 2.28 & 7 & 141 & 21.3 & 0.05 & 0.5 & 13.1 \\
\hline 11/1/2008 13:13 & 43.7415 & -110.9212 & 1.1 & Mc IE & 150.4 & 9.88 & 9 & 104 & 17.3 & 0.18 & 0.8 & 2.8 \\
\hline 11/1/2008 17:20 & 43.8475 & -110.9787 & 1.1 & ML IE & 146.9 & 2.01 & 6 & 161 & 6.3 & 0.06 & 0.8 & 13.6 \\
\hline $11 / 2 / 20084: 48$ & 44.2463 & -114.3355 & 1.1 & Mc IE & 141.1 & 7.39 & 6 & 144 & 35.9 & 0.09 & 1.3 & 14.4 \\
\hline $11 / 2 / 20087: 24$ & 42.7327 & -111.5987 & 0.8 & Mc IE & 140.3 & 5.81 & 5 & 280 & 11.1 & 0.03 & 1.6 & 2.4 \\
\hline $11 / 2 / 20087: 40$ & 44.2468 & -114.3793 & 1.6 & $\mathrm{Mc}$ IE & 144.3 & 7.24 & 13 & 100 & 36.6 & 0.08 & 0.5 & 14.0 \\
\hline 11/2/2008 7:45 & 44.2652 & -114.1775 & 1.2 & Mc IE & 131.1 & 7.00 & 9 & 182 & 33.8 & 0.06 & 13.1 & 13.3 \\
\hline 11/2/2008 8:07 & 44.2513 & -114.3738 & 2.4 & Mc IE & 144.1 & 7.11 & 28 & 100 & 36.0 & 0.11 & 0.4 & 15.4 \\
\hline $11 / 2 / 20088: 23$ & 44.2500 & -114.3727 & 1.2 & ML IE & 144.0 & 6.90 & 7 & 136 & 36.2 & 0.15 & 1.3 & 17.7 \\
\hline 11/2/2008 8:37 & 44.2482 & -114.3760 & 1.4 & Mc IE & 144.1 & 7.90 & 10 & 100 & 36.4 & 0.15 & 0.6 & 16.0 \\
\hline 11/2/2008 9:31 & 44.2540 & -114.3855 & 1.3 & Mc IE & 145.1 & 7.07 & 8 & 130 & 36.0 & 0.10 & 0.7 & 15.2 \\
\hline $11 / 2 / 20089: 43$ & 44.2437 & -114.3715 & 1.5 & Mc IE & 143.6 & 8.11 & 12 & 80 & 36.8 & 0.16 & 0.8 & 13.9 \\
\hline $11 / 2 / 2008$ 12:25 & 44.2533 & -114.3782 & 0.8 & Mc IE & 144.5 & 8.08 & 12 & 87 & 35.9 & 0.12 & 0.7 & 14.6 \\
\hline $11 / 2 / 200818: 51$ & 43.7417 & -110.8965 & 2.3 & Mc IE & 152.4 & 2.27 & 20 & 69 & 17.6 & 0.25 & 0.6 & 22.2 \\
\hline 11/2/2008 18:53 & 43.7238 & -110.8668 & 1.1 & Mc IE & 154.6 & 15.68 & 10 & 75 & 24.6 & 0.17 & 0.8 & 1.1 \\
\hline 11/2/2008 21:22 & 43.7462 & -110.8750 & 2.3 & Mc IE & 154.1 & 2.34 & 38 & 106 & 17.5 & 0.17 & 0.4 & 15.2 \\
\hline 11/2/2008 22:27 & 43.7453 & -110.8692 & 2.2 & ML IE & 154.6 & 2.48 & 13 & 142 & 17.8 & 0.11 & 0.5 & 13.1 \\
\hline $11 / 2 / 200823: 33$ & 43.7503 & -110.8615 & 2.3 & Mc IE & 155.2 & 2.18 & 30 & 109 & 17.5 & 0.10 & 0.4 & 15.2 \\
\hline
\end{tabular}




\begin{tabular}{|c|c|c|c|c|c|c|c|c|c|c|c|c|}
\hline ORIGIN TIME & LAT N & LONG W & MAG & -TYPE & DIST & $Z$ & $\mathrm{NO}$ & GAP & DMIN & RMS & $\mathrm{ERH}$ & ERZ \\
\hline $11 / 2 / 2008$ 23:35 & 43.7468 & -110.8678 & 2.4 & Mc IE & 154.7 & 2.10 & 30 & 107 & 17.6 & 0.14 & 0.4 & 16.9 \\
\hline 11/2/2008 23:46 & 3.7380 & -110.8890 & 1.3 & Mc IE & 152.9 & 2.49 & 7 & 167 & 18.1 & 0.28 & 1.5 & 22.9 \\
\hline $11 / 3 / 20081: 56$ & 43.7228 & -110.9312 & 1.0 & Mc IE & 149.5 & 2.49 & 6 & 245 & 19.4 & 0.11 & 1.3 & 14.9 \\
\hline 11/3/2008 14:20 & 44.2473 & -114.3628 & 1.3 & Mc IE & 143.1 & 7.90 & 12 & 138 & 36.2 & 0.15 & 0.7 & 15.5 \\
\hline 11/3/2008 15:33 & 44.2477 & -114.3347 & 0.6 & ML IE & 141.1 & 7.45 & 7 & 185 & 35.7 & 0.10 & 2.2 & 15.0 \\
\hline 11/3/2008 16:48 & 44.2478 & -114.3780 & 0.8 & ML IE & 144.2 & 7.16 & 4 & 225 & 36.5 & 0.21 & 4.4 & 21.4 \\
\hline 11/3/2008 17:06 & 43.7477 & -110.8717 & 2.0 & Mc IE & 154.4 & 2.19 & 18 & 106 & 17.5 & 0.11 & 0.4 & 15.4 \\
\hline 11/3/2008 23:26 & 44.2477 & -114.3945 & 1.5 & Mc IE & 145.4 & 7.25 & 12 & 83 & 36.9 & 0.21 & 1.0 & 20.7 \\
\hline $11 / 4 / 2008$ 2:28 & 43.7150 & -110.9408 & 1.0 & ML IE & 148.6 & 2.45 & 7 & 248 & 20.2 & 0.13 & 2.1 & 15.2 \\
\hline 11/4/2008 6:12 & 44.2468 & -114.3838 & 1.6 & Mc IE & 144.6 & 6.73 & 19 & 81 & 36.7 & 0.37 & 0.8 & 4.0 \\
\hline $11 / 4 / 20086: 13$ & 44.2442 & -114.3733 & 1.5 & Mc IE & 143.7 & 7.78 & 12 & 135 & 36.8 & 0.15 & 0.8 & 15.4 \\
\hline $11 / 4 / 20086: 17$ & 44.2577 & -114.3530 & 1.6 & Mc IE & 143.0 & 7.16 & 12 & 104 & 35.0 & 0.16 & 0.7 & 18.0 \\
\hline $11 / 4 / 20086: 25$ & 43.7162 & -110.9350 & 1.0 & Mc IE & 149.1 & 2.50 & 7 & 247 & 20.1 & 0.18 & 1.6 & 18.2 \\
\hline $11 / 4 / 20086: 54$ & 43.7350 & -110.8932 & 1.0 & Mc IE & 152.6 & 2.50 & 8 & 99 & 18.4 & 0 & 0.9 & 23.6 \\
\hline 11/4/2008 8:04 & 44.2 & -114 & 1.6 & Mc IE & 14 & 8.20 & 11 & 133 & 37.5 & 0 & 0.9 & 16.3 \\
\hline 11/4/2008 13:56 & 43.7445 & -110.8645 & 1.3 & Mc IE & 154.9 & 2.49 & 7 & 143 & 18.0 & 0.09 & 0.9 & 13.6 \\
\hline 11/4/2008 14:02 & 43.7390 & -110.8773 & 1.5 & $\mathrm{~N}$ & 153.9 & 2.50 & 10 & 72 & 18.2 & 0.18 & 0.7 & 17.4 \\
\hline 11/4/2008 14:37 & 43.7418 & -110.8573 & 1.3 & Mc IE & 155.5 & 2.48 & 11 & 145 & 18.5 & 0.10 & 0.5 & 13.8 \\
\hline $11 / 5 / 20084: 54$ & 44.3122 & -111.0080 & 0.9 & Mc IE & 160.3 & 4.86 & 4 & 239 & 16.9 & 0.01 & 3.0 & 11.8 \\
\hline 11/5/2008 10:03 & 43.7467 & -110.8768 & 1.0 & Mc IE & 154.0 & 2.46 & 7 & 163 & 17.4 & 0. & 1.7 & 14.2 \\
\hline 11/5/2008 11:51 & 43. & -11 & 1.2 & ML IE & 146.9 & 2.64 & 5 & 145 & 6.2 & 0 & 1.5 & 9.3 \\
\hline 11/5/2008 14:13 & 43.7 & -11 & 1.7 & M & 1 & 2.47 & 11 & 136 & 8 & & 0.7 & 13.2 \\
\hline 11/5/2008 16:07 & 43 & -1 & 1.2 & $\mathrm{~N}$ & 6 & 2 & 6 & 1 & & & 2 & 12.7 \\
\hline 11/11/2008 5:51 & 43.4730 & -110.9510 & 0.7 & ML IE & 149.3 & 8.88 & 7 & 245 & 1.9 & 0.01 & 2.7 & 0.8 \\
\hline 11/13/2008 6:39 & 42.3188 & -112.9487 & 0.9 & Mc IE & 148.7 & 5.01 & 5 & 154 & 31.3 & 0.14 & 1.0 & 14.7 \\
\hline $11 / 14 / 200822: 58$ & 44.3300 & -114.5298 & 2.2 & Mc IE & 159.2 & 5.03 & 9 & 190 & 35.6 & 0.02 & 1.2 & 12.6 \\
\hline 11/15/2008 11:20 & 44.3905 & -114.1000 & 1.1 & Mc IE & 133.9 & 5.40 & 9 & 214 & 22.9 & 0.09 & 4.3 & 4.8 \\
\hline 11/15/2008 19:00 & 43.1047 & -111.5 & 0.6 & M & 117.2 & 5.16 & 4 & 206 & 15.3 & 0.15 & 2.7 & 16.1 \\
\hline 11/17/2008 1:16 & & & & & & & 18 & & & & & 0.5 \\
\hline 11/17/2008 8:35 & 42.9742 & -111.1888 & 1.2 & Mc le & 149.5 & 9.93 & 8 & 152 & 17.2 & 0.08 & 0.9 & 3.0 \\
\hline 11/17/2008 10:08 & 44.1807 & -110.9850 & 1.2 & Mc IE & 156.0 & 2.50 & 5 & 118 & 15.8 & 0.08 & 0.8 & 13.0 \\
\hline 11/18/2008 10:12 & 44.5412 & -113.2022 & 1.2 & Mc MB & 104.7 & 7.09 & 10 & 119 & 15.6 & 0.05 & 0.6 & 11.5 \\
\hline 11/18/2008 15:58 & 42.8523 & -111.5888 & 1.4 & ML IE & 131.4 & 7.14 & 5 & 180 & 2.2 & 0.14 & 3.0 & 3.6 \\
\hline $11 / 18 / 200815: 58$ & 42.8442 & -111 & 1.3 & ML IE & 13 & 7.79 & 0 & 190 & . & 6 & .0 & 1.7 \\
\hline 11/18/2008 17:01 & 42.8682 & -111.5820 & 1.1 & Mc IE & 130.6 & 5.04 & 11 & 123 & 4.0 & 0.09 & 0.9 & 1.6 \\
\hline $11 / 18 / 200822: 33$ & 44.2752 & -114.3292 & 0.9 & ML IE & 142.2 & 6.24 & 6 & 136 & 32.7 & 0.04 & 0.8 & 13.0 \\
\hline $11 / 21 / 200812: 01$ & 43.6852 & -113.5897 & 1.7 & Mc IE & 65.2 & 4.27 & 18 & 123 & 11.6 & 0.12 & 0.3 & 0.7 \\
\hline $11 / 22 / 200815: 37$ & 42.7282 & -111.3030 & 2.0 & ML IE & 158.0 & 1.35 & 9 & 103 & 17.1 & 0.14 & 1.1 & 16.8 \\
\hline 11/23/2008 19:35 & 43.5545 & -111.0788 & 1.2 & ML IE & 137.9 & 12.50 & 6 & 97 & 9.6 & 0.02 & 1.3 & 3.0 \\
\hline $11 / 23 / 200820: 20$ & 43.5522 & -111.0752 & 1.5 & ML IE & & 13.44 & 9 & 98 & 10.0 & 0.04 & 0.8 & 2.0 \\
\hline $11 / 23 / 2008$ 20:22 & 43.5598 & -111.0822 & 1.0 & ML IE & 137.6 & 12.76 & 10 & 108 & 9.1 & 0.03 & 0.9 & 1.9 \\
\hline 11/25/2008 0:40 & 44.0458 & -114.6645 & 1.1 & ML IE & 157.5 & 20.40 & 6 & 129 & 46.8 & 0.07 & 0.8 & 11.4 \\
\hline $11 / 25 / 200811: 33$ & 44.0427 & -114.6700 & 1.6 & Mc IE & 157.8 & 19.99 & 9 & 129 & 46.3 & 0.12 & 1.0 & 12.7 \\
\hline $11 / 25 / 200813: 20$ & 44.0432 & -114.6418 & 1.1 & ML IE & 155.7 & 7.10 & 10 & 125 & 48.2 & 0.17 & 0.8 & 11.7 \\
\hline 11/25/2008 13:31 & 44.0458 & -114.6565 & 1.6 & Mc IE & 156.9 & 6.84 & 11 & 110 & 47.4 & 0.10 & 0.5 & 5.7 \\
\hline $11 / 26 / 20087: 44$ & 44.0430 & -114.6538 & 2.4 & Mc IE & 156.6 & 6.47 & 21 & 110 & 45.4 & 0.10 & 0.3 & 2.9 \\
\hline $11 / 26 / 200811: 21$ & 44.4760 & -111.1502 & 0.9 & Mc IE & 159.8 & 14.85 & 5 & 159 & 26.5 & 0.03 & 2.0 & 3.8 \\
\hline $11 / 26 / 200817: 33$ & 44.0455 & -114.6440 & 3.7 & MLUS & 155.9 & 6.59 & 32 & 102 & 44.7 & 0.20 & 0.3 & 1.8 \\
\hline $11 / 26 / 200817: 41$ & 44.0462 & -114.6560 & 2.4 & Mc IE & 156.9 & 6.76 & 17 & 153 & 45.7 & 0.06 & 0.5 & 4.8 \\
\hline $11 / 26 / 200817: 50$ & 44.0333 & -114.6457 & 2.1 & Mc IE & 155.7 & 7.48 & 11 & 230 & 44.4 & 0.13 & 1.9 & 14.5 \\
\hline 11/26/2008 17:52 & 44.0508 & -114.6542 & 2.0 & ML IE & 156.9 & 6.75 & 21 & 155 & 45.7 & 0.15 & 0.5 & 1.9 \\
\hline
\end{tabular}




\begin{tabular}{|c|c|c|c|c|c|c|c|c|c|c|c|c|}
\hline ORIGIN TIME & LAT N & LONG W & MAG & -TYPE & DIST & $Z$ & $\mathrm{NO}$ & GAP & DMIN & RMS & $\mathrm{ERH}$ & ERZ \\
\hline $11 / 26 / 200817: 54$ & 44.0477 & -114.6422 & 1.9 & Mc IE & 155.8 & 7.70 & 13 & 153 & 44.7 & 0.17 & 0.5 & 17.7 \\
\hline $11 / 26 / 2008$ 18:21 & 44.7632 & -111.7308 & 1.1 & Mc IE & 149.7 & 10.88 & 6 & 163 & 6.3 & 0.06 & 1.4 & 1.5 \\
\hline $11 / 26 / 2008$ 20:22 & 44.0293 & -114.5768 & 1.4 & Mc IE & 150.2 & 25.62 & 6 & 218 & 39.1 & 0.08 & 4.3 & 11.1 \\
\hline $11 / 26 / 2008$ 23:54 & 44.7002 & -111.9803 & 1.6 & Mc IE & 133.3 & 6.16 & 7 & 120 & 25.1 & 0.02 & 0.6 & 12.1 \\
\hline 11/27/2008 3:14 & 44.0490 & -114.6488 & 3.6 & MLUS & 156.4 & 6.84 & 33 & 109 & 45.2 & 0.25 & 0.4 & 2.1 \\
\hline 11/27/2008 3:25 & 44.0472 & -114.6458 & 2.1 & Mc IE & 156.1 & 7.78 & 11 & 109 & 44.9 & 0.13 & 0.5 & 14.4 \\
\hline 11/27/2008 3:35 & 44.0443 & -114.6508 & 2.4 & Mc IE & 156.4 & 7.22 & 14 & 109 & 45.2 & 0.20 & 0.6 & 14.4 \\
\hline 11/27/2008 7:08 & 44.0433 & -114.6488 & 1.6 & Mc IE & 156.2 & 6.43 & 13 & 109 & 45.0 & 0.23 & 0.6 & 4.0 \\
\hline 11/27/2008 8:39 & 43.4380 & -113.5757 & 1.9 & Mc IE & 68.2 & 20.52 & 23 & 106 & 3.0 & 0.17 & 0.5 & 1.2 \\
\hline 11/27/2008 13:39 & 44.0438 & -114.6560 & 1.9 & Mc IE & 156.8 & 9.00 & 10 & 110 & 45.6 & 0.07 & 0.4 & 13.1 \\
\hline 11/27/2008 17:44 & 44.0453 & -114.6577 & 2.3 & Mc IE & 157.0 & 7.11 & 20 & 110 & 45.8 & 0.07 & 0.3 & 6.9 \\
\hline 11/27/2008 18:42 & 44.0430 & -114.6543 & 2.3 & ML IE & 156.6 & 8.90 & 20 & 110 & 45.4 & 0.08 & 0.3 & 11.4 \\
\hline $11 / 28 / 2008$ 1:25 & 44.6232 & -112.9913 & 2.4 & Mc IE & 109.5 & 8.85 & 18 & 87 & 25.4 & 0.08 & 0.6 & 4.5 \\
\hline 11/28/2008 6:50 & 44.0367 & -114.6608 & 1.8 & Mc IE & 156.9 & 18.35 & 9 & 110 & 45.7 & 0.08 & 0.8 & 13.9 \\
\hline 11/28/2008 8:46 & 44.6633 & -113.0173 & 2.2 & Mc IE & 114.3 & 8.23 & 21 & 99 & 22.6 & 0.05 & 0.6 & 3.3 \\
\hline 11/28/2008 9:21 & 44.2722 & -114.0235 & 1.3 & Mc IE & 121.2 & 7.40 & 10 & 158 & 37.3 & 0.07 & 0.7 & 13.0 \\
\hline $11 / 28 / 200820: 49$ & 44.0508 & -114.4827 & 2.0 & $\mathrm{~N}$ & 143.7 & 8.12 & 12 & 90 & 33.0 & 0.10 & 0.4 & 12.6 \\
\hline 11/29/2008 17:09 & 44.6320 & -112.9953 & 1.4 & Mc MB & 110.6 & 5.00 & 6 & 174 & 27.9 & 0.08 & 5.8 & 8.5 \\
\hline $11 / 30 / 200810: 25$ & 44.4383 & -114.0752 & 2.2 & Mc IE & 135.7 & 1.82 & 12 & 122 & 20.0 & 0.05 & 0.9 & 1.6 \\
\hline $11 / 30 / 200817: 28$ & 43.7120 & -111.1123 & 1.7 & ML IE & 134.8 & 10.57 & 10 & 99 & 24.8 & 0.07 & 0.4 & 3.9 \\
\hline 12/1/2008 9:02 & 43.4838 & -110 & 2.4 & ML IE & 152.0 & 10.51 & 21 & 86 & 3.0 & 0.06 & 0.3 & 0.7 \\
\hline 12/1/2008 12:47 & 44. & -11 & 1.7 & Mc IE & 1 & 7.19 & 10 & 109 & 3 & 29 & 0.8 & 14.5 \\
\hline $12 / 2 / 20084: 23$ & 44.0 & -1 & 21 & $N$ & 1 & 2 & 13 & 155 & & 9 & 5 & 4.5 \\
\hline 12/2/2008 9:54 & 44.0833 & -113.9303 & 2.0 & Mc IE & 104.0 & 2.73 & 18 & 56 & 24.0 & 0.17 & 0.6 & 1.2 \\
\hline 12/2/2008 12:03 & 44.0755 & -114.5685 & 0.9 & ML IE & 151.1 & 18.01 & 6 & 148 & 55.0 & 0.08 & 0.8 & 14.2 \\
\hline 12/3/2008 5:33 & 44.0482 & -114.6443 & 0.5 & ML IE & 156.0 & 9.43 & 4 & 234 & 44.9 & 0.08 & 1.7 & 12.6 \\
\hline 12/3/2008 18:03 & 44.0273 & -114.6437 & 0.8 & ML IE & 155.3 & 7.61 & 7 & 150 & 44.1 & 0.08 & 1.7 & 14.2 \\
\hline 12/3/2008 18:03 & 44.0503 & -114 & 0.7 & ML IE & 156.5 & 8.99 & 5 & 154 & 45.4 & 0.15 & 0.7 & 16.1 \\
\hline 12/3/2008 18:31 & & & & & & & 8 & 153 & & & & 12.1 \\
\hline $12 / 4 / 20081: 45$ & 44.6280 & -112.0973 & 1.7 & Mc IE & 121.8 & 14.92 & 13 & 112 & 23.9 & 0.07 & 0.6 & 1.3 \\
\hline 12/4/2008 16:30 & 44.0405 & -114.6482 & 1.5 & Mc IE & 156.1 & 6.72 & 9 & 152 & 44.9 & 0.30 & 1.1 & 3.9 \\
\hline 12/4/2008 22:03 & 43.2273 & -111.0063 & 2.0 & ML IE & 151.3 & 12.17 & 16 & 132 & 28.2 & 0.11 & 0.5 & 3.0 \\
\hline 12/4/2008 22:09 & 43.2317 & -111.0152 & 1.0 & ML IE & 150.4 & 9.88 & 7 & 177 & 27.9 & 0.02 & 1.2 & 4.2 \\
\hline 12/4/2008 22:12 & 42.7313 & -111.2883 & 1.6 & Mc IE & 15 & 9.92 & 6 & 135 & 15.8 & 0 & 1.1 & 4.2 \\
\hline 12/4/2008 22:17 & 43.2567 & -111.0135 & 0.8 & ML IE & 149.7 & 10.54 & 7 & 229 & 26.4 & 0.10 & 1.3 & 3.7 \\
\hline $12 / 5 / 20082: 54$ & 43.3597 & -110.8518 & 1.5 & Mc IE & 159.4 & 11.63 & 13 & 137 & 11.4 & & 0.7 & 1.3 \\
\hline 12/5/2008 6:46 & 44.0452 & -114.6467 & 1.1 & Mc IE & 156.1 & 7.28 & 7 & 153 & 44.9 & 0.09 & 0.7 & 14.5 \\
\hline 12/5/2008 9:46 & 44.0427 & -114.6525 & 2.1 & Mc IE & 156.5 & 6.71 & 24 & 110 & 45.3 & 0.15 & 0.4 & 1.9 \\
\hline 12/5/2008 9:58 & 44.0433 & -114.6595 & 2.5 & Mc IE & 157.0 & 7.22 & 22 & 110 & 45.8 & 0.08 & 0.4 & 13.4 \\
\hline 12/5/2008 10:38 & 44.0287 & -114.6425 & 1.4 & Mc IE & 155.3 & 18.80 & 6 & 150 & 44.0 & 0.02 & 0.7 & 11.9 \\
\hline 12/5/2008 15:20 & 43.3645 & -110.8462 & 1.3 & ML IE & 159.7 & 10.93 & 10 & 135 & 10.9 & 0.17 & 0.7 & 1.5 \\
\hline 12/6/2008 6:11 & 44.0288 & -114.6452 & 2.3 & Mc IE & 155.5 & 7.13 & 22 & 150 & 44.3 & 0.14 & 0.5 & 16.9 \\
\hline $12 / 6 / 20088: 15$ & 44.0255 & -114.6450 & 1.2 & Mc IE & 155.4 & 9.76 & 8 & 150 & 44.1 & 0.09 & 0.9 & 10.8 \\
\hline 12/6/2008 10:53 & 44.0428 & -114.6443 & 0.3 & ML IE & 155.9 & 7.36 & 7 & 152 & 44.7 & 0.09 & 0.4 & 14.1 \\
\hline 12/6/2008 11:02 & 44.0227 & -114.6450 & 0.8 & Mc IE & 155.3 & 7.29 & 8 & 149 & 44.0 & 0.07 & 0.6 & 13.7 \\
\hline 12/6/2008 11:08 & 43.1842 & -111.0097 & 0.9 & ML IE & 152.6 & 10.91 & 6 & 197 & 32.8 & 0.10 & 2.1 & 8.2 \\
\hline 12/6/2008 11:20 & 44.0255 & -114.6460 & 0.6 & ML IE & 155.5 & 8.68 & 9 & 150 & 44.2 & 0.13 & 0.6 & 13.3 \\
\hline 12/6/2008 21:02 & 44.0053 & -114.6423 & 0.6 & ML IE & 154.6 & 19.38 & 5 & 146 & 43.4 & 0.20 & 1.8 & 17.4 \\
\hline 12/7/2008 8:09 & 44.0310 & -114.6435 & 1.2 & Mc IE & 155.4 & 7.80 & 10 & 150 & 44.2 & 0.08 & 0.5 & 13.5 \\
\hline 12/7/2008 8:11 & 44.0280 & -114.6448 & 1.0 & Mc IE & 155.5 & 7.26 & 8 & 150 & 44.2 & 0.10 & 0.6 & 14.8 \\
\hline 12/7/2008 14:26 & 43.2460 & -111.0090 & 1.2 & ML IE & 150.4 & 10.59 & 13 & 164 & 27.4 & 0.10 & 0.9 & 4.3 \\
\hline
\end{tabular}




\begin{tabular}{|c|c|c|c|c|c|c|c|c|c|c|c|c|}
\hline ORIGIN TIME & LAT N & LONG W & MAG & -TYPE & DIST & $Z$ & $\mathrm{NO}$ & GAP & DMIN & RMS & $\mathrm{ERH}$ & ERZ \\
\hline 12/7/2008 16:02 & 44.0315 & -114.6547 & 0.9 & ML IE & 156.3 & 21.23 & 5 & 152 & 45.1 & 0.11 & 1.4 & 11.7 \\
\hline 12/7/2008 16:25 & 4.0392 & -114 & 0.5 & C IE & 155.9 & 8.15 & 8 & 152 & 44.7 & 0.12 & 0.9 & 14.6 \\
\hline $12 / 8 / 20084: 59$ & 43.6988 & -111.1290 & 1.1 & AL IE & 133.4 & 6.22 & 5 & 192 & 26.8 & 0.36 & 2.7 & 23.9 \\
\hline $12 / 8 / 20086: 21$ & 44.0440 & -114.6567 & 1.7 & Mc IE & 156.8 & 7.26 & 12 & 110 & 45.6 & 0.09 & 0.4 & 12.5 \\
\hline 12/8/2008 6:24 & 44.0272 & -114.6467 & 1.8 & Mc IE & 155.6 & 7.07 & 8 & 150 & 44.3 & 0.13 & 0.8 & 16.6 \\
\hline $12 / 9 / 20084: 42$ & 44.0372 & -114.6482 & 1.4 & Mc IE & 156.0 & 8.62 & 9 & 152 & 44.8 & 0.13 & 0.6 & 13.2 \\
\hline $12 / 9 / 20086: 48$ & 43.7702 & -111.1635 & 0.9 & ML IE & 131.1 & 10.76 & 6 & 145 & 22.9 & 0.05 & 0.8 & 4.5 \\
\hline 12/10/2008 4:50 & 44.0398 & -114.6448 & 1.9 & Mc IE & 155.8 & 7.19 & 17 & 108 & 44.6 & 0.12 & 0.4 & 13.3 \\
\hline 12/11/2008 8:46 & 43.2253 & -111.0030 & 1.5 & ML IE & 151.6 & 3.34 & 14 & 171 & 28.1 & 0.11 & 0.6 & 12.8 \\
\hline 12/13/2008 9:02 & 44.0248 & -114.5808 & 0.7 & Mc IE & 150.4 & 25.13 & 5 & 219 & 39.2 & 0.04 & 3.2 & 9.3 \\
\hline $12 / 14 / 200813: 52$ & 43.3125 & -111.0278 & 0.8 & ML IE & 146.8 & 5.01 & 8 & 141 & 20.7 & 0.05 & 0.7 & 11.3 \\
\hline $12 / 14 / 2008$ 18:10 & 43.2055 & -111.3903 & 1.2 & Mc IE & 123.1 & 16.28 & 6 & 126 & 16.7 & 0.13 & 1.6 & 3.6 \\
\hline $12 / 14 / 2008$ 18:56 & 44.0512 & -114.6558 & 1.2 & $\mathrm{Mc}$ IE & 157.0 & 7.20 & 8 & 111 & 45.8 & 0.12 & 0.7 & 16.0 \\
\hline $12 / 14 / 2008$ 19:26 & 43.7847 & -111.0500 & 1.3 & Mc IE & 140.4 & 6.28 & 10 & 141 & 36.6 & 0.07 & 0.8 & 11.2 \\
\hline 12/15/2008 1:30 & 44.0 & -114 & 1.0 & IE & 155.7 & 7.24 & 8 & 108 & 5 & 0.10 & 0.6 & 15.1 \\
\hline $12 / 15 / 2008$ 20:25 & 44.6823 & -112.1303 & 0.9 & ML IE & 126.1 & 9.56 & 5 & 164 & 23.2 & 0.11 & 1.1 & 10.8 \\
\hline 12/18/2008 2:54 & 43.0320 & -111.3110 & 0.9 & M & 13 & 5.58 & 5 & 263 & & 0.02 & 3.2 & 1.5 \\
\hline 12/18/2008 9:50 & 44.4543 & -112.9020 & 1.6 & Mc IE & 90.0 & 12.10 & 7 & 218 & 14.2 & 0.04 & 1.6 & 1.6 \\
\hline $12 / 18 / 2008$ 15:31 & 44.0357 & -114.6517 & 1.7 & Mc IE & 156.2 & 6.64 & 14 & 152 & 45.0 & 0.12 & 0.5 & 2.9 \\
\hline $12 / 18 / 2008$ 20:33 & 43.2770 & -110.9213 & 1.2 & ML IE & 156.2 & 3.67 & 9 & 295 & 19.5 & 0.01 & 1.6 & 8.0 \\
\hline $12 / 18 / 2008$ 22:46 & 44.0462 & -114 & 1.9 & ML IE & 156.8 & 7.29 & 13 & 110 & 45.6 & 0 & 0.3 & 13.8 \\
\hline $12 / 18 / 200822: 56$ & 44. & -11 & 2.5 & IE & 1 & 7.09 & 22 & 109 & & & 0.4 & 12.9 \\
\hline 12/19/2008 3:30 & 44 & -1 & 1 & $\mathrm{~N}$ & 1 & 8 & 9 & 1 & & & 9 & 4.7 \\
\hline 12/19/2008 8:04 & 43.4315 & -111.0750 & 1.7 & ML IE & 140.1 & 11.26 & 18 & 106 & 12.0 & 0.06 & 1.0 & 1.0 \\
\hline 12/19/2008 9:08 & 43.4430 & -111.0825 & 0.9 & ML IE & 139.3 & 11.15 & 9 & 181 & 11.9 & 0.06 & 1.5 & 1.1 \\
\hline $12 / 19 / 200814: 20$ & 43.4298 & -111.0735 & 1.2 & ML IE & 140.3 & 11.03 & 7 & 142 & 12.0 & 0.02 & 2.3 & 1.4 \\
\hline 12/20/2008 2:51 & 42.9145 & -111.2960 & 0.9 & ML IE & 145.8 & 6.54 & 4 & 141 & 10.6 & 0.00 & 1.1 & 3.9 \\
\hline 12/20/2008 6:10 & 44.0508 & -114 & 0.9 & IE & 156.3 & 7.84 & 7 & 153 & 45.1 & 0.11 & 0.6 & 15.1 \\
\hline $12 / 20 / 200811: 15$ & & & 1.1 & & & & 10 & 186 & & & & 1.6 \\
\hline $12 / 20 / 200812: 19$ & 43.4520 & -111.0957 & 0.8 & ML IE & 138.1 & 10.54 & 9 & 187 & 12.5 & 0.06 & 1.1 & 1.1 \\
\hline 12/20/2008 19:59 & 44.0442 & -114.6480 & 1.9 & Mc IE & 156.2 & 6.90 & 12 & 140 & 45.0 & 0. & 0.8 & 4.0 \\
\hline $12 / 21 / 200813: 30$ & 44.1728 & -114.5087 & 1.2 & ML IE & 150.3 & 7.55 & 9 & 140 & 42.5 & 0.07 & 0.5 & 13.8 \\
\hline 12/22/2008 5:02 & 43.9388 & -110.9247 & 1.2 & Mc IE & 152.9 & 1.84 & 16 & 79 & 25.6 & 0.27 & 0.8 & 2.7 \\
\hline 12/22/2008 5:28 & 43.9385 & -110.9045 & 1.5 & Mc IE & 154.5 & 2.49 & 23 & 77 & 24.7 & 0 & 0.8 & 18.7 \\
\hline $12 / 22 / 200813: 52$ & 44.6350 & -112.6140 & 0.8 & Mc IE & 110.4 & 10.18 & 6 & 138 & 3.1 & 0.03 & 1.4 & 1.4 \\
\hline $12 / 22 / 200815: 24$ & 44.6673 & -112.5588 & 2.2 & ML IE & 114.6 & 10.39 & 22 & 87 & 8.7 & & 0.4 & 0.8 \\
\hline $12 / 22 / 200817: 32$ & 44.6442 & -112.5857 & 1.4 & ML IE & 111.7 & 6.63 & 13 & 128 & 5.5 & 0.10 & 1.6 & 1.6 \\
\hline $12 / 22 / 200820: 24$ & 44.6538 & -112.5812 & 1.6 & Mc IE & 112.8 & 5.45 & 8 & 117 & 6.4 & 0.10 & 3.0 & 4.5 \\
\hline $12 / 23 / 200810: 52$ & 43.5932 & -111.1752 & 0.5 & Mc IE & 129.9 & 10.49 & 6 & 201 & 0.8 & 0.04 & 2.1 & 4.5 \\
\hline $12 / 23 / 200813: 14$ & 44.0370 & -114.6532 & 1.7 & Mc IE & 156.4 & 6.57 & 13 & 220 & 45.1 & 0.13 & 0.9 & 3.3 \\
\hline $12 / 23 / 200817: 16$ & 44.3277 & -113.4472 & 1.0 & $\mathrm{Mc}$ IE & 92.3 & 7.08 & 15 & 137 & 32.7 & 0.11 & 0.5 & 5.4 \\
\hline 12/24/2008 0:14 & 44.3123 & -114.5548 & & NM & 160.1 & 0.04 & 17 & 98 & 35.6 & 0.28 & 0.5 & 2.3 \\
\hline 12/24/2008 5:13 & 44.7297 & -111.7645 & 1.4 & Mc IE & 145.1 & 7.66 & 13 & 89 & 7.8 & 0.10 & 0.4 & 0.9 \\
\hline $12 / 24 / 200815: 18$ & 44.0400 & -114.6558 & 1.1 & Mc IE & 156.7 & 7.25 & 13 & 153 & 45.4 & 0.07 & 0.5 & 10.3 \\
\hline $12 / 24 / 200815: 19$ & 44.0338 & -114.6568 & 0.7 & Mc IE & 156.6 & 7.14 & 7 & 152 & 45.3 & 0.05 & 0.6 & 13.2 \\
\hline $12 / 24 / 200816: 04$ & 44.0372 & -114.6517 & 1.3 & Mc IE & 156.3 & 7.37 & 12 & 220 & 45.0 & 0.06 & 0.6 & 13.1 \\
\hline $12 / 24 / 200817: 11$ & 44.6263 & -112.5962 & 1.2 & Mc IE & 109.6 & 5.71 & 7 & 143 & 3.9 & 0.04 & 0.5 & 0.5 \\
\hline $12 / 24 / 200821: 18$ & 44.3230 & -114.5358 & 1.5 & Mc IE & 159.2 & 0.03 & 13 & 161 & 35.8 & 0.10 & 0.8 & 2.5 \\
\hline 12/25/2008 4:13 & 44.0302 & -114.6537 & 1.2 & Mc IE & 156.2 & 7.72 & 15 & 152 & 45.0 & 0.11 & 0.5 & 14.1 \\
\hline 12/25/2008 18:05 & 44.6537 & -112.5915 & 1.2 & Mc IE & 112.7 & 5.00 & 9 & 113 & 5.8 & 0.15 & 1.8 & 2.7 \\
\hline $12 / 25 / 2008$ 22:04 & 42.9088 & -111.2440 & 1.5 & Mc IE & 149.6 & 7.38 & 27 & 83 & 31.8 & 0.12 & 0.4 & 2.1 \\
\hline
\end{tabular}




\begin{tabular}{|c|c|c|c|c|c|c|c|c|c|c|c|c|}
\hline ORIGIN TIME & LAT N & LONG W & MAG & -TYPE & DIST & Z & $\mathrm{NO}$ & GAP & DMIN & RMS & ERH & ERZ \\
\hline $12 / 26 / 200817: 10$ & 44.6530 & -112.5832 & 1.7 & ML IE & 112.7 & 5.51 & 16 & 118 & 6.2 & 0.09 & 1.9 & 2.8 \\
\hline $12 / 27 / 200820: 01$ & 44.6482 & -112.0797 & 1.4 & ML IE & 124.5 & 5.87 & 8 & 179 & 25.7 & 0.06 & 1.2 & 13.3 \\
\hline 12/28/2008 8:55 & 44.2563 & -114.5008 & 1.3 & ML IE & 153.4 & 6.75 & 10 & 215 & 39.4 & 0.14 & 1.4 & 4.9 \\
\hline $12 / 28 / 200811: 28$ & 44.1387 & -113.9473 & 0.9 & ML IE & 108.2 & 1.59 & 10 & 241 & 28.4 & 0.10 & 4.6 & 5.8 \\
\hline $12 / 29 / 200816: 39$ & 44.0313 & -114.6408 & 0.6 & ML IE & 155.2 & 7.11 & 5 & 227 & 44.0 & 0.09 & 0.9 & 14.7 \\
\hline 12/30/2008 0:14 & 44.6398 & -112.5992 & 1.2 & ML IE & 111.1 & 8.42 & 8 & 133 & 4.3 & 0.06 & 1.2 & 1.7 \\
\hline $12 / 30 / 200817: 17$ & 42.8843 & -111.2413 & 1.1 & ML IE & 151.4 & 13.98 & 7 & 145 & 17.5 & 0.03 & 1.0 & 2.4 \\
\hline 12/31/2008 8:13 & 42.8497 & -111.2575 & 1.3 & ML IE & 152.5 & 2.98 & 11 & 140 & 15.9 & 0.08 & 0.7 & 9.5 \\
\hline
\end{tabular}

